\title{
New Teachers in Nordic Countries \\ - Ecologies of Mentoring and Induction
}

Knut-Rune Olsen, Eva M. Bjerkholt and Hannu L. T. Heikkinen (Eds.)

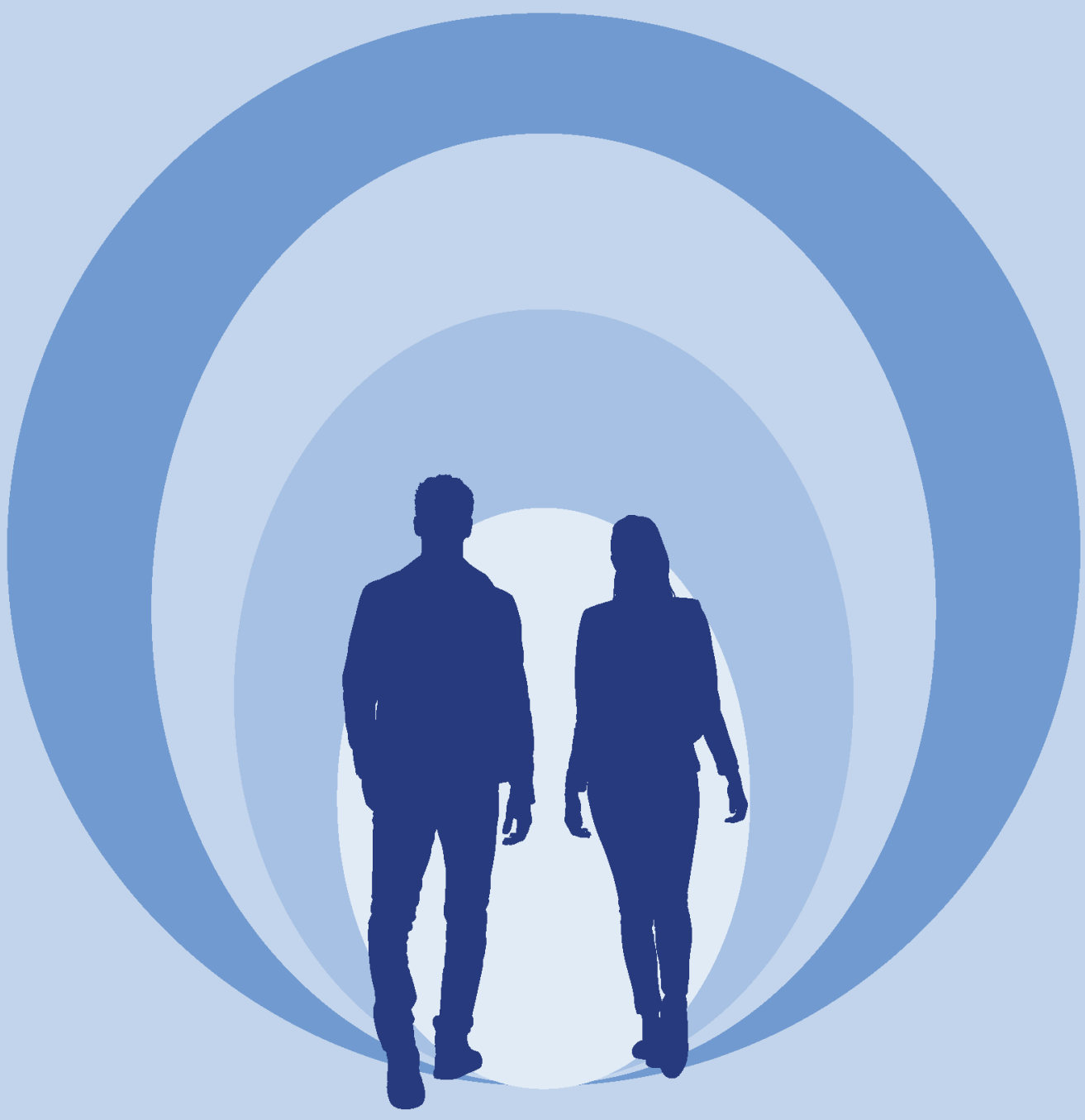

CAPPELEN DAMM AKADEMISK 
New Teachers in Nordic Countries Ecologies of Mentoring and Induction 

Knut-Rune Olsen, Eva M. Bjerkholt and

Hannu L. T. Heikkinen (eds.)

\section{New Teachers in Nordic Countries - Ecologies of Mentoring and Induction}


(C) 2020 Knut-Rune Olsen, Eva M. Bjerkholt, Hannu L. T Heikkinen, Lisbeth Lunde Fredriksen, Åsa Bonde, Eve Einsenschmidt, Katrin Poom-Valickis, Matti Pennanen, Ilona Markkanen, Päivi Tynjälä, Birna Svanbjörnsdóttir, Hildur Hauksdóttir, Maria Steingrimsdóttir and Göran Fransson.

This work is protected under the provisions of the Norwegian Copyright Act (Act No. 2 of May 12, 1961, relating to Copyright in Literary, Scientific and Artistic Works) and published Open Access under the terms of a Creative Commons CC-BY 4.o License (http://creativecommons.org/licenses/by/4.o/). This license allows third parties to freely copy and redistribute the material in any medium or format as well as remix, transform or build upon the material for any purpose, including commercial purposes, provided the work is properly attributed to the author(s), including a link to the license, and any changes that may have been made are thoroughly indicated. The attribution can be provided in any reasonable manner, however, in no way that suggests the author(s) or the publisher endorses the third party or the third party's use of the work. Third parties are prohibited from applying legal terms or technological measures that restrict others from doing anything permitted under the terms of the license. Note that the license may not provide all of the permissions necessary for an intended reuse; other rights, for example publicity, privacy, or moral rights, may limit third party use of the material.

All articles in this anthology are peer-reviewed, including the introduction.

ISBN trykt bok: 978-82-02-69240-7

PDF: 978-82-02-66527-2

EPUB: $978-82-02-69442-5$

HTML: 978-82-02-69441-8

XML: 978-82-02-69443-2

DOI: https://doi.org/10.23865/noasp.105

Cover design: Cappelen Damm AS

Cover illustration: Getty Images

Cappelen Damm Akademisk/NOASP

noasp@cappelendamm.no 


\section{Preface}

This anthology is the result of a collaboration between teacher educators, researchers and representatives of teacher organizations in Denmark, Finland, Estonia, Iceland, Norway and Sweden. This network has organized presentations and symposia at several conferences, carried out projects, written articles and edited books. The background for the collaboration is a desire to share experiences and research-based knowledge of measures aimed at induction and mentoring for newly qualified teachers (NQTs) in the Nordic countries. The collaboration has mainly been funded by Nordplus ${ }^{1}$, which is a program created by The Nordic Council of Ministers'. The purpose of the program is to stimulate research and educational policy cooperation between the Nordic countries and the Baltic states. Therefore, representatives from Tallinn University in Estonia have also actively participated in the group. For practical reasons, in this anthology we refer to our group as Nordic in the sense that the representatives of Estonia are also included in this term.

The Nordic model is a commonly used concept. The Nordic countries have a lot in common in terms of geography, climate and vegetation, to mention a few. They also have similarities in their history; affected by the same European and global political and ideological currents and they have also influenced each other in many ways. Therefore, there are similarities in religion, culture, social structure, political systems, and, generally speaking, in the way of life.

The Nordic model refers to an economic and social model, which is based on the combination of market economy and a large public sector financed mostly by taxes. It is also often referred to as the Nordic welfare state model. This political and social model is usually associated with ideas of individual autonomy, social mobility and an emphasis on basic

\footnotetext{
https://www.nordplusonline.org/eng

https://www.norden.org/en/nordic-council-ministers
} 
human rights, as well as a significant impact of the state in the economy. Trade unions are strong in the Northern countries whereas the nongovernmental organizations and voluntary charitable approaches are less influential than in many other countries.

The educational sector is an important element of the Nordic model: it is almost entirely funded by the public sector, and the citizens have equal access to free education from early childhood to adulthood. So, we may argue that education is one of the fundamental elements of the Nordic model. Education is highly valued and considered to be both economically important and the very basis of human flourishing and wellbeing. This is evident in the high quality of education in the Nordic countries.

On this basis, one would assume that the induction and mentoring practices in these countries would also have much in common. However, the articles of this book quite clearly show that this is not the case. On the contrary, one can see a wide diversity in the ecosystems of mentoring and induction.

A number of people and organizations have facilitated the writing and publication of this book. A special thanks to all those who for many years have contributed to the collaboration that have made our Nordic network a powerful forum for research and quality development when it comes to induction and mentoring for new teachers. This applies not only to those who have contributed in this book (see the author presentations), but also to the representatives of student and teacher organizations who have participated in the work.

Special thanks also go to the Nordic Council, which through the Nordplus Horizontal ${ }^{3}$ program has made it possible for us to meet physically, attend conferences and set up the administrative support functions such co-operation requires. We also thank The Teacher Education Development Program of the Ministry of Education and Culture in Finland, VIA University College in Aarhus, Denmark and the University of South-Eastern Norway who have contributed financially to the production of the book. 
Our thanks also go to the publisher Cappelen Damm Akademisk, who in an excellent and professional way has contributed to this book being realized.

We as editors hope this book will contribute to the development of a comprehensive and sustainable ecosystem for professional development, built through partnerships between a wide variety of educational and political stakeholders. This will create a necessary basis for research, a comprehensive professional development program for all teachers and a better school for all who live and learn in it.

Drammen, Notodden and Jyväskylä, $18^{\text {th }}$ of August 2020

Knut-Rune Olsen, Eva M. Bjerkholt and Hannu L. T. Heikkinen 



\section{Contents}

Introduction: Mentoring and Induction in the Nordic Countries 11

Knut-Rune Olsen, Eva M. Bjerkholt and Hannu L. T. Heikkinen

Article 1 Understanding Mentoring Within an Ecosystem of Practices ....... 27 Hannu L. T. Heikkinen

Article 2 Support for Newly Qualified Teachers Through Teacher Induction Programs - a Review of Reviews.

Lisbeth Lunde Frederiksen

Article 3 The Lack of Induction Programs in Denmark .71 Lisbeth Lunde Frederiksen and Åse Bonde

Article 4 Induction in Estonia: Over Fifteen Years of Experience Successes and Struggle

Eve Eisenschmidt and Katrin Poom-Valickis

Article 5 A Brief History of the Peer-Group Mentoring Model in Finland: Struggling for Space in a Contested Niche 107

Hannu L. T. Heikkinen, Matti Pennanen, Ilona Markkanen and Päivi Tynjälä

Article 6 Mentoring in Iceland: An Integral Part of Professional

Development? 129

Birna Svanbjörnsdóttir, Hildur Hauksdóttir and Maria Steingrímsdóttir

Article 7 Induction and Mentoring of Newly Qualified Teachers in Kindergartens and Schools in Norway 151

Eva M. Bjerkholt and Knut-Rune Olsen

Article 8 Mentoring for Newly Qualified Teachers in Sweden:

Reforms and Challenges 177

Göran Fransson

Author Biographies 199 



\title{
Introduction: Mentoring and Induction in the Nordic Countries
}

\author{
Knut-Rune Olsen
}

University of South-Eastern Norway, Norway

Eva M. Bjerkholt

University of South-Eastern Norway, Norway

Hannu L. T. Heikkinen

University of Jyväskylä, Finland

The professional collaboration that forms the basis of this book dates back to the beginning of the 2000 s when some of the authors started what was then called Newly Qualified Teachers in Northern Europe (NQTNE). In 2017, the network was expanded to a cross-sectoral network financed via https:// www.nordplusonline.org/Who-can-apply/Nordplus-horizontal Nordplus Horizontal. ${ }^{1}$ In this network called Newly Qualified Teachers and Induction: A Nordic Cross-Sectorial Network - NTI, representatives of teacher organizations in the Nordic region were also invited to participate. This book can therefore be understood as a result of a continuation of almost 20 years of Nordic cooperation on research and development work on induction and mentoring.

Some initial results of the studies introduced in this book have been presented and shared with the international research community at

1 https://www.nordplusonline.org/eng

Citation of this article: Olsen, K.-R., Bjerkholt, E. M. \& Heikkinen, H. L. T. (2020). Introduction: Mentoring and Induction in the Nordic Countries. In K.-R. Olsen, E. M. Bjerkholt \& H. L. T. Heikkinen (Eds.), New teachers in Nordic countries - ecologies of mentoring and induction (pp. 11-26). Oslo: Cappelen Damm Akademisk. https://doi.org/10.23865/noasp.105.cho

License: CC-BY 4.0. 
NERA and https://eera-ecer.de/ ECER ${ }^{2}$ conferences in 2018 and 2019. The network also hosted a https://www.usn.no/nti/ Teacher Development Summit in Iceland in 2019. In this anthology, we present and discuss significant parts of this material, aiming at stimulating a research-oriented and evidence-based development of induction and mentoring for newly qualified teachers (NQTs) in the Nordic countries.

\section{Discussion of some key concepts and principles}

When it comes to the Nordic languages, those with Norwegian, Danish or Swedish as their mother tongue will usually easily understand each other. The same does not apply to Finnish, Icelandic and Estonian. For example, in the case of "newly qualified teachers": in Denmark, they will, for the most part, use the concept nyuddannede loerere; in Norway, nyutdannede loerere; in Sweden, nyutdbildade lärare; in Estonia, äsja kvalifitseeritud õpetajad; in Finland, vastavalmistuneet opettajat; and in Iceland, nýliðar í kennslu. The common language in our collaboration group has, therefore, been English, and consequently this anthology is also written in English.

In the articles in this book, terms such as "teacher education", "newly qualified teachers" NQTs, "induction" and "mentoring” will be frequently referred to. We will briefly explain our understanding of these concepts.

\section{Teacher Education}

The main model for initial teacher education in the Nordic countries is an integrated three to five year teacher education, where the student teachers' main focus throughout the whole program is how to become a professional teacher. The knowledge base of the teacher education is complex, cross-disciplinary and consists of ethical values, advanced skills and

2 https://www.norden.org/en/nordic-council-ministers 
professional judgment. That is why teacher education takes place both on the university/university college campus and in kindergartens and schools.

There are also alternative routes for becoming teachers in the Nordic countries. The most common model is to build a one-year teacher education program on top of a master's degree in special subjects (mathematics, science, English, etc.). This program is mainly a study of pedagogy and didactics at a university or university college, combined with practice periods where the students get supervision from practice teachers.

\section{Newly qualified teachers - NQTS}

One of the main concepts used in this anthology is newly qualified teachers - NQTs. In some of the articles, you will meet concepts like new teachers, first-year teachers, newly graduated teachers, beginning teachers, early-career teachers or novice teachers. There is no common clarification of the differences or similarities between these terms, but there are some nuances between how the different countries define the period of being a newly qualified teacher. Researchers often use the concept newly qualified teachers or beginning teachers for new teachers in their first five years as teachers in schools and kindergartens.

\section{Induction}

In the Nordic countries, none of the languages have a single term like "induction" referring to NQTs. In most articles, you will find that the terms induction, induction and mentoring, or just mentoring, frequently are used. In English, induction is a complex concept covering NQTs' learning processes, need for support, vulnerability, special activities and programs. Although most induction programs include mentoring, the authors of this book sometimes use the term "induction and mentoring", mostly to emphasize the importance of mentoring in induction (Attard-Tonna, Bjerkholt \& Holland, 2017; Ingersoll \& Strong, 2011; Langdon, Alexander, Ryde \& Baggetta, 2014; Shanks et al., 2020). We refer to the explanation of the term mentoring below.

Feiman-Nemser et al. (1999) claim that the concept induction has to be understood as more than only a program, special activities and 
mentoring for NQTs. Induction is also an important phase and learning process in a teaching career. Referring to this, Britton, Paine, Pimm and Raizen (2003), frame the term induction by pointing to four broad categories of meanings: A process for learning; a special phase in teaching; a particular period of time; and a system (Britton et al., 2003, p. 3).

New teachers are new in the profession and at their workplace. They have little experience in teaching and are constantly developing their identity and competence as a teacher. Eraut (2007) states that "professional competence also has a large and important tacit dimension" (2007, p. 404). This tacit dimension plays a significant role in teachers' professional learning throughout their careers. In many cases, tacit knowledge determines how they react in situations that require advanced skills and knowledge. In the case of NQTs, this holistic professional competence is little developed and must be acquired and learned over time. This has important consequences for how to organize induction programs for NQTs. To some extent, tacit knowledge can be gained by instructing new teachers and encouraging them to imitate their more experienced colleagues' professional actions, but in many cases this is not sufficient. Therefore, mentoring is an important part of induction programs. Through conversations and reflection with mentors related to experiences and challenges in the profession, both the NQTs and their mentors are given access also to the underlying and often unconscious basis for professional action (Grimen \& Molander, 2008; Kessels \& Korthagen, 1996).

Britton et al. (2003, p. 2) distinguish between "limited" and "comprehensive" use of the term induction. Limited induction refers to a program consisting of targeted supportive activities for NTQs. The duration of this kind of program varies, but it often lasts from one to two years. Many researchers (Bjerkholt, 2013; Feiman-Nemser et al., 1999) underline that "limited" induction has to be seen as more than "simply the filling in of gaps", like the lack of teaching experience (Britton et al., 2003, p. 1). According to the Norwegian principles for mentoring NQTs, ${ }^{3}$ it is also important to recognize their competence and encourage them to

3 https://www.regjeringen.no/contentassets/oo81e41fad994cfdbb4e0364a2eb8f65/veiledning-av-nyutdannede-nytilsatte-larere-i-barnehage-og-skole.pdf 
express and use their resources and expertise in collaboration with their colleagues.

However, if you consider induction as a special phase in teachers' careers, researchers often define this period to be the first five years of work after completing initial teacher education. Britton et al. (2003) name this perspective on induction "comprehensive induction". This indicates that there are many possible goals for induction and induction as a continuum of developing as a professional teacher.

Comprehensive induction includes not only activities and special induction programs for NQTs, but also a wider range of measures to promote the professional learning of new teachers and the NQTs to be included in the profession. It requires attention to teaching as well as the whole responsibility of being a teacher. The activities are not only mentoring programs but facilitate also multiple complementary teaching and learning activities specially focused on NQTs' needs (Attard Tonna et al., 2017; Shanks et al., 2020).

In different countries the concept of induction has also been understood differently, so the concept of induction is understood to mean different practices in different countries. This problem has also been encountered in international Teaching and Learning International Survey (TALIS) research. For example, in the Finnish TALIS questionnaire, the word perehdyttäminen is used for “induction”. In Swedish, the expression "induction program" has been translated as introduktionsprogram, and in Norway as introduksjonsprogram (OECD, 2019). However, Finns have a slightly different meaning for the word perehdyttäminen than Norwegians and Swedes have for the related concepts introduktion/ introduksjon. In Finnish, the word perehdyttäminen stems from the verb "perehtyä", which refers to an in-depth study of the matter, so the word has a deeper meaning than "introduction" or "induction". These kinds of complexity and differences in how to understand the concept induction are a challenge and complicate international comparative research.

\section{Mentoring}

In most of the Nordic countries, a word derived from the national language has been introduced to describe mentoring: vejledning (Danish), 
juhendamine (Estonian), leiðsögn (Islandic), veiledning (Norwegian) and handledning (Swedish). Finland seems to be an exception: in Finnish, the most-used concept is mentorointi, which is a fairly direct translation of the word mentoring. Most of the concepts used in the Nordic languages translate well into English, but the English concept the researchers prefer to use varies. For example, sometimes the Norwegian word veiledning is translated as guidance or counseling, whereas some other authors prefer to use the concepts supervision or coaching (Bjørndal, 2008; Kemmis \& Heikkinen, 2012; Skagen, 2014). In Sweden and Norway, you can find the English words mentor/mentoring and coach/coaching used both in everyday language and as titles for a variety of different supporting activities.

Kemmis and Heikkinen (2012) point out that these concepts have different nuances of meaning. Sometimes, mentoring refers to an interaction between a more-experienced and a less-experienced person, for example, a relationship between a novice teacher and a more-experienced teacher. Bozeman and Freeney (cited in Kemmis \& Heikkinen, 2012) use the concept mentoring as "a process of the informal transmission of knowledge, social capital and psychosocial support from a person who is perceived to have greater relevant knowledge, wisdom, or experience (the mentor) to a person who is perceived to have less (the protégé)" (Bozeman \& Freeny, as cited in Kemmis \& Heikkinen, 2012, p. 145).

Many researchers and authors however have pointed to the concepts mentoring, coaching and supervision as "a practice ill-defined, poorly conceptualized and weakly theorized" (Colley, 2003; Skagen, 2014; Attard-Tonna et al., 2017). It is more about which concept the authors prefers to use, rather than different actual concepts (Bjerkholt, 2017; Skagen, 2014). In the international field of research in induction and mentoring NQTs, the most common concept is mentoring.

In the Norwegian framework for national principles on (veiledning) mentoring NQTs (Kunnskapsdepartementet, 2018), the concept "mentoring" is clarified as: "A planned, systematic and structured process conducted individually and in groups." The term "qualified mentor" is clarified as: "An educated teacher who has formal mentor skills, necessary professional skills and at least three years of experience as a teacher." A mentor 
and mentee relationship is, in the Norwegian tradition of mentoring NQTs, based on a non-hierarchical relationship and a more equal status.

\section{International perspectives}

Before we take a closer look at the situation in the Nordic countries, we will briefly refer to some international surveys that document main features regarding induction "in countries it is natural to compare us to", i.e. the so-called OECD countries.

We primarily focus on two OECD reports published in 2018 and 2019. The first of these is TALIS 2018: Results. Volume 1. Teachers and School Leaders as Lifelong Learners ${ }^{4}$ (OECD, 2018), which contains data collected from upper secondary education in a wide range of countries in and outside Europe. The second report, called A Flying Start, ${ }^{5}$ published in April 2019 (OECD, 2019), includes the results of a comprehensive survey of induction and mentoring for NQTs in the OECD countries. It is supported by an interactive website, Teacher Ready, ${ }^{6}$ that explains how work on the report was organized and conducted, and describes some of the main principles of the OECD's recommendations on induction and mentoring for member countries.

The OECD reports are based on three important perspectives that also form the basis of this anthology. First: "No matter how good initial teacher education is, it is not expected to prepare teachers for all the challenges they face during their first regular employment as a teacher" (OECD, 2018, p. 138). Consequently, special measures must be taken to address this particular part of a teacher's career.

Second, it is stated with reference to Ingersoll and Strong (2011) (see Lisbeth Lunde Fredriksen's review article in this book) that there is empirical evidence for the claim that support and assistance for beginning teachers have a positive influence on outcomes such as commitment

\footnotetext{
4 http://www.oecd.org/education/talis-2018-results-volume-i-1dobc92a-en.htm

5 http://www.oecd.org/education/talis/a-flying-start-cf74e549-en.htm

6 http://www.oecdteacherready.org/
} 
and retention of teachers, classroom teaching practices and student achievement.

Third, according to the OECD, it is important that induction and mentoring must not only be regarded as an isolated measure to support new teachers in a demanding situation and ensure that they continue in the profession, but also as an integral part of a "coherent system of initial teacher preparation that can serve as the foundation for a process of continued development throughout the full duration of a teacher's career." In the report (ibid., p. 18) this is illustrated by the following model:

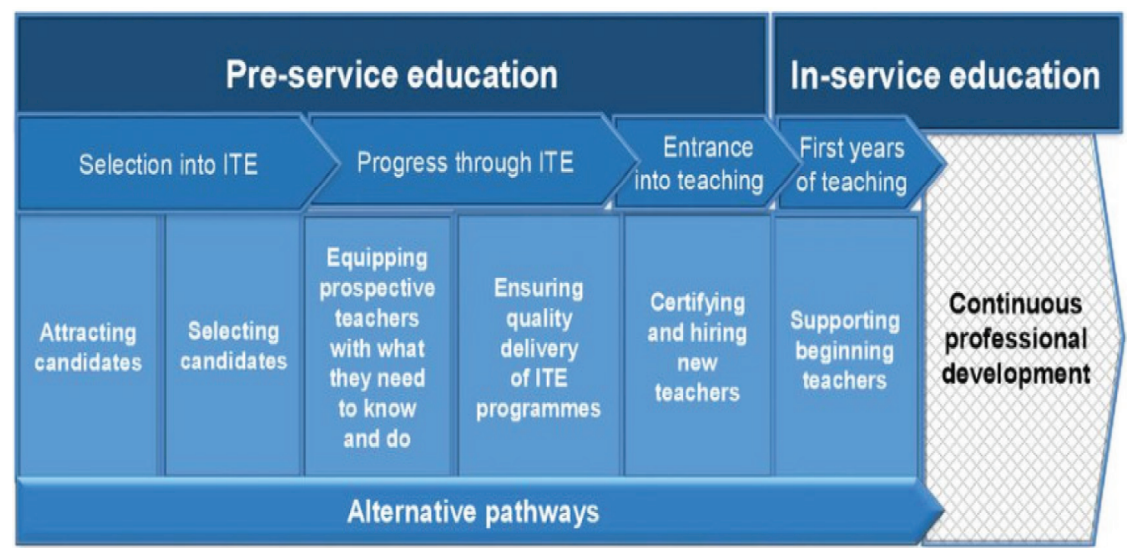

Figure 1.

The model shows the connection between the different phases and the prerequisites that are important to ensure that a nation has teachers with high academic and didactic competence. As can be seen from the model, the measures can be divided into two main phases: pre-service education and in-service education.

The first phase of pre-service education is about admission quality, in the sense that one must ensure good access to highly-qualified applicants and then select the candidates who have the best potential to become proficient teachers. Finland is the most successful country in the Nordic region in this respect. (See article on Finland in this anthology).

The next step is to ensure that student teachers have a high-quality education of the greatest possible relevance for future work as a teacher. When it comes to the Nordic countries, including Estonia, all except 
Denmark have a five-year university or university college education at the master's level as the main model for the education of teachers working in primary and secondary education (Elstad, 2020).

The second phase, in-service education, is comprised of two main types of measures: induction and mentoring for NQTs, which can include a period of two to five years in work after completing basic education, and continuous professional development that includes all teachers in a lifelong career perspective.

\section{The content of the anthology}

Accordingly, the OECD emphasizes the importance of a systemic perspective as a basis for identifying key stakeholders and recognizes induction and mentoring as a necessary part of an overall commitment to increased quality and more learning for students in schools. In the article "Understanding Mentoring Within an Ecosystem of Educational and Political Practices" in this book, Hannu L. T. Heikkinen explains an ecosystemic approach to mentoring, which in recent years has been the basis for the Nordic group's symposia and presentations at international conferences and seminars. This way of understanding human activity has its origin in ecosystemic theory and systems-analytic approaches, as we know them from, for example, Urie Bronfenbrenner (1997) and Fritjof Capra (2016). An ecosystemic approach makes it possible to both describe and analyze practices of induction and mentoring inhabiting a given ecological niche and to see this niche within a larger educational policy context. When it comes to this anthology, the editors have left the authors free to choose their own theoretical approach, but some of the ecosystemic concepts are used in some of the articles.

In the article "Support for Newly Qualified Teachers Through Teacher Induction Programs - A Review of Reviews" in this book, Lisbeth Lunde Fredriksen discusses research within the field of induction and mentoring. She refers to the main findings from six review articles that summarize research findings from more than 230 individual studies. Lunde Fredriksen concludes that the current research provides a basis for claiming that systematic and targeted high-quality measures in the form of 
mentoring and induction for NQTs have significant positive effects, not only for the new teachers themselves, but also for their students' learning and well-being. Accordingly, the article supports the assumptions and main conclusions reported in the OECD publications mentioned above.

In recent history, there have been many commonalities and close collaborations, both culturally and politically, between the Nordic countries. This applies, not least, to the educational policy field, where free access to high-quality education for all has been a high priority in all of the countries. However, when it comes to induction and mentoring for NQTs, it is difficult to point out commonalities between the Nordic countries, except that none of them currently have a legal binding national program that gives NQTs the right and access to support.

The main part of this book comprises six articles which, in alphabetical order, discuss the historical background for, and the current situation regarding, induction and mentoring in Denmark, Estonia, Finland, Iceland, Norway and Sweden. We will briefly present some key features regarding the current situation in the Nordic countries. For more detailed information and relevant references, see the articles that present each country.

In the case of Denmark, researchers from VIA University College published the results of a survey in 2017 that documents the extent of induction and mentoring measures aimed at NQTs appointed after January 1, 2013. The results were disappointing in the sense that only $38 \%$ of the NQTs answered "yes" to "having participated in a program in which an experienced teacher was charged with assisting and supporting - mentor/ tutor program". Only $17 \%$ of these mentors had formal mentor education.

The situation in Denmark is also characterized by the aftermath of a nationwide labor conflict in spring 2013, which resulted in a lockout that shut all teachers in primary and secondary schools out of work for almost four weeks. Furthermore, there are indications that Denmark may face a considerable teacher shortage in coming years. At present, publiclyappointed committees are in the process of evaluating and assessing the need for changes in Danish teacher education. There are also negotiations between state authorities and teacher organizations regarding salary and working conditions for teachers. In this connection, the need to 
strengthen measures aimed at NQTs has been pointed out. This could mean incipient shifts in the political ecosystem of education that might result in new efforts to strengthen induction and mentoring for NQTs in Denmark.

Although Estonia does not formally fall under the term "Nordic countries", there have been targeted political and cultural processes in the period after 1945 aimed at strengthening relations between the countries on both sides of the Baltic Sea. As early as 2004, the universities of Tartu and Tallinn, in collaboration with schools and authorities, launched a national program of induction and mentoring for NQTs in Estonia. The role of the universities included both mentoring and campus gatherings for the NQTs. An interesting feature of this program was that it was emphasized from the outset that induction had to be seen as part of a holistic approach to develop the entire school as an organization.

In recent years, Estonian teacher education has undergone changes, partly because of facing significant challenges when it comes to educating a sufficient number of teachers. The average age of Estonian teachers is among the highest in the OECD countries, and the dropout rate from the teaching profession is also high (OECD, 2019). As a result, the recruitment to what is referred to in the model above as "alternative pathways" to formally-approved teacher education has increased significantly. This includes, among other things, relatively short vocational courses aimed at giving candidates who have a different career background the opportunity to obtain a formally-approved teacher education. Internationally, these teacher education programs are referred to as Teach First ${ }^{7}$ and Teach for All, ${ }^{8}$ and have branches in a number of countries in Europe, including England, Wales, and Estonia (Tatto \& Menter, 2019; Elstad, 2020). It is worth noting that OECD warns against what they refer to as alternative routes into teaching, because "although they might temporarily resolve supply-demand issues, they also carry the risk and diminish the value of teacher education, and can work against sustainable solutions" (OECD,

\footnotetext{
7 https://www.teachfirst.org.uk/

8 https://teachforall.org/
} 
2019, p. 12). Estonia is now working on developing induction strategies that can be adapted to different types of teacher education and NQTs.

In many ways, Finland has a special status internationally, both in terms of teacher education and results on international surveys such as PISA, ${ }^{9}$ TIMSS and PIRLS ${ }^{10}$ on the level of knowledge of the pupils. Finnish teacher education has been a five-year master's program since 1978. Recruitment and selection strategies related to what is referred to in the above model as "selection into initial teacher education" have been very successful and, unlike other Nordic countries, Finnish teacher education has followed a stable pattern with few fundamental changes in recent decades. This may be one of the reasons why Finland has not developed targeted national mentoring and induction programs for NQTs, although international comparative studies such as TALIS 2018 clearly indicate that there is a need for mentoring.

Finland has, however, had a comprehensive national program for peergroup mentoring (PGM) where experienced teachers and NQTs have worked together and reflected on experiences aimed to promote professional development and learning. This work is based on theoretical principles rooted in theories of professional learning and development that we know of from constructivism and integrative pedagogy.

In recent years, the Finnish PGM model has been challenged, among other things, by competing educational policy focus areas, with an intention to develop Finnish teachers' ICT competence. At the same time, there has been a declining trend in the recruitment of students for initial teacher education, especially in early childhood teacher education. This may trigger a discussion about further needs to develop induction and mentoring programs for NQTs also in Finland (Heikkinen, Utriainen, Markkanen, Pennanen, Taajamo \& Tynjälä, 2020).

Like Estonia, Iceland faces a challenging situation when it comes to securing a sufficient number of qualified teachers in the years to come. Failure to recruit to teacher education, relatively high average age, and significant dropout from the teaching profession, were some of the reasons

\footnotetext{
9 https://www.oecd.org/pisa/test/

$10 \mathrm{https}: / /$ timssandpirls.bc.edu/
} 
why a group of stakeholders was appointed in 2018 in order to investigate and point out measures that could address this situation. This resulted in the Ministry of Education launching a series of measures in 2019 aimed at securing new teachers with quality mentoring during the first three years after completing basic teacher education. This includes, among other things, state funding of further education for experienced teachers who want to be mentors for NQTs (30 ECTS credits). The Icelandic authorities are now implementing these measures in collaboration with the relevant stakeholders. As in Estonia, work has also been initiated to strengthen the provision of alternative educational pathways into the teaching profession.

In Norway, work began on securing NQTs induction and mentoring as a national project in 2003 and gained the immediate support of teacher education programs at universities and university colleges. In 2009, a letter of intent was signed by the Ministry of Education and Research and the Norwegian Association of Local and Regional Authorities ${ }^{11}$ (KS) which aimed to increase the number of NQTs who received mentoring. Formal national and regional collaborative forums were also set up with representatives from employers, teachers' unions, universities and political authorities to coordinate the work. A special feature of the Norwegian model is that the measures include all teacher groups from kindergartens to upper secondary education.

During the period from 2009 to the present, collaboration between the stakeholders has been continued and further developed. A number of evaluations and reports show a gradual increase of the measures locally, resulting in about $65 \%$ of all NQTs in kindergartens and schools receiving induction and mentoring in the first two years after completing teacher education in 2020. About half of the mentors have formal competence equivalent to 15 ECTS credits or more. At present, a comprehensive national survey is being commissioned by state authorities, and the results are expected to be available during 2021 . It is announced that this will be the basis for political and professional discourses and decisions on the further work on induction and mentoring in Norway.

11 https://www.ks.no/om-ks/ks-in-english/ 
Sweden is the only Nordic country that has tried out a scheme with a probationary induction year before teachers are formally certified as teachers. With the support of the teacher organizations, this reform was implemented in the fall of 2011 as part of a major competency reform for teachers in Swedish schools. However, the probation element in the induction year program was discontinued in 2014, partly because it had proven demanding to implement both professionally and administratively and it also risked deterring people from entering teacher education programs and later on risking not getting a teacher qualification. Today, the responsibility for taking care of new teachers is formally delegated to the principals of the schools where they work, but this is followed up only to a limited extent. Unlike in Norway, no state funding has been allocated to motivate universities and university colleges to provide mentoring or mentoring education for experienced teachers. A survey conducted by the Swedish Teachers' Union in May 2019 showed that only $5 \%$ of the municipalities "always" offered an induction period to NQTs, while $20 \%$ "never" did. 13 \% offered this "often", $31 \%$ "rarely did" and $31 \%$ offered it "sometimes". Corresponding figures from the OECD publications referred to above show that Sweden currently has poorer induction and mentoring results than the average of the OECD countries.

\section{References}

Attard-Tonna, M., Bjerkholt, E., \& Holland, E. (2017). Teacher mentoring and the reflective practitioner approach. International Journal of Mentoring and Coaching in Education, 6(3), 1-18. Retrieved from https://www.emerald.com/ insight/content/doi/10.1108/IJMCE-04-2017-0032/full/html. doi:Doi 10.1108/ IJMCE-04-2017-0032

Bjerkholt, E. (2013). Åpning av lukkede rom: En kvalitativ studie av innholdet og dialogene $i$ veiledningssamtaler mellom nyutdannede loerere og lokale veiledere. (PhD thesis, monography). Faculty of Educational Science. Oslo: University of Oslo.

Bjerkholt, E. (2017). Profesjonsveiledning. Fra praktisk virksomhet til teoretisk felt. Oslo: Cappelen Damm Akademisk.

Bjørndal, C. (2008). Bak veiledningens dør-symmetri og asymmetri $i$ veiledningssamtaler, del 1-3 og del 4-6. (PhD thesis, monography). Universitetet i Tromsø. 
Britton, E., Paine, L., Pimm, D., \& Raizen, S. (2003). Comprehensive Teacher Induction. Dordrecht/Boston/London: Kluwer Academic Publishers.

Bronfenbrenner, U. (1979). The ecology of human development. Cambridge: Harvard University Press.

Capra, F. (2016). The systems view of life: A unifying vision. Cambridge: Cambridge University Press.

Colley, H. (2003). Mentoring for social inclusion: A critical approach to nurturing mentor relationships. London and New York: Routledge Falmer.

Elstad, E. (Ed.) (2020). Lorerutdanning i nordiske land. Oslo: Universitetsforlaget

Eraut, M. (2000). Non-formal learning and tacit knowledge in professional work. British Journal of Educational Psychology, 70, 113-136.

Eraut, M. (2004). Informal learning in the workplace. Studies in continuing Education, 26(2).

Eraut, M. (2007). Learning from other people in the workplace. Oxford Review of Education, 33(4), 403-422.

Eraut, M. (2010). Knowledge, working, practices, and learning. In S. Billett (Ed.), Learning Through Practice (pp. 37-58). Dordrecht: Springer.

Feiman-Nemser, S., Carver, C., Schwille, S., \& Yusko, B. (1999). A conceptual review of literature on new teachers' induction. Retrieved from https://files.eric.ed.gov/ fulltext/ED449147.pdf

Frederiksen, L. L., Paaske, K., Halse, E., Rosholm, K., \& Krøjgaard, F. (2017). Loererstart og fodfoeste. Endelige rapport. Retrieved from https://www.ucviden. $\mathrm{dk} /$ portal/da/publications/laererstart-og-fodfaeste(5of27281-c18f-4e81-b98e$8 \mathrm{a} 147 \mathrm{dcf} 4138) \cdot \mathrm{html}$

Grimen, H., \& Molander, A. (2008). Profesjon og skjønn. In A. Molander \& L. I. Terum (Eds.), Profesjonsstudier: En introduksjon. Oslo: Universitetsforlaget.

Heikkinen, H. L. T., Jokinen, H. \&. Tynjälä, P. (2012). Peer-Group Mentoring for Teacher Development. Milton Park: Routledge.

Heikkinen, H. L. T., Utriainen, J. Markkanen, I., Pennanen, M., Taajamo, M., \& Tynjälä, P. (2020). Opettajankoulutuksen vetovoima [Attractivity of teacher education]. Publications of the Finnish Ministry of Education and Culture.

Ingersoll, R. M., \& Strong, M. (2011). The impact of induction and mentoring. Programs for beginning teachers: A critical review of the research. Review of Educational Research, 81(2), 201-233. Retrieved from http://rer.aera.net.

Kemmis, S., \& Heikkinen, H. L. T. (2012). Future perspectives: Peer-group mentoring and international practices for teacher development. In H. L. T. Heikkinen, H. Jokinen \& P. Tynjälä (Eds.), Peer-group mentoring for teacher development (pp. 144-171). London and New York: Routledge Taylor \& Francis Group. 
Kessels, J. P. A., \& Korthagen, F. A. (1996). The relationship between theory and practice: Back to the classics. Educational Researcher, 25(3), 17-22. Retrieved from http://www.jstor.org/stable/117664

Kunnskapsdepartementet (2018). Veiledning av nyutdannede nytilsatte lærere i barnehage og skole. https://www.regjeringen.no/contentassets/oo81e41 fad $994 \mathrm{cfdbb} 4 \mathrm{eO}_{3} 64 \mathrm{a} 2 \mathrm{eb} 8 \mathrm{f} 65 /$ veiledning-av-nyutdannede-nytilsatte-larere-ibarnehage-og-skole.pdf

Lacey, C. (1977). The socialization of teachers. London: Methuen.

Langdon, F. J., Alexander, P. A., Ryde, A., \& Baggetta, P. (2014). A national survey of induction and mentoring: How it is perceived within communities of practice. Teaching \& Teacher Education, 44, 92-105. Retrieved from http:// www.sciencedirect.com/science/article/pii/So742051X14001012\#. doi:10.1016/j. tate.2014.08.004

Mausethagen, S., \& Smeby, J.-C. (Eds.) (2017). Kvalifisering til profesjonell yrkesutøvelse. Oslo: Universitetsforlaget.

OECD (2018). TALIS 2018 results. Teachers and S leaders as lifelong learners. http:// www.oecd.org/education/talis-2018-results-volume-i-1dobc92a-en.htm

OECD (2019). A flying start - improving initial teacher preparation systems. http:// www.oecd.org/education/talis/a-flying-start-cf74e549-en.htm

Shanks, R., Attard-Tonna, M., Robson, D., Kroejgaard, F., Paaske, K., \& Bjerkholt, E. (2020). A comparative study of mentoring for new teachers (pp. 1-15).

Professional Development in Education. https://doi.org/10.108o/19415257.2020.174 4684

Skagen, K. (2014). Kunnskap og handling i pedagogisk veiledning. (2nd ed.) Bergen: Fagbokforlaget.

Tatto, M. T., \& Menter, I. (Eds.) (2019). Knowledge, policy and practice in teacher education: A cross-national study. London: Bloomsbury. 


\title{
ARTICLE 1
}

\section{Understanding Mentoring Within an Ecosystem of Practices}

\author{
Hannu L. T. Heikkinen \\ University of Jyväskylä, Finland
}

\begin{abstract}
The aim of this article is to introduce an ecosystemic approach to mentoring, inspired by the theory of ecologies of practices (Kemmis, Edwards-Groves, Wilkinson, \& Hardy, 2012). It is suggested that relationships between practices and their environment resemble in many ways the relationships between natural organisms and ecosystems. From this perspective, mentoring is understood as a social practice that exists in the midst of other social practices and derives its essential qualities and its existence from its relation to other practices. The theory of ecologies of practices is based on the conception of practices as 'living entities'. From the perspective of ecologies of practice, practices of mentoring and induction can be regarded as ecosystems of their own within the wider ecosystems of social, political and educational practices. In the research literature, the concept of ecosystem has been represented in a number of different variations. The concept was first introduced in education research by the developmental psychologist Urie Bronfenbrenner (1979), who described human development and socialisation in terms of nested circles of varying sizes. Lately, the ecosystem concept has also been used in the context of learning in ways that have been influenced by research in the fields of economics, business and information technology. The theory of ecologies of practices is rooted in an ontological understanding of the importance of learning for human existence: the human species exists as part of the natural ecosystem and, consequently, social practices are based on how the species acts to survive and thrive in the ecosystem. Based on these assumptions, ten ecological principles are introduced and applied to practices of mentoring: (1) networks, (2) nested systems, (3) niches, (4) interdependence, (5) diversity, (6) cycles, (7) flows, (8) development, (9) dynamic balance, and (10) resilience. Finally, some limitations and criticisms of the ecosystem approach are reflected upon.
\end{abstract}

Keywords: mentoring, induction, ecologies of practices, practice theory, ecosystems of learning

Citation of this article: Heikkinen, H. L. T. (2020). Understanding mentoring within an ecosystem of practices. In K.-R. Olsen, E. M. Bjerkholt \& H. L. T. Heikkinen (Eds.), New teachers in Nordic countries ecologies of mentoring and induction (Ch. 1, pp. 27-47). Oslo: Cappelen Damm Akademisk. https://doi. org/10.23865/noasp.105.ch1

License: CC-BY 4.o. 


\section{Introduction: Mentoring as a 'living thing'}

The unifying goal of this book is to explore the practices of mentoring newly qualified teachers in the Nordic countries and Estonia. Mentoring practices are introduced by presenting the special characteristics and historical developments of mentoring in these particular educational and political settings. Mentoring is understood as a special kind of social practice that exists in the midst of other social practices.

We can view the relationships between different practices and the environments in which they exist as closely analogous to organisms and their relationships within the natural environment. These relationships are the subject of ecological research. In order to apply the conceptual tools derived from ecology, we need to look upon mentoring as a kind of 'living thing', or, at least, very much like a living thing (Kemmis et al., 2012). Social practices resemble living organisms in many ways. Practices, like living organisms, evolve, live and die in a particular setting. They can move from one place to another, form territories and compete with one another. Some of these living entities are more sustainable or more resilient than others and occupy larger territories than others. Practices also develop the qualities they need to survive in the struggle for survival. Some gradually evolve into increasingly powerful forms. Others lose the evolutionary struggle, disappear and die out. Similar to organisms competing for their place within natural ecosystems, natural selection and evolution also seem to take place among human practices.

The whole set of social practices in the midst of which mentoring lives can be understood as an ecosystem of education. We can consider mentoring as a particular species, or an ecosystem of its own, that lives and exists within a wider ecosystem of social, political and educational practices. This ecosystemic view has been represented in a number of different variations in the recent literature and conceptualised slightly differently in terms of ecologies of practice (Kemmis et al., 2012), ecosystems of schools (Godfrey \& Brown, 2019), ecosystems of innovation or ecosystems of learning (Virolainen, Heikkinen, Siklander, \& Laitinen-Väänänen, 2019), ecologies of learning (Barnett \& Jackson, 2020) or learning ecologies (Savin-Baden, 2020).

The aim of this article is to introduce and elaborate a theoretical perspective on mentoring as an ecosystem. Particular attention will be paid to 
the theory of ecologies of practices and the ecological principles developed on the basis thereof. In addition to the principles previously presented in the literature (Capra, 2004, 2005; Kemmis \& Heikkinen, 2012; Kemmis \& Mutton, 2012), one new principle is introduced, namely the principle of resilience. Some of these ecological principles are applied in other articles of this book. Finally, some limitations and criticisms regarding the application of the ecosystemic approach are introduced.

\section{A short genealogy of ecologies of mentoring}

In order to better understand the potentials and limitations of the concept of ecosystem in educational research, we must first take an excursion to the historical background, or genealogical roots, of the concept. In historical terms, the concept of ecology was first coined by the German zoologist Ernst Haeckel, who is also known as the founder of the discipline. Haeckel's research was inspired by Charles Darwin's On the Origin of Species (1859/2009). Haeckel came up with the concept of ecology by combining two Greek words, oikos and logos. Depending on the context, oikos may mean a heart, a fireplace, a home or home-economy. Metaphorically, it refers to the most important, relevant, or active point of a thing or place, such as the heart or centre of a city or village. Such a place may also be called a nucleus, familiar to us from physics and biology; the central and most important part of an entity, forming the basis for its existence and activity. The meaning of the word logos, in turn, has been the subject of long philosophical debate, but in its simplest sense it means a word, a speech, a talk or a lesson. The etymological background of the concept of ecology thus refers to speaking, lecturing or understanding (logos) about the relationship between the place of interest, or nucleus (oikos), and its surroundings. Ecology, in short, is the study of the relationship between organisms and the environment; it focuses on the interaction between living entities and their surroundings and the conditions of existence of species and the larger entities formed by them (Wals, 2020; Virolainen et al., 2019).

Subsequently, the combination of systemic thinking and ecology gave rise to the concept of ecosystem, as first introduced by the British botanist 
Arthur Tansley in 1935 (Willis, 1997). System theory is not, however, a necessary element of ecological research, and some scholars have claimed that system theory assumptions are ontologically problematic when considering nature, and that such assumptions can even prevent understanding of ecological phenomena as they are (Virolainen et al., 2019).

The concept of ecosystem was first introduced in education research by the developmental psychologist Urie Bronfenbrenner (1979), who described human development and socialisation through a model of nested circles of varying sizes. The circles defined by Bronfenbrenner characterise interactions between individuals (microsystems), interconnections between environments (mesosystems), interconnections and processes of the evolving human individual (exosystems), and, more broadly, cultural values, habits and norms in societies. Later, Bronfenbrenner introduced the concept of a chronological system to describe temporal change. Bronfenbrenner's theory has recently been systematically applied to the study of learning ecosystems (e.g. Godfrey \& Brown, 2019).

However, lately, the ecosystem concept has been used in educational research in ways that are influenced by economics and information technology. For example, in the EU there has been much discussion about innovation-driven or university-based entrepreneurship ecosystems (e.g. Fetters, Greene, Rice, \& Butler, 2010; Groth, Esposito, \& Tse, 2015). The concept of ecosystem is widely used to refer to business-to-business networks. One of the pioneers in applying an ecosystemic approach to business research was James F. Moore, whose article 'Predators and Prey' (1993) laid the foundation for understanding business through the ecosystem analogy by introducing the concept of business ecosystems. According to Moore, business competitors can be metaphorically seen as predators chasing prey. Businesses struggle for survival in a particular market niche, just like animals and plants compete for space in an ecological niche.

From the point of view of the business ecosystem, education can be seen as a subsystem of the economic system, generating a skilled workforce and potential consumers. From this perspective, education is subordinate to the economy. As a result, it is most productive to invest in so-called human capital (Peters \& Bulut, 2011). Human cognitive skills are thus reduced to a means of production. This approach has been conceptualised as the 
knowledge economy (Powell \& Snellman, 2004), knowledge capitalism (Burton-Jones, 2003) and cognitive capitalism (Boutang, 2003; Heikkinen, 2018; Peters \& Bulut, 2011).

There seem to be many different ways of applying the concept of ecosystem to educational practices. A genealogical analysis of the concept (Virolainen et al., 2019) reveals that ecosystem refers to a wide range of phenomena in multiple contexts, to the extent, even, that the use of the term verges on eclecticism. Despite the wide use of multiple terms rooted in the concepts of ecology or ecosystem, the concept has not been adequately defined in the educational field.

The impact of economics seems therefore to be significant in how the concept of ecosystem has come to be understood in education, which generally reflects an economic imperative and a neoliberal perspective. Through the concept of ecosystem, new models of organising collaboration between businesses and educational institutions are being developed in the intermediate space between (higher) education and the world of work. These ecosystems are often enabled by digitalisation; the 'new ecosystems of learning' are often digital ecosystems.

However, one would expect the field of education to also reflect on how the ecosystem concept relates to the ecological challenges of our time. It is somewhat confusing to see that, despite our increasing awareness of the threat of an eco-crisis, the 'new ecosystems of learning' talk rarely addresses the very real environmental challenges that we face or the ontological importance of learning for human beings. The decisive factor in the evolutionary success of humans has been the development of a big brain and the capacity to learn new things to survive. Yet, the current discussion rarely mentions how vital it is for humans to learn to avoid ecological disaster - even when the very existence of our species in the global ecosystem depends on our ability to learn.

\section{Understanding mentoring through ecological principles}

The view of mentoring as an ecosystem of practices introduced in this article is based on the theory of ecologies of practices. In this theoretical 
approach, ecology is taken in its true ontological sense: the human species exists as part of the natural ecosystem and, consequently, human social practices are based on how the species acts to survive and thrive in the ecosystem. Ontologically speaking, humans form a living system that exists within a larger living system. Capra crystallises this ontological view in the following way:

First, every living organism, from the smallest bacterium to all the varieties of plants and animals, including humans, is a living system. Second, the parts of living systems are themselves living systems. A leaf is a living system. A muscle is a living system. Every cell in our bodies is a living system. Third, communities of organisms, including both ecosystems and human social systems such as families, schools and other human communities, are living systems. (Capra, 2005, p. 19)

On this basis, it is clear that human social practices are ontologically intertwined with the other living systems of the global ecosystem. It is also reasonable to assume that human practices form their own level within the natural ecosystem. Therefore, social practices can be supposed, subject to certain reservations, to function in a similar way to species in nature. Practices exist in ecological relationships with one another and in a whole ecosystem of interrelated practices. The theory of ecologies of practices explores whether and (if so) how practices are ecologically connected with one another. We are accustomed to thinking about relationships between practices in terms of the relationships between the practitioners who relate to one another, but we are less familiar with thinking about ecological relationships between practices themselves, which is the main focus in ecologies of practices (Kemmis et al., 2012; Kemmis \& Heikkinen, 2012; Kemmis \& Mutton, 2012).

Assuming practices live and interact with each other, much like an ecosystem, it is possible to study the relationships between them by applying ecological principles. These principles of ecology were first introduced by Fritjof Capra $(2004,2005)$ and further developed and applied to practices of mentoring (Kemmis \& Heikkinen, 2012). Capra originally introduced eight ecological principles and, following Capra's specifications, Kemmis and Heikkinen (2012) introduced another: the principle of ecological niches. In this book, one more principle is suggested, that of ecological resilience. 
Through these ten principles, the intention is to show how (a) mentoring practices, by analogy with species, and (b) ecologies of mentoring practices, by analogy with ecosystems, meet the criteria implied by these ten principles.

Table 1. Ecological Principles (Capra, 2004, 2005; Kemmis et al., 2012; Kemmis \& Heikkinen, 2012; Kemmis \& Mutton, 2012).

\begin{tabular}{|c|c|c|}
\hline $\begin{array}{l}\text { Ecological } \\
\text { principles }\end{array}$ & $\begin{array}{l}\text { If practices are living things and } \\
\text { ecologies of practices are living } \\
\text { systems, then ... }\end{array}$ & $\begin{array}{l}\text { If mentoring is a special practice } \\
\text { within the educational, social } \\
\text { and political ecosystem, then ... }\end{array}$ \\
\hline 1. Networks & $\begin{array}{l}\text { Practices derive their essential } \\
\text { properties and their existence } \\
\text { from their relationships with other } \\
\text { practices. }\end{array}$ & $\begin{array}{l}\text { Mentoring practices derive } \\
\text { their essential properties from } \\
\text { local, regional, national and } \\
\text { international educational and } \\
\text { political practices. }\end{array}$ \\
\hline 2. Nested systems & $\begin{array}{l}\text { Different levels and networks of } \\
\text { practice are nested within one } \\
\text { another. }\end{array}$ & $\begin{array}{l}\text { Mentoring practices are nested } \\
\text { within other educational } \\
\text { practices. }\end{array}$ \\
\hline 3. Niches & $\begin{array}{l}\text { To survive in an ecosystem, the } \\
\text { species (the particular social } \\
\text { practice) must find an ecological } \\
\text { niche that provides optimal living } \\
\text { conditions for that particular species. }\end{array}$ & $\begin{array}{l}\text { Mentoring practices inhabit a } \\
\text { given ecological niche that exists } \\
\text { within certain political and social } \\
\text { conditions in society. }\end{array}$ \\
\hline 4. Interdependence & $\begin{array}{l}\text { Practices within a given ecology } \\
\text { of practices are dependent on one } \\
\text { another, as are different ecologies } \\
\text { of practices. }\end{array}$ & $\begin{array}{l}\text { How mentoring can be } \\
\text { organised depends on how other } \\
\text { educational practices exist and } \\
\text { function within that ecosystem. }\end{array}$ \\
\hline 5. Diversity & $\begin{array}{l}\text { An ecology of practices includes } \\
\text { many different practices with } \\
\text { overlapping ecological functions } \\
\text { that can partially replace one } \\
\text { another. }\end{array}$ & $\begin{array}{l}\text { There are different practices in } \\
\text { the educational ecosystem that } \\
\text { can partially replace one another, } \\
\text { such as mentoring, tutoring, } \\
\text { coaching, supervision, guidance } \\
\text { and counselling. }\end{array}$ \\
\hline 6. Cycles & $\begin{array}{l}\text { Some (particular) kinds of } \\
\text { matter (or in education - practice } \\
\text { architectures, activities, orders } \\
\text { or arrangements) cycle through } \\
\text { practices or ecologies of practices- } \\
\text { for example, as in a food chain. }\end{array}$ & $\begin{array}{l}\text { When new mentoring practices } \\
\text { emerge, they are composed of } \\
\text { elements or features of previous } \\
\text { educational practices that are } \\
\text { being circulated in a new kind } \\
\text { of composition, e.g. peer- } \\
\text { group mentoring evolved from } \\
\text { traditional mentoring. }\end{array}$ \\
\hline 7. Flows & $\begin{array}{l}\text { Energy flows through an ecology } \\
\text { of practices and the practices } \\
\text { within it, being transformed from } \\
\text { one kind of energy to another } \\
\text { (in the way that solar energy is } \\
\text { converted into chemical energy } \\
\text { by photosynthesis) and eventually } \\
\text { being dissipated. }\end{array}$ & $\begin{array}{l}\text { Physical energy flows through } \\
\text { the 'doings', semantic energy } \\
\text { flows through the 'sayings', and } \\
\text { social energy flows through the } \\
\text { 'relating' of the people involved } \\
\text { in the mentoring practices. }\end{array}$ \\
\hline
\end{tabular}

(Continued) 
Table 1. (Continued)

\begin{tabular}{|l|l|l|}
\hline 8. Development & $\begin{array}{l}\text { Practices and ecologies of practices } \\
\text { develop through stages. }\end{array}$ & $\begin{array}{l}\text { Different stages of development } \\
\text { can be seen in the development } \\
\text { of mentoring practices. }\end{array}$ \\
\hline 9. Dynamic balance & $\begin{array}{l}\text { Ecologies of practices regulate } \\
\text { themselves through processes } \\
\text { of self-organisation, and (up to } \\
\text { breaking point) maintain their } \\
\text { continuity in relation to internal } \\
\text { and outside pressures. }\end{array}$ & $\begin{array}{l}\text { The amount of importance given } \\
\text { to mentoring in society varies; } \\
\text { sometimes it is higher on the } \\
\text { political agenda, sometimes } \\
\text { lower. }\end{array}$ \\
\hline 10. Resilience & $\begin{array}{l}\text { To a greater or lesser degree, } \\
\text { practices resist interference from } \\
\text { the outside, and maintain their } \\
\text { balance without changing their } \\
\text { self-organised processes and } \\
\text { structures. }\end{array}$ & $\begin{array}{l}\text { Mentoring practices withstand } \\
\text { disturbances in their } \\
\text { political, social and economic } \\
\text { environment. }\end{array}$ \\
\hline \multicolumn{2}{|l}{} \\
\hline
\end{tabular}

Next, these ecological principles will be applied more closely to the ecosystems of mentoring.

\section{Networks}

Different practices derive their essential properties and their existence from their relationships with other practices.

The practices of mentoring are developed in networks of other educational and political practices (Bjerkholt \& Hedegaard, 2008). Mentoring derives its essential properties and its existence from its relation with other practices, such as the education practices that inform and influence the social practices of a society or state which, in turn, inform and influence the conduct and content of education. The networks in schools, teacher education and continuous professional development are more often informal and based on self-organisation. While some of these networks are explicit and formalised, most are not well-defined and are tacit and implicit in nature. For example, this book is the result of the work of an explicitly and formally-established network. However, the network can also be characterised by its informal and implicit features. Initially, the Nordic Network for Mentoring was developed on the basis of informal communication between researchers, and it was formalised through formal projects funded by, for example, the 
EU, NordPlus and national ministries of education. Sometimes the degree of formality has been higher and sometimes lower (Kemmis \& Heikkinen, 2012).

\section{Nested systems}

Different levels and networks of practice are nested within one another.

The complex of practices that constitute the different national practices of mentoring appear to be 'nested' in other practices and, in this way, to be ecologically related. The idea of nested systems was implied already in the ecological system theory introduced by Bronfenbrenner (Bronfenbrenner, 1979; Godfrey \& Brown, 2019). The practices of teacher induction are constituted in a complex system of education, initial and continuing teacher education, educational policy and administration, and educational research and evaluation in which different systems are nested within one another. The practices of mentoring and teacher induction, for example, are nested in the practices of teacher education and continuing professional development of teachers, which are nested in the general practices of education which, in turn, are nested in national practices that are functionally, politically and economically determined. The chain does not operate in a one-way direction, however. Together, these practices can be said to form an ecology within which the different practices are nested. Each of these practices shapes and influences the other practices that are 'external' to it, and those external practices, in turn, shape and influence the practices that are internal or subsidiary to them (Kemmis et al., 2012). A simplified illustration of this 'nestedness' is visualised in Figure 2 below.

\section{Niches}

To survive in an ecosystem, the species (the particular social practice) must find an ecological niche that provides optimal living conditions for that particular species.

In ecology, 'niche' refers to the distribution of resources and competitors necessary for the survival of an organism. The concept of 'niche' is close 


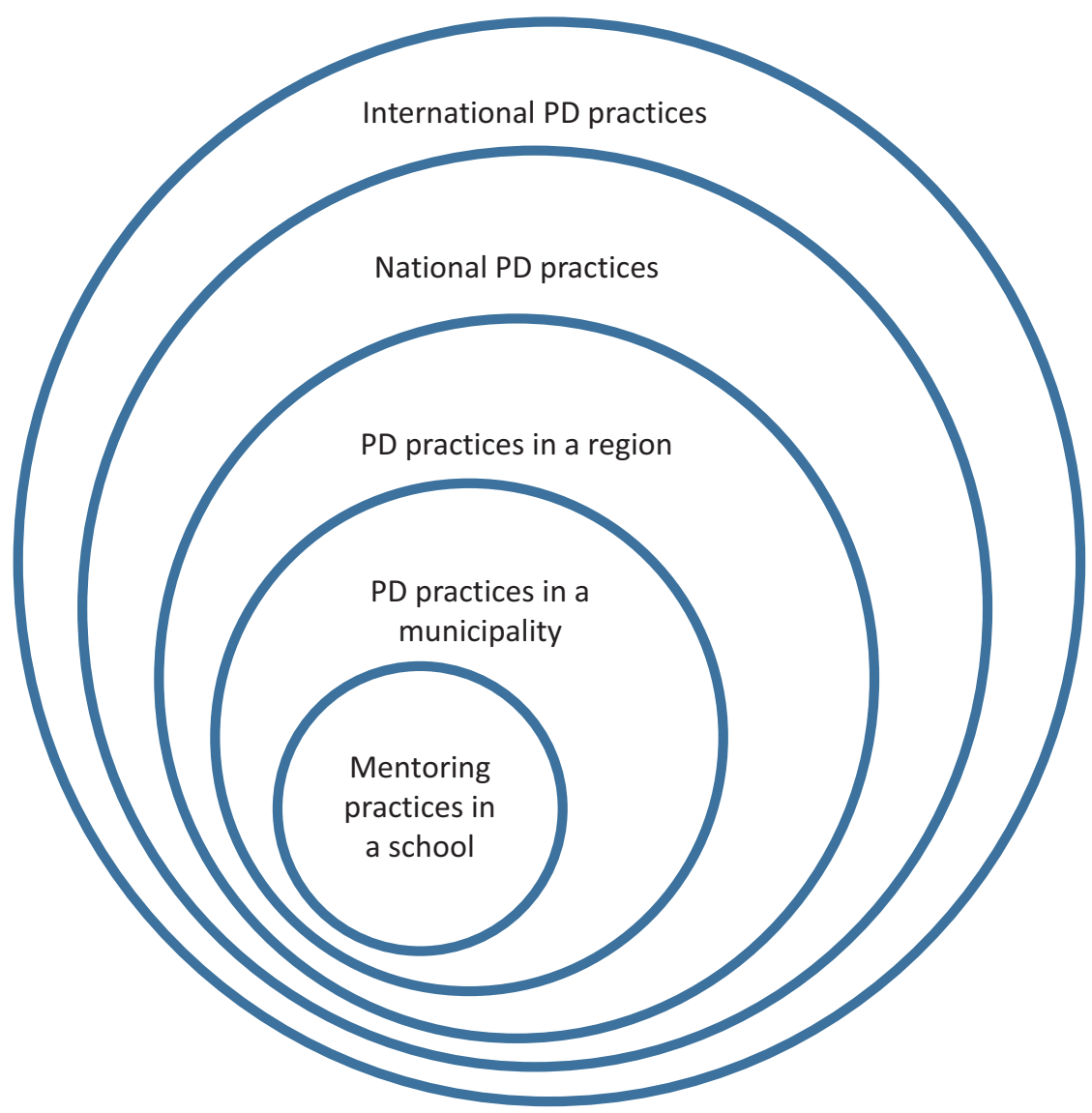

Figure 2. Nestedness of mentoring practices within the municipal, regional, national and international practices of professional development (PD).

to the previous idea of 'nestedness', but emphasises instead the particular substantive content of an environment that provides an organism - or a practice - with the conditions it needs to survive. According to Smith (1999), drawing upon the ideas of Gibson (1986), an ecological niche is

that into which an animal fits ... The niche is that in relation to which the animal is habituated in its behaviour (Gibson, 1986, p. 129). It embraces not only things of different sorts, but also shapes, textures, boundaries (surfaces, edges), all of which are organized in such a way as to enjoy affordancecharacter for the animal in question in the sense that they are relevant to its survival. The given features motivate the organism; they are such as to 
intrude upon its life, to stimulate the organism in a range of different ways.

(Smith, 1999, p. 126)

Similarly, a niche stimulates a practice, providing it with motivations (points of departure), purposes (ends) and the characteristic places and paths in and through which it is enacted. The concept is used not only in ecology but also in business and economy. A 'niche market' is a subset of the market that a specific product seeks to colonise; therefore, the niche defines the specific product features that are needed to satisfy its specific market needs. In both contexts, the entity (an organism or a product) finds its ideal living space in relation to other entities in given conditions and circumstances. Without its niche, a practice cannot be enacted and it cannot survive. On the other hand, a suitable niche can exist and then be colonised by a practice. This relationship is complex, however, because many aspects of niches of practices do not occur in the absence of human agency but as a result of it - as languages and discourses are made and developed by linguistic communities, for example. In this sense, practices appear to build the niches that support them. Thus, both niche and practice develop and evolve in interaction with one another (Kemmis \& Heikkinen, 2012).

\section{Interdependence}

Different practices (understood as different species of practices, manifested in particular individual instances of that practice) are dependent on one another in ecologies of practices (understood as ecosystems) and can be sustained only in interaction with these other practices.

It is easy to imagine how different species in nature are dependent on each other, like bees are dependent on flowers. It is more challenging to understand how whole ecosystems are interdependent, like a coastal rainforest may be dependent on an alpine ecology above it, and vice versa. Some ecosystems are sustained only by their connections with these other ecologies. The same applies to ecologies of practices: to survive and flourish, practices are dependent upon their relationships with other ecologies.

All educational practices, like mentoring and induction, are dependent upon one another and dependent upon their relationships with the processes and practices of the wider society in which they exist. Some 
of these practices are even symbiotic. In Europe, specific national educational practices may also be more or less interdependent with practices in other countries, such as international practices of research collaboration and their administration nationally. At the international level, a clear indication of the interdependence of the practices of teacher induction is that the European Union and the OECD have released a number of political outlines for teacher education and teacher induction (European Commission, 2001, 2007 and 2010; OECD, 2005). Typically, funding instruments are targeted at international projects, making the interconnectedness between mentoring practices even stronger (Kemmis et al., 2012; Kemmis \& Heikkinen, 2012).

\section{Diversity}

An ecology of practices includes many different practices with partiallyoverlapping ecological functions that can partially replace one another.

In teacher induction, many practices seem to co-exist and overlap with one another. There are also informal and spontaneous ways to support new teachers in creating diversity. Many schools employ special local practices through which new teachers are supported. Some of these activities can substitute, or replace, others as needs and circumstances require. These arrangements diversify according to the size of the school or municipality or, for example, geographical and population structures. In capital regions, for example, practical arrangements look quite different from those in more remote northern parts of the Nordic region.

At the international level, we can find a lot of diversity in the practices of teacher education and induction. In many countries, induction practices are more or less based on classical one-to-one mentoring. Sometimes the term 'tutoring' is even used synonymously with mentoring. In the school context, tutoring often refers to older students, i.e. tutors, acting as advisers, guides and 'databanks' for younger students or pupils. Tutoring activities have been actively developed in various educational institutions and, for example, most universities provide yearly tutor training for students to be able to support new students. Tutoring is sometimes also 
provided by teachers: at the initial stage, student groups are guided by one of the school's teachers. In this, the main difference between tutoring and mentoring is the context: tutoring is often used in an educational context while mentoring often occurs in working life. In other words, tutoring is associated with formal education, while mentoring is a form of non-formal training and guidance implemented in the workplace. As the forms of non-formal and formal education overlap, it is natural that the interpretations of mentoring and tutoring also overlap to some extent (Heikkinen, Jokinen, \& Tynjälä, 2012; Kemmis \& Heikkinen, 2012).

Sometimes, however, the term 'tutor' is used in the context of working life, for example in the UK where the term induction tutor has been introduced. The induction tutor is a more experienced teacher who has dayto-day responsibility for monitoring, supporting and assessing a newly qualified teacher. Induction tutors are expected to provide guidance and support, and make judgments on the performance of the new teacher through formative assessment activities that include observations and meetings to review progress at least every half-term. The induction tutor is expected to provide formative assessment and often be involved in the formal, summative assessment at the end of induction (Heikkinen et al., 2012; Kemmis \& Heikkinen, 2012).

Coaching has been adopted into working life as a staff training method. Its meaning is fairly broad and vague, and its relation to the concepts of mentoring and on-the-job instruction is interpreted in a variety of ways. It is common for training enterprises to offer coaching and mentoring simultaneously. Educational services are marketed under the concept of coaching also with such names as change coaching, solution-based coaching, life coaching and brain-based coaching. The concept of coaching has also been linked to mentoring outside of business-world staff training. In the context of teacher education, the term 'coaching' is often used synonymously with mentoring. Mentoring in these contexts is associated with supervision and control, whereas coaching provokes a mental image of support provided to students in a way that respects their autonomy in order for them to achieve the goals they have set for themselves. This interpretation, nevertheless, has not been broadly used within the international teacher education debate (Kemmis \& Heikkinen, 2012). 
Another example of the diversity of practices is the Norwegian practice of 'veiledning', related to that of mentoring although there seems to be no national consensus among Norwegians on the precise meaning of this concept (Olsen, 2011, p. 16). There are also some advocates of mentoring in Norway, and this conceptualisation seems to be associated with a certain group of educationalists who highlight certain differences in how things are done within the practice of mentoring. Thus, diversity exists not only in concepts, but also in the actions and arrangements and the collective identity of researchers and teacher educators. In the latter example, the collective identity of advocates of mentoring is achieved through a sense of otherness in contrast to those associated with veiledning.

\section{Cycles}

Matter cycles through practices.

From this perspective, we can observe that different kinds of matter cycle through practices like nutrients in a food chain. Although the food chain concept can be portrayed as linear, it is more accurately understood as a cycle in which the predators at the top of the chain die and are eaten by creatures further down. Specific practices cycle through history in the form of practice traditions that vary across time and space. For example, a child becomes a student who practises learning from a teacher who practises teaching, and goes on to become a teacher teaching students in the rising generations that follow. In turn, a new teacher enters the practice traditions of the school and the national educational culture. Some of these practice traditions seem to carry features of the initiation rites of ancient tribes; the newcomer has to meet with pain and public humiliation so as to achieve the status of an adult and full member of the tribe. In military service, for example, there is a long tradition of humiliation of newcomers, and we may easily find sad examples of those practices also within the school tradition being reproduced by new generations.

These practice traditions are not, however, reproduced without variation or difference; they are also constantly being transformed in the light 
of changing historical, social and local conditions. Thus, ideas that first emerged centuries or millennia ago still circulate today with changed nuances or more elaborate meanings - or even come to mean something very different to what they once meant. And the same holds true for different kinds of activities and different kinds of relationships between people in different roles. For example, the relationships between moreexperienced teachers and new teachers and students are reproduced and transformed cyclically. When a new practice emerges, it is composed of elements or features of previous practices that are then recirculated as part of the new composition (Kemmis \& Heikkinen, 2012).

The circulation of practices is evident, too, in the various national practices supporting new teachers. They circulate each other's practices and the practices of local traditions. The Norwegian veiledning is, again, a good example. It fruitfully circulates many of the practices common to many of the pre-service teacher education programmes in the Western world. The circulation of practices therefore takes place in many ways and at many levels and - as in the natural world - the 'food chains' involved vary in length.

\section{Flows}

Energy flows through ecologies of practices and the practices within them, being transformed from one kind of energy to another (in the way that solar energy is converted into chemical energy by photosynthesis) and eventually being dissipated.

In ecology, physical energy is transformed from one form to another as it flows through biological systems. In the human and social world, we can draw an analogy with the different kinds of energy transferred and expended when people carry out various practices. Like other biological organisms, the participants need physical energy. That is, physical energy flows through practices as it does through the 'doing' of the people involved in a practice. However, there are also different forms of energy that flow through practices: what we might call semantic energy that flows through practitioners' 'sayings' in a practice, and social energy that flows through practitioners' 'relating' in a practice. In each of these 
additional dimensions there is a flow of energy analogous to the flow of physical energy through the biological entities participating in practices (Kemmis et al., 2012; Kemmis \& Heikkinen, 2012).

\section{Development}

Practices and ecologies of practices develop through stages.

The practices of teacher induction have evolved from mentoring practices over a very long time. The origin of the concept of mentoring is based on Homer's (between $8^{\text {th }}$ and $6^{\text {th }}$ century BCE) epic poem The Odyssey about Odysseus, King of Ithaca. In this ancient tale, Odysseus asks his friend Mentor to watch over his son Telemachus while he fights the Trojan War. The first recorded modern usage of the term has been traced to another book 'Les Aventures de Télémaque', written by Francois Fénelon in 1699 in France. This has been regarded as the source of the modern use of the word 'mentor' to mean a trusted friend, counsellor or teacher, usually a more-experienced person. In traditional one-to-one mentoring, newcomers are paired with a more-experienced person who advises them and serves as a role model. Today, mentors often provide expertise to lessexperienced individuals to help them advance in their career, enhance their education, and build networks. In education, this type of mentoring still seems to be the most commonly practiced internationally. Newer forms of mentoring, such as the Finnish peer-group mentoring (PGM) model, have, however, emerged in recent years, indicating that the practice of mentoring does seem to be evolving.

Likewise, mentoring as a part of the induction arrangements for new teachers is developing within wider ecologies of practices. Where teacher education is regarded as the formation of each individual teacher, and where induction is seen as the responsibility of the employer to each individual employee, then more individualist forms of mentoring are likely to be found and individualist perspectives will pervade throughout the ecology of practices. Similarly, where more communitarian practices are pursued, more collectivist ecologies of practices will emerge (Heikkinen et al., 2012; Kemmis et al., 2012; Kemmis \& Heikkinen, 2012). 


\section{Dynamic balance}

Ecologies of practices regulate themselves through processes of self-organisation, and maintain (up to breaking point) their continuity in relation to internal and outside pressures.

Living systems are not static; they are in a dynamic balance. This is contrary to the kind of balance reached when equal opposing forces meet, when things are in stasis, and action stops. Living systems are characterised by constant change, as are practices in the day-to-day life of a school or a classroom. But keeping things in balance is possible only within limits. Living systems continually bring themselves back into balance when they encounter crisis points, resistance, critical incidents, confusion, instability, lack of flexibility and disturbance.

In the case of teacher induction practices, many national education practices have reached a crisis point or a critical stage as the number of teacher retirements and resignations has increased. To address this crisis in the teaching workforce, governments are having to find new balance within and between different ways of conceptualising the process of beginning teaching: the material-economic resources allocated to teacher education and induction; and the ways of connecting the students and teachers involved in pre-service teacher education, teachers in schools, new teachers coming to schools, and the people assisting them in making their transition to school work and to the school as a workplace. In doing so, they are engaging in developing a variety of individual practices that contribute to the ecology of practices, and thus assisting the development of the ecology as a whole (Heikkinen et al., 2012; Kemmis et al., 2012; Kemmis \& Heikkinen, 2012).

\section{Resilience}

To a greater or lesser degree, practices resist interference from the outside, and maintain their balance without changing their self-organised processes and structures.

The concept of resilience, originally derived from physics, has been utilised in many fields, such as ecology and psychology. Generally speaking, 
resilience refers to the capacity to rebound, to 'bounce back'. In positive psychology, it means an ability to resist or recover from adversity, uncertainty, conflict or failure. It can also be defined as 'the ability of an individual, team, or school to adapt to changing demands, to recover, and to remain vigorous after the changes have occurred' (Kunnari, 2018, p. 112).

The principle of resilience is closely related to the above-mentioned ecological principles and, especially, to the concepts of interdependence and dynamic balance. Practices sometimes come into conflict with each other - this indicates that these practices are interdependent of each other, i.e. out of balance with each other, in the ecosystem. If the dynamic balance of a given practice is disturbed to tipping point, the practice can either lose its state of stability and collapse or die, or, alternatively, transform to another stable state. Resilience means resistance to critical incidents, confusion and instability. Resilient practices are flexible and can sustain disturbances in their political, social and economic environment and thus maintain their balance without changing their self-organised processes and structures.

\section{Conclusions: possibilities and limitations of the ecological view}

Many of the ecological principles that we have introduced above are explored in a variety of fruitful ways in the forthcoming articles of this book. As we delve deeper into these, it is good to be aware of the limitations of the analogy between social practices and ecosystems. We can easily agree with Capra about the ontological foundations and the ecological layers or levels of practices. It sounds plausible to suggest that if every living organism is a living system, also communities of organisms, including social systems, are living systems (Capra, 2005, p. 19). However, there are also some ontological differences. Homo sapiens is, in many unique respects, very different from other species, and we must be careful not to over-simplify social action; our species is also developing qualities that might earn us the title of Homo Deus, the divine man (Harari, 2016). Anthony Giddens (1979) also points out the ontological differences between natural systems and human social systems in terms 
of reflexivity: human social systems are reflexive systems, capable of self-organisation through human reason and communication, whereas other natural systems operate merely through homeostatic causal loops (mechanical systems) or organic self-regulation (autopoietic systems).

The theory of ecologies of practices helps us understand the practices of mentoring to a point, but it does not quite illuminate all of the features of mentoring. Perhaps it would be wise to suggest that all theories have both their limitations and their opportunities. As Ludwig Wittgenstein (1922/2015) suggested, theories can be used as ladders to climb to new levels of understanding. But as soon as we achieve that new understanding and aspire to reach an even higher level, we can no longer use the same ladder; we have to throw it away, and find a new one.

\section{References}

Barnett, R., \& Jackson, N. (2020). Ecologies for learning and practice: Emerging ideas, sightings and possibilities. Abingdon, England: Routledge.

Bjerkholt, E., \& Hedegaard, E. (2008). Systems promoting new teachers' professional development. In G. Fransson \& C. Gustafsson (Eds.), Newly qualified teachers in Northern Europe: Comparative perspectives on promoting professional development (pp. 45-75). Gävle: University of Gävle.

Boutang, Y. M. (2003). Capitalisme cognitif et nouvelles formes de codification du rapport salarial [Cognitive capitalism and new forms of codification of salarial relationships]. In C. Vercellone \& F. Chesnais (Eds.), Sommes-nous sortis $d u$ capitalisme industriel? [Are we out of industrial capitalism?] (pp. 305-328). Paris, France: La Dispute.

Bronfenbrenner, U. (1979). The ecology of human development: Experiments by nature and design. Cambridge, MA: Harvard University Press.

Burton-Jones, A. (2003). Knowledge capitalism: The new learning economy. Policy Futures in Education, 1(1), 143-159.

Capra, F. (2004). The hidden connections: A science for sustainable living. New York, NY: Anchor.

Capra, F. (2005). Speaking nature’s language: Principles for sustainability. In M. K. Stone \& Z. Barlow (Eds.), Ecological literacy: Educating our children for a sustainable world (pp. 18-29). San Francisco, CA: Sierra Club Books.

Darwin, C. (2009, original work published 1859). On the origin of species: Or the preservation of favoured races in the struggle for life. Retrieved from http://www. gutenberg.org/files/1228/1228-h/1228-h.htm 
European Commission (2001). Making a European area of lifelong learning a reality. Brussels, Belgium. Retrieved from https://epale.ec.europa.eu/en/resource-centre/ content/making-european-area-lifelong-learning-reality-communicationcommission-com

European Commission (2007). Improving the quality of teacher education. Brussels, Belgium. Retrieved from https://eur-lex.europa.eu/legal-content/EN/TXT/ $\mathrm{PDF} /$ ?uri=CELEX:52007DC0392\&from $=\mathrm{EN}$

European Commission (2010). Developing coherent and system-wide induction programmes for beginning teachers: A handbook for policymakers. Brussels, Belgium. Retrieved from https://ec.europa.eu/assets/eac/education/policy/school/ doc/handbooko410_en.pdf

Fetters, M. L., Greene, P. G., Rice, M. P., \& Butler, J. S. (Eds.) (2010). The development of university-based entrepreneurship ecosystems: Global practices. Cheltenham, England: Edward Elgar.

Gibson, J. J. (1986). The ecological approach to visual perception. Hillsdale, NJ: Lawrence Erlbaum Associates.

Giddens, A. (1979). Central problems in social theory: Action, structure and contradiction in social analysis. Berkeley, CA: University of California Press.

Godfrey, D, \& Brown, C. (Eds.) (2019). An ecosystem for research-engaged schools: Reforming education through research. Abingdon, England: Routledge.

Groth, O. J., Esposito, M, \& Tse, T. (2015). What Europe needs is an innovationdriven entrepreneurship ecosystem: Introducing EDIE. Thunderbird International Business Review, 57(4), 263-269.

Harari, Y. N. (2016). Homo Deus: A brief history of tomorrow. London, England: Harvill Secker.

Heikkinen, H. L. T. (2018). Education, work and life. In C. Edwards-Groves, P. Grootenboer \& J. Wilkinson (Eds.), Education in an era of schooling: Critical perspectives of educational practice and action research. A festschrift for Stephen Kemmis, (pp. 79-9o). Singapore, the Republic of Singapore: Springer Nature.

Heikkinen, H. L. T., Jokinen, H., \& Tynjälä, P. (2012). Teacher education and development as lifelong and lifewide learning. In H. L. T. Heikkinen, H. Jokinen \& P. Tynjälä (Eds.), Peer-group mentoring for teacher development (pp. 3-30). Abingdon, England: Routledge.

Kemmis, S., \& Heikkinen, H. L. T. (2012). Future perspectives: Peer-group mentoring and international practices for teacher development. In H. L. T. Heikkinen, H. Jokinen \& P. Tynjälä (Eds.), Peer-group mentoring for teacher development (pp. 144-170). Abingdon, England: Routledge.

Kemmis, S., \& Mutton, R. (2012). Education for sustainability (EfS): Practice and practice architectures. Environmental Education Research, 18(2), 187-207. 
Kemmis, S., Edwards-Groves, C., Wilkinson, J., \& Hardy, I. (2012). Ecologies of practices. In P. Hager, A. Lee \& A. Reich (Eds.), Practice, learning and change: Practice-theory perspectives on professional learning (pp. 33-49). Dordrecht, Germany: Springer.

Kunnari, I. (2018). Teachers changing higher education: From coping with change to embracing change. Doctoral dissertation, University of Helsinki, Finland.

Moore J. F. (1993). Predators and prey: A new ecology of competition. Harvard Business Review, 71(3), 75-86.

OECD. (2005). Attracting, developing and retaining effective teachers - final report: Teachers matter. Retrieved from https:/www.oecd.org/education/school/attractin gdevelopingandretainingeffectiveteachers-finalreportteachersmatter.htm

Olsen, K.-N. (2011). Aktører og roller [Actors and roles]. In E. Høihilder \& K.-R. Olsen (Eds.), Veiledning av de nye loerere i skole og barnehage [Mentoring of new teachers in schools and kindergartens] (pp. 14-18). Oslo, Norway: PEDLEX.

Peters, M. A., \& Bulut, E. (Eds.) (2011). Cognitive capitalism, education, and digital labor. New York, NY: Peter Lang.

Powell, W. W., \& Snellman, K. (2004). The knowledge economy. Annual Review of Sociology, 30(1), 199-220.

Savin-Baden, M. (2020). Learning ecologies: Liminal states and student transformation. In R. Barnett \& N. Jackson (Eds.), Ecologies for learning and practice: Emerging ideas, sightings, and possibilities (pp. 46-6o). Abingdon, England: Routledge.

Smith B. (1999). Truth and the visual field. In Petitot J., Varela F. J., Pachoud B., \& Roy J.-M. (Eds.), Naturalizing phenomenology: Issues in contemporary phenomenology and cognitive science (pp. 317-329). Stanford, CA: Stanford University Press.

Virolainen, M., Heikkinen, H. L. T., Siklander, P., \& Laitinen-Väänänen, S. (2019). Mitä ovat oppimisen ekosysteemit? [What are ecosystems of learning?]. Ammattikasvatuksen aikakauskirja, 14(4), 4-25.

Wals, A. E. J. (2020). Sustainability-oriented ecologies of learning: A response to systemic global dysfunction. In R. Barnett \& N. Jackson (Eds.), Ecologies for learning and practice: Emerging ideas, sightings and possibilities (pp. 98-120). Abingdon, England: Routledge.

Willis, A. J. (1997). The ecosystem: An evolving concept viewed historically. Functional Ecology, 11(2), 268-271.

Wittgenstein, L. (2015, original work published 1922). Tractatus Logico-Philosophicus: Logisch-philosophische abhandlung. Retrieved from http://writing.upenn.edu/ library/Wittgenstein-Tractatus.pdf 



\title{
Support for Newly Qualified Teachers Through Teacher Induction Programs - a Review of Reviews
}

\author{
Lisbeth Lunde Frederiksen \\ VIA University College, Denmark
}

\begin{abstract}
This article gives an overview - in the form of a "review of reviews" of existing knowledge in the research on teacher induction programs in primary and secondary schools. The article is based on seven reviews. The article describes the various elements that can make up teacher induction programs in primary and secondary schools, and shows that such programs - with their various content and contexts - can contribute to the professionalization of teaching. This includes the development of insight, self-efficacy, and self-esteem. Induction training can counteract burnout, strengthen teacher resilience and thereby facilitate continuing professional development and a firm foothold in the job as a teacher.
\end{abstract}

Keywords: teacher induction program, mentoring, teacher retention, professional development, school culture, foothold

\section{Introduction}

For some decades, there has been national and international interest in researching how newly qualified teachers gain a foothold in the profession.

In the research literature, various challenges are identified in relation to starting work as a new teacher. One challenge is that a large proportion of the work takes place in isolation from colleagues, despite teamwork being widespread in schools; thus, the new graduate is left to his or her own classroom, to either fail or succeed (Ingersoll \& Strong, 2011; Johnsen

Citation of this article: Frederiksen, L. L. (2020). Support for newly qualified teachers through teacher induction programs - a review of reviews. In K.-R. Olsen, E. M. Bjerkholt \& H. L. T. Heikkinen (Eds.), New teachers in Nordic countries - ecologies of mentoring and induction (Ch. 2, pp. 49-70). Oslo: Cappelen Damm Akademisk. https://doi.org/10.23865/noasp.105.ch2

License: CC-BY 4.0. 
\& Birkeland, 2003). Teaching in primary and secondary schools is a job with a relatively high degree of attrition, especially among new graduates. Some studies show that up to $40 \%$ leave their jobs within the first five years (Ingersoll \& Strong, 2011, p. 3). One reason is lack of adequate support from school management (Ingersoll \& Strong, 2011).

Beyond Denmark, in the past few decades, there has been an increase in the number of newly qualified teachers participating in some form of teacher induction. Teacher induction programs refer to a number of different types of activities, which may vary locally. Induction programs can be described as representing a "bridge from student of teaching to teacher of students" (Ingersoll \& Strong, 2011, p. 203).

At the Center for Pedagogy and Education, VIA UC, in the "Mentoring and Guidance" program, we are developing design principles for the implementation of effective teacher induction programs in a Danish context. In relation to that I have been interested in gaining an overview of existing international knowledge and, therefore, ask the following questions: What does international research say about teacher induction schemes? What elements can such a program comprise, and what should one be aware of if it is to be effective and give teachers a firm foothold throughout an active and continuing lifelong learning process?

\section{Method}

The ambition was to establish an overview of existing knowledge in this research area and the significance of such programs in giving teachers a foothold in their teaching work. With regard to approach I chose a review of reviews. A traditional review is based on a systematic survey of all relevant studies in the form of primary studies about a specific issue (Launsø \& Rieper, 2016). Instead, I chose to conduct a review based on a systematic survey of secondary studies, in the form of relevant systematic reviews, surveys, meta-analyses and syntheses, in the period 2006-2016. The general principles from the review method have been used (Dyssegaard, Larsen, Lindstrøm \& Johansen, 2013; Gough, Thomas \& Oliver, 2012; Rosén, 2012). In this way, with relatively few resources, I could summarize already-existing knowledge in the field. 
The review process consisted of a literature search, relevance screening, quality screening, and a synthesis of the results of the selected secondary studies through a thematic analysis.

\section{Literature search and relevance screening}

A number of keywords were identified as the starting point for my search. I started out with a broad topic search and narrowed the search criteria as I went along. The subject search was structured as a block search (Kristiansen \& Hjørland, 2013) in the following search string: (systematic review OR meta-analysis OR metaanalysis OR meta-synthesis OR metasynthesis OR overview) AND (beginning teacher ${ }^{\star} \mathrm{OR}$ novice teacher ${ }^{\star} \mathrm{OR}$ new teacher ${ }^{\star} \mathrm{OR}$ newly qualified teacher ${ }^{\star} \mathrm{OR}$ newly employed teacher) AND (induction program ${ }^{\star} \mathrm{OR}$ mentor ${ }^{*} \mathrm{OR}$ retention ${ }^{\star} \mathrm{OR}$ support ${ }^{*}$ ).

I searched two bibliographic databases: ERIC (Education Resource Information Center) and PsycINFO. The search criteria were peerreviewed articles published between 2006 and 2016. Then I conducted an exclusion process based on relevance (Dyssegaard et al., 2013). All references found were read, based on explicit relevance criteria, in order to determine whether a reference should be included or excluded. My inclusion criteria were: meta-analyses, meta-syntheses, systematic reviews and overviews of the significance of teacher induction programs and other forms of support for newly qualified and newly-employed teachers and, specifically, their significance in retention and in their professional, personal and social development of new teachers. The results were:

In ERIC, nine articles were found out of 39 references, and in PsycINFO, two articles out of 12 references. Furthermore, a chain search was performed based on the included references with no results returned.

\section{Screening for quality}

The literature search resulted in 11 relevant articles, evaluated in full text. The next phase of the review process was quality screening (Dyssegaard et al., 2013). All included articles were evaluated for quality based on the following criteria: credibility, transparency, and the degree of methodological reflection (Tanggaard, 2015). The specific preparation and 
organization of the checklists (Walsh \& Downe, 2005) for the assessment were determined by the research method of each article.

\section{Checklists and evidence assessment of the reviews}

I did quality screening on the basis of the following quality criteria: 1. Clear method description (is there a systematic data collection, transparency, and methodological reflection in the inclusion work, the analysis process, and the synthesis process?) 2. Discussion and conclusion (is the usefulness of the results discussed? Is the conclusion credible?)

The quality screening led to the exclusion of four reviews based on their low quality (Rosén, 2012), while articles assessed with medium or high quality were included. This led to the inclusion of the following seven articles in the further process: Greenfield (2014), Guarino, Santibanez, \& Daley (2006), Hobson, Ashby, Malderez, \& Tomlinson (2009), Ingersoll and Strong (2011), Schaefer, Long, \& Clandinin (2012), Shockley et al. (2013) and Wang, Odell, \& Sharon (2008).

Tabel 2. Scope of studies in the included reviews, and the research questions/aims linked to the reviews.

\begin{tabular}{|l|l|l|}
\hline Review & Scope & Aims/Research questions \\
\hline $\begin{array}{l}\text { Greenfield } \\
\text { (2015) }\end{array}$ & 6 studies & $\begin{array}{l}\text { How can teacher resilience be protected and } \\
\text { supported? }\end{array}$ \\
\hline $\begin{array}{l}\text { Guarino et al. } \\
\text { (2006) }\end{array}$ & 46 studies & $\begin{array}{l}\text { What strategies promote the recruitment and } \\
\text { retention of teachers? }\end{array}$ \\
\hline $\begin{array}{l}\text { Hobson et al. } \\
\text { (2009) }\end{array}$ & $\begin{array}{l}\text { 170 relevant texts } \\
\text { The article is included } \\
\text { because of relevant } \\
\text { content }\end{array}$ & $\begin{array}{l}\text { What do we know about the mentoring of new } \\
\text { teachers: pros and cons for new teachers, benefits for } \\
\text { mentors, for schools and for the education system? }\end{array}$ \\
\hline $\begin{array}{l}\text { Ingersoll and } \\
\text { Strong (2011) }\end{array}$ & $\begin{array}{l}15 \text { studies } \\
\text { Schaefer et al. }\end{array}$ & $\begin{array}{l}\text { A study of what we know and don't know about the } \\
\text { effectiveness of teacher induction programs and } \\
\text { mentoring schemes. }\end{array}$ \\
\hline $\begin{array}{l}\text { Shockley } \\
\text { et al. (2013) }\end{array}$ & 10 studies & $\begin{array}{l}\text { A study of research on attrition and retention of } \\
\text { teachers. }\end{array}$ \\
\hline $\begin{array}{l}\text { Wang et al. } \\
\text { (2008) }\end{array}$ & 21 studies & $\begin{array}{l}\text { Which elements of teacher induction programs help } \\
\text { to reduce teacher attrition and promote the quality of } \\
\text { teaching? }\end{array}$ \\
\hline
\end{tabular}


In my present review of reviews, I have relied solely on the descriptive studies mentioned above, as the review method generally does (Dyssegaard et al., 2013; Gough et al., 2012; Rosén, 2012). This means that, apart from the included articles, I have not included other relevant publications or materials that were not published within the time frame or that did not meet the above quality criteria.

\section{Thematic analysis}

In accordance with the purpose of this review of reviews I conducted a thematic analysis vertically and horizontally based on the condensation of the texts. First, I made an analysis of the individual study/review; next, I made a transverse reading with subsequent thematization (Braun \& Clarke, 2006). The following themes were identified: 1) Teacher induction programs; 2) The mentor; 3) School culture and context; and 4) A firm footing as teacher, including transition from student to teacher.

\section{Teacher induction programs}

To facilitate the overview, I have divided the first theme "teacher induction programs" into three sub-themes: elements of teacher induction programs, goals and duration, and joint planning and collaboration.

\section{Elements of teacher induction programs}

In five of the seven reviews (Guarino et al., 2006; Ingersoll \& Strong, 2011; Schaefer et al., 2012; Shockley et al., 2013; Wang et al. 2008), the program includes and extends beyond mentoring; there may also be collaboration with colleagues, various network groupings (new and experienced teachers together or as peers), peer-teaching observations, observation of the newly qualified teacher, management support and assistance, salary conditions, and time compensation. In two reviews, leadership support is an element of the program, exemplified by supportive communication, and support from management and administration (Shockley et al., 2013; Schaefer et al., 2012). Furthermore, teacher induction may include 
seminars, courses, workshops and team teaching (Shockley et al., 2013; Wang et al., 2008). However, these elements are not elaborated on in more detail in the mentioned five reviews.

Furthermore, time reduction is a factor, albeit a weak one (Ingersoll \& Strong, 2011), if such resource allocation is not coupled with support for professional learning and/or joint planning time (Schaefer et al., 2012). With regard to salary conditions (e.g. salary for mentoring time), the studies do not show clear results concerning their effect (Schaefer et al., 2012).

\section{Objectives and duration vary in the programs}

The goals and duration of the programs vary in the studies included in the reviews. The primary goals are to become better at teaching ("performance") and to retain teachers. However, the reviews show that there is a relatively wide range of goals that are contextualized locally - which is a point in itself (Schaefer et al., 2012).

According to Schaefer et al. (2012), there are not many programs in which new recruits are regarded as knowledgeable teachers, or as contributing members of a collegial group from whom other experienced teachers can learn. From this perspective, Schaefer et al. (2012), point out that there is a need for mentors who appreciate the knowledge of new graduates. They also point out that new teacher induction programs in the United States and New Zealand argue against "one size fits all" versions of programs. There is often talk of deficit thinking in such programs, and an idea that teacher induction should "fix" a problem. Instead, they believe that programs should draw on the knowledge and experience that the new teacher brings; i.e. that they be considered as contributing members who can teach experienced colleagues something:

Beginning teachers need mentors that value the knowledge and past experiences they bring to the professional landscape. They also need mentors who are skilled in helping them learn in, and from practice. Induction policies need to focus attention equally on new teachers and on their mentors. (Schaefer et al., 2012, p. 117) 
Teacher induction programs should, therefore, not only retain newly qualified teachers in the teaching profession, but also sustain and develop them so that they feel satisfied and regard themselves as being able to contribute in a qualified way in a professional context. "We suggest the need to shift the conversation from one focused only on retaining teachers towards a conversation about sustaining teachers throughout their careers." (Schaefer et al., 2012, p. 118).

The duration of induction programs is briefly touched on in two reviews (Ingersoll \& Strong, 2011; Shockley et al., 2013). The longer and more comprehensive schemes, which run over at least two years and offer depth of support, have an effect as evidenced by six studies (Ingersoll \& Strong, 2011). However, Shockley et al. (2013) mention that the length of programs varies to such an extent that nothing can be inferred in general.

\section{Joint planning and collaboration}

An important element of the five reviews mentioned above is variation of joint planning and collaboration (Wang et al., 2008; Guarino et al., 2006; Ingersoll \& Strong, 2011; Schaefer et al., 2012; Shockley et al., 2013). In addition to joint planning and close collaboration with the mentor, planning with other colleagues is effective. This is also true of regular scheduled collaboration meetings with colleagues (Wang et al., 2008; Guarino et al, 2006; Ingersoll \& Strong, 2011; Shockley et al., 2013). Ingersoll and Strong (2011) further point out, with reference to Kapadia, Cora, \& Easton's study (2007), that teacher collaboration and support from management appear to be the most influential factors for new teachers.

According to Wang et al. (2008), good opportunities to learn from each other and develop one's own teaching are provided when newly qualified teachers - based on what they have learned in their teacher training - collaborate with other newly qualified teachers who have the same starting point, visions, norms and teaching values. Thus, Wang et al. (2008) emphasize that learned notions of good teaching and basic knowledge play a major role in what newly qualified teachers can learn through teacher induction programs. Therefore, with reference to Feiman-Nemser $(1983,2001)$ and 
Odell, Huling, \& Sweeny (1999), Wang et al. (2008) suggest that programs should be considered as a continuum from teacher training to the profession, which is elaborated in the discussion section in this article. In this context, with reference to Wang and Odell (2002), it is emphasized that mentors need increased knowledge and skills (Wang et al., 2008). Networks of both new and experienced teachers together are another element of some programs (Guarino et al., 2006; Shockley et al., 2013).

One of the most valued approaches to supporting new teachers' induction is mutual lesson observation and observation-based discussion. It may include observation of one's own and experienced colleagues' teaching, and can be followed by discussions and feedback with a mentor and/ or colleagues (Hobson et al., 2009; Schaefer et al., 2012; Shockley et al., 2013; Wang et al., 2008).

\section{Mentoring schemes}

A mentoring scheme is often included as an element of teacher induction, and such schemes are identified in the literature as the most frequently found teacher induction strategy (Shockley et al., 2013). The studies show that the overall purpose of associating a newly qualified or newly employed teacher with a mentor has primarily been to give the newcomer a "local guide". To facilitate the overview the theme of mentoring schemes is divided into four sub-themes, elaborated below: characteristics and content, retention of new teachers, personal development and mentor knowledge and training. The sub-themes emerged from a cross-analysis with subsequent categorization of the findings.

\section{Characteristics and content}

The mentoring schemes described in the studies have a wide variation in character and content, and they take place in very different contexts. A mentoring scheme can range from a single meeting at the start of employment to a structured and formalized course with several meetings over a period of several years where time is allocated to both mentor and mentee for this collaboration (Ingersoll \& Strong, 2011). Shockley 
et al. (2013) emphasize that regular reflection meetings between an experienced colleague and a recent graduate are an inexpensive, easy-toimplement strategy (Shockley et al., 2013). Several studies emphasize that a mentoring scheme needs to have three key elements for supporting retention and professional development: a) that the mentor is trained to be a mentor; b) that mentoring is not the only strategy in a teacher induction; and c) that contextual conditions (e.g. school culture) are essential for mentoring to be an effective strategy in the retention of new teachers in the job, and in supporting new teachers' professional, personal and social development (Guarino et al., 2006; Hobson et al., 2009; Ingersoll \& Strong, 2011; Schaefer et al., 2012; Shockley et al., 2013; Wang et al., 2008).

In Wang et al.'s review, it is stated with reference to Hall, Johnson, and Bowman (1995), Luft and Cox (2001) and Williams, Prestage, and Bedward (2001), that newly qualified teachers value formalized and structured mentoring that focuses on teaching observation and observationbased discussions, i.e. lesson-based discussions with a mentor in combination with interactions and feedback.

\section{Retention of new teachers}

Mentoring and other forms of support can promote retention. For example, Guarino writes, “Those who experienced induction and mentoring support in their first year of teaching were less likely to leave teaching or change schools." (Guarino et al., 2006, p. 197). However, there are conflicting results (Guarino et al., 2006; Schaefer et al., 2012; Shockley et al., 2013).

According to Ingersoll and Strong (2011), mentoring is identified as a crucial factor in teacher induction programs in relation to retaining new teachers at schools in well-performing school districts, especially when the mentor is from the same professional field and age. However, with reference to Glazerman et al.'s (2010) research in a school district with socioeconomic challenges, Ingersoll and Strong (2011) emphasize that the inclusion of mentoring in teacher induction programs is not enough to reduce the incidence of new teachers' relocating in cases where the schools are in areas with many socioeconomic challenges. 
As previously mentioned, Shockley et al. (2013) underline that it is important for mentors to be trained in mentoring if such schemes are to work, and that mentoring is not the only induction strategy (Shockley et al., 2013).

\section{Personal development - development of resilience}

Teacher induction programs that include mentoring schemes have a positive impact on new teachers' classroom management (Hobson et al., 2009) and teaching quality (Hobson et al., 2009; Ingersoll \& Strong, 2011), and have a positive impact on students' learning outcomes (Ingersoll \& Strong, 2011). Hobson et al. (2009) state that mentoring schemes also reduce the experience of isolation in the newly qualified teacher, and increase self-confidence and self-esteem. Likewise, mentoring can increase one's capacity for professional self-reflection and the ability to solve problems.

Mentoring can support the development of resilience in newly qualified teachers. Resilience is considered by Greenfield as “a ... relative, dynamic and developmental process involving interaction between individual, relational and contextual/organizational conditions" (Greenfield, 2014, p. 54).

Among others, some of the key elements of this contextual understanding of resilience are the importance of access to professionally-supportive relationships, as well as the opportunity to develop approaches to teaching. The latter refers to problem-solving approaches, characterized by reflection and the ability to see a challenge from multiple perspectives.

Greenfield's review identifies, for example, mentoring support for newly qualified teachers as one of the ways to support the development of resilience in newly qualified teachers. The mentor can act as both part of a relationally-supportive professional network and support the development of reflective, reframed and problem-solving approaches to teaching. A similar result can be seen in the research mapping by Schaefer et al. (2012) of newly qualified teachers and burnout. In their study, burnout is understood as bodily and mental fatigue that adversely affect the perception of the work and of colleagues, and in the long term also influence the development of a negative self-image. The survey shows that mentoring together with supportive management - can counteract such burnout. 


\section{Mentors' knowledge and training}

Mentors' knowledge of a subject area, along with their supervisory skills, are identified in the literature as key prerequisites for them to be able to support the process that newly qualified teachers go through in finding their footing as teachers (Hobson et al., 2009; Ingersoll \& Strong, 2011; Shockley et al., 2013; Wang et al., 2008). Mentors' knowledge of the subject areas relates to having experience and knowledge of the subjects and the age groups being taught, but is also about general methods and approach issues and themes, such as differentiation or classroom management (Ingersoll \& Strong, 2011).

Several reviews highlight the importance of mentors receiving training in mentoring (Hobson et al., 2009; Ingersoll \& Strong, 2011; Shockley et al., 2013; Wang et al., 2008). For example, Wang et al. (2008) conclude in their review that mentors who had participated in mentoring training were better able to engage in dialogue with new teachers and were more likely to share their teaching experiences with them. Newly qualified teachers whose mentors were trained were better able to transfer mentor input and create good classroom routines than new teachers with untrained mentors.

In addition, newly qualified teachers with trained mentors had students with more positive student behavior and engagement than teachers with untrained mentors (Wang et al., 2008, p. 145). This review, thus, concluded that the mentor's knowledge of and skills in mentoring and guidance are crucial. In addition, role clarification as a mentor in a teacher induction program is crucial to the quality of mentoring (Wang et al., 2008). Hobson et al. (2009) refer to studies that show that inappropriate mentoring support from unqualified mentors can be a contributory factor in the decision to quit as a teacher. Experiences of unqualified mentoring support are linked to feelings of being overburdened with work, which further generates uncertainty in relation to one's own teaching practice (Hobson et al., 2009).

In supporting newly qualified teachers' development towards becoming effective teachers, mentoring works best if the mentor creates frameworks and processes where the new teacher is given the opportunity to reflect on their teaching practice with the mentor, rather than receiving 
expert advice from mentors. Helping someone learn to teach can be seen as a mentoring-assisted inquiry process that is contextualized and situated in the new teacher's practice (Wang et al., 2008).

Mentors' counseling skills thus relate to being able to identify and support the focus on topics related to teaching throughout the study process, in the form of guidance related to the new teacher's specific context and their teaching practices (Wang et al., 2008). Mentor support should, therefore, be adapted to the task and the experienced needs of the newly qualified teacher (Hobson et al., 2009).

In encouraging the new teacher's developing practice, a key mentoring strategy is to offer multi-faceted perspectives and alternative interpretations of challenges in the classroom and teaching, by reframing the issue from other perspectives or by shifting the focus. This is frequently seen through work on teaching principles, modeling and observation of teaching, with subsequent feedback, discussion and reflection (Wang et al., 2008).

\section{School culture and context}

Four reviews directly address school culture and the school context for both retention and professional development of newly qualified teachers, including the school's and teaching management's interest in and support for newly qualified teachers (Greenfield, 2014; Schaefer et al., 2012; Shockley et al., 2013; Wang et al., 2008).

These four reviews indicate that new teachers have very different opportunities to develop professionally, depending on the school culture. The effect of the teacher induction program depends on the social, cultural and organizational context in which it is situated. Reviews indicate that collaboration between teachers and a collaborative school culture are, in general, important. In this context, a supportive, interested and encouraging management team is identified as a key factor in developing an open, collegial and collaborative school culture. It is, thus, an important factor when it comes to professional development, development of resilience in teachers and retention, together with motivation to stay in the teaching job. Teacher induction programs can support retention and 
effectiveness, but these can be undermined if there is poor leadership and a non-conducive culture at the school, with a lack of, for example, professional communities (Shockley et al., 2013; Wang et al., 2008). Wang et al. (2008) refer to, for example, a study of structured teaching observation and discussions of new classroom management (Williams et al., 2001) where, for instance, effectiveness was found to depend on whether the newly qualified teachers were working in an individualistic or collaborative school culture. The same point is emphasized by Schaefer et al. (2012), with reference to Johnson and Birkeland (2003). Johnson and Birkeland (2003) distinguish between three types of professional cultures in their study of newly qualified teachers' career decisions: a) an experience-oriented culture (veteran); b) a novice-oriented culture; and c) an integrated culture. Their study showed that newly qualified teachers were more likely to remain in the teaching profession and be satisfied with their jobs if they were part of an integrative professional culture that encouraged collaboration and collegiality.

In addition, Wang et al. (2008) refer to a study by Williams et al. (2001) that includes a focus on mentoring. It was shown in that study that mentoring had a greater impact on newly graduated teachers' teaching if they were part of a collaborative school environment, while, "those in the individualistic school culture reported that the influence of mentors on beginning teaching was limited because the relationships were not supported in the school culture." (Wang et al., 2008, p. 139).

According to Wang et al. (2008, p. 145), there are not many studies on the effect of mentoring newly qualified teachers that have had a direct focus on discussing or analyzing the extent to which a mentoring scheme can be reinforced or neutralized by a school culture, organization or environment. They stress that this is an area that should receive more focus in future research.

The reviews of both Wang et al. (2008) and Greenfield (2014) point to the importance of problem-solving in collegial collaboration. Similarly, shared reflections on teaching and relationships with colleagues in the form of emotional support and mutual exchange of experiences are a great help in developing teaching and thus self-efficacy and robustness (resilience). 
Furthermore, Wang et al. (2008) emphasize the importance of administrators' and principals support, with reference to a study by Holahan, Jurkat and Friedman (2000). In their study, the effect of ongoing, intensive mentor training for mentors and mentoring for newly qualified teachers was investigated. The results showed that in the schools where administrators and principals were in a position to support mentors and mentoring, it had an impact on the quality of how newly qualified teachers developed their teaching.

Some of the difficulties frequently encountered in mentoring schemes are identified in Shockley et al.'s review as contextual and organizational. They revolve around a lack of regular meetings and a lack of follow-up (Shockley et al., 2013).

Hobson et al. (2009) identify that mentoring schemes are more likely to be effective when:

- mentors have reduced teaching time and are allocated extra time to prepare and perform the mentoring role

- schedules allow mentors and new teachers to meet during the school day

- mentors receive a financial allowance and/or other recognition for their mentoring work

- mentoring support takes place in contexts relatively exempt from externally-set goals and agendas

- mentors are involved in designing the induction program of which the mentoring is a part

- the induction program of which the mentoring is a part is coherent and not fragmented with many contributors

- both mentors and new teachers have access to support other than the mentor relationship itself

- mentoring support takes place in a school culture that can be characterized by a collegial, collaborative culture.

\section{A firm foothold as teacher}

All seven reviews point to elements that influence the work of newly qualified teachers in gaining a foothold in the teaching profession, 
including developing their skills as a teacher. A foothold in teaching means that the teacher continually strengthens their professional agency, professional identity and, thereby, the chance to be vitalized and recognized. The elements concern: mentoring and other forms of support; the motivation and positioning of newly qualified teachers at the school; contextual factors; and also, the transfer of what the graduates learned in their teacher training.

The transformation process from student to new teacher is characterized by a reflection of the individual's objectives in becoming a teacher. If newly qualified teachers do not gain a firm footing and end up leaving the teaching profession, the reasons for dropping out may be related to their intentions or visions in becoming a teacher (Guarino et al., 2006; Schaefer et al., 2012). Furthermore, contextual factors within and outside the school come into play.

Teacher induction programs alone are not sufficient for beginning teachers to gain a foothold and remain in the profession (Ingersoll \& Strong, 2011; Shockley et al., 2013). Teachers could, for example, find it difficult to get onto a firm footing in schools in low-income areas, as these generally have a higher proportion of ethnic minority pupils and children with behavioral issues. Some teachers have difficulties tackling and understanding these children (Guarino et al., 2006; Ingersoll \& Strong, 2011; Schaefer et al., 2012).

Only the study of Schaefer et al. focuses on the difference between female and male teachers regarding attrition. Their study showed that newly qualified female teachers have a higher attrition rate and leave the profession more often than their male counterparts (Schaefer et al., 2012). Generally, teachers will not accept poor working conditions. There seems to be a pattern where, in particular, it is the newly qualified teachers with multiple competencies that go beyond the teaching job who leave their positions (Guarino et al., 2006). A school with poor leadership and culture, and a lack of professional communities, also undermines the retention of newly qualified teachers (Shockley et al., 2013; Guarino et al., 2006). By contrast, close collaboration with colleagues, a collaborative work culture, and the exchange of experience between colleagues have, as previously mentioned, a positive influence on retention (Greenfield, 2014; Schaefer et al., 2012; Wang et al., 2008). 
Gaining a firm foothold and being well integrated into a school culture do not necessarily mean that new teachers will be good teachers. Graduate teachers are at various different stages in developing their teaching, depending on the quality of their teacher training (Wang et al., 2008). Effective teacher induction should, therefore, increase focus on teacher retention and continuously support their professional development (Schaefer et al., 2012). Greenfield's review (2014) of studies that address teacher resilience shows that a teacher's relationship with a key person or mentor acts as a kind of buffer that protects their self-belief.

In the conclusion of their review, Shockley et al. (2013) put forward a hypothesis that motivational factors, such as versatile teacher induction programs, work assignments for which they receive acknowledgement, recognition of competencies, delegation of responsibilities, opportunities for promotion, professional relationships, and supervision and development opportunities, contribute more to beginning teachers' job satisfaction than does material compensation, e.g. their salary. These motivational factors relate to self-esteem and belonging, and to avoid teachers being on an insecure footing, these elements must be upheld by a supportive school culture.

\section{Discussion}

\section{Limitations and weaknesses of the empirical studies}

It is worth noting that several reviews (Guarino et al., 2006; Ingersoll \& Strong, 2011; Shockley et al., 2013; Wang et al., 2008) point to certain limitations and weaknesses in the empirical studies under investigation.

Shockley et al. (2013) are concerned that most of their included studies are of a descriptive and qualitative nature, and tend towards evaluations. There are only a few longitudinal studies and some reports were not yet peer reviewed. In the case of quantitative studies, these do not include statistical measurements that can provide a basis for traditional quantitative meta-analyses. Wang et al. (2008) are concerned about the generalizability of the results. Guarino et al. (2006) conclude that evidence-based 
research is needed to answer questions regarding teacher recruitment and retention.

The reservations of the various authors are, first and foremost, that qualitative research is involved, and that in the existing research there is little evidence-based research. But evidence-based research, in the form of randomized controlled trials, does not necessarily mean a guarantee of quality. Ingersoll and Strong (2011) are the only ones to refer to a largescale quantitative randomized trial study in their review (Glazerman et al., 2008, 2010), and refute that only evidence-based research can be generalized and is of the required quality. Ingersoll and Strong (2011) are particularly critical of this quantitative randomized trial study, in that it appears to have major weaknesses; for example, it assumed that all school districts involved had the same level of teacher induction. However, it turned out that there was considerable variation in support, from mentoring support, orientation, and time on release to attend learning communities between schools. Furthermore, the control group was not aware of whether or not the control group of schools already had teacher induction programs similar to the "intervention" offered at the schools involved. Therefore, the comparison between control and intervention was not valid. Furthermore, in this study, mentors' experiences and training had not been considered. It was found that all mentors in the intervention group were new, while mentors in the control group were more experienced (Ingersoll \& Strong, 2011).

Ingersoll and Strong (2011) in their review also point to the lack of a single concept of the "effective teacher" as a weakness in many empirical studies, in general. The concept is not well defined. Thus, precise definitions of what is understood by an effective teacher are needed, since it is important for the assessment of outcome and to clarify objectives of teacher induction programs. Ingersoll and Strong (2011) point out that there are many and competing definitions of an effective teacher. The definitions range from teachers who engage students and teach them to ask critical questions, to those who educate students to be mature citizens, to those who are sensitive to teaching regarding student diversity, to teachers who focus on student care, or those who are good at supporting social and behavioral development, to those teachers who are best at 
getting students to achieve the highest marks in examinations (Ingersoll \& Strong, 2011, p. 227).

Although I am primarily interested in teacher induction programs that support newly qualified teachers' professional development, this did not become an independent theme in my analysis of the included reviews in my review of reviews. The theme, although not explicitly stated as such, is considered as an underlying basis of understanding in this review. Professional development is implicitly included in the various themes in the analysis without being an independent theme which, in itself, is quite remarkable. In their review, Wang et al. (2008) touch on this issue. They emphasize, with reference to Feiman-Nemser (2001) and Odell et al. (1999), that teacher induction programs that primarily focus on teaching teachers to teach and develop their teaching are rare. They call for teacher induction not to be seen in isolation, but as being on a continuum from teaching training to professional teaching, given that induction can facilitate and support professional development.

The above issue, therefore, calls for a general review in the future of recent empirical research focusing on professional development. Professional development must be understood as something other than, and more than, the extent to which teachers are able to teach, based on centrally-standardized methods, principles and learning standards. Likewise, professional development and teacher induction programs must be about factors other than the extent to which teacher induction programs have a bearing on students' examination results and teacher effectiveness (Shockley et al., 2013; Ingersoll and Strong, 2011).

The concept of educational mentoring (Bradbury, 2010; Whatman, 2016), which takes a bifocal approach (to both student and new teacher learning, respectively), may be the first step in this direction. The focus on educational mentoring is supported by the OECD report on induction programs for newly qualified teachers which points to the fact that newly qualified teachers need personal, social and professional support (European Commission, 2010).

This review of reviews has included reviews and meta-analyses, all of which were published in the period 2006-2016, so these must be based on studies before 2011. This means that the latest research results within 
the area of teacher induction programs are not included in this review. In my current review of reviews, my searches have mainly resulted in finding American, Canadian and English studies, i.e. studies based on an Anglo-Saxon research and education tradition. Teacher induction programs are also widely used in other countries, such as Norway, the Netherlands, Finland, Estonia, France, Japan and New Zealand. Therefore, there may also be other perspectives in further reviews which include the latest empirical research in teacher induction programs in countries other than those who educate within the Anglo-Saxon tradition.

I consider that one of the strengths of the methodological approach to preparing a review of reviews, meta-analyses and surveys, is that a comprehensive knowledge of teacher induction programs is collected and summarized in one review. The limitation, as I see it, is that recent empirical research is not included. There are some more comprehensive studies and reports, for example from Norway, which could complement the picture, but these are single empirical studies, not reviews, which was an including criterion for this study.

\section{Conclusion}

Despite all the reservations, almost all reviews seem to point to the fact that teacher induction programs consisting of various elements adapted to the context have a positive effect on the professional, social and personal development of newly qualified teachers.

Teacher induction programs can contribute to effectiveness, and can motivate and encourage (Shockley et al., 2013). They can enhance student achievement, teacher job satisfaction, the establishment of a firm foothold (Ingersoll \& Strong, 2011), counter burnout, and strengthen teacher resilience, self-esteem and confidence (Greenfield, 2014; Guarino et al., 2006; Schaefer et al., 2012). Teacher induction programs have an impact on the quality of teaching by supporting and professionalizing the teacher's teaching and insight into how children learn, and the programs facilitate the continuing professional development of newly qualified teachers (Hobson et al, 2009; Ingersoll \& Strong, 2011; Wang et al., 2008). 
Ingersoll and Strong's (2011) combined studies - with one exception (Glazerman et al., 2008; 2010) - point out that teachers who participated in teacher induction programs are, for example, better at keeping students on track with regard to teaching goals, developing curricula that work, adapting classroom activities to students' interests, and maintaining a good teaching environment. With regard to student achievement, their studies showed that their students achieved higher marks in "academic achievement tests". The above can be assumed to contribute to retention. Teacher induction programs can also streng then teachers' relationships with students and support their classroom management skills (Wang et al., 2008).

However, the effect seems to depend on the duration of the program (Ingersoll \& Strong, 2011), and on the social, cultural and organizational context in which it is situated (Wang et al., 2008). The outcome may also depend on the teacher training received by the teacher (Wang et al., 2008), along with the mentor's skills and knowledge (Hobson et al., 2009; Ingersoll \& Strong, 2011; Shockley et al., 2013; Wang et al., 2008). Finally, it should be mentioned that Shockley et al. (2013) recommend that a standardized definition of teacher induction program should be formulated. Such a program would involve various independent components and extend beyond solely mentoring. The definition must not, however, lead to standardized programs. The programs must always be organized based on the local context and the needs of the teachers involved. In other words, a teacher induction program must always be developed within the context of local creative thinking.

\section{References}

Bradbury, L. U. (2010). Educative mentoring: Promoting reform-based science teaching through mentoring relationships. Journal of Science Teacher Education, 94(6), 1049-1071. Retrieved from https://doi.org/10.1002/sce.20393

Braun, V., \& Clarke, V. (2006). Using thematic analysis in psychology. Qualitative Research in Psychology, 3(2), 77-101.

Dyssegaard, C. B., Larsen, M. S., Lindstrøm, M., \& Johannsen, C. G. V. (2013). Inklusion og eksklusion af forskningsresultater. In C. G. Johannsen \& N. O. Pors (Eds.) Evidens og systematiske reviews. Frederiksberg: Samfundslitteratur. 
European Commission. (2010). Developing coherent and system-wide induction programmes for beginning teachers - a handbook for policy makers. European Commission. Retrieved from http://ec.europa.eu/education/policy/school/doc/ handbooko410_en.pdf

Feiman-Nemser, S. (1983). Learning to teach. In L. S. Shulman \& G. Sykes (Eds.), Handbook of teaching and policy (pp. 150-170). London: Longman.

Feiman-Nemser, S. (2001). From preparation to practice: Designing a continuum to strengthen and sustain teaching. Teachers College Record, 103(6), 1013-1055.

Glazerman, S., Isenberg, E., Dolfin, S., Bleeker, M., Johnson, A., Grider, M., \& Jacobus, M. (2010). Impacts of comprehensive teacher induction: Final results from a randomized controlled study (NCEE 2010-4027). Washington: U.S. Department of Education.

Glazerman, S., Dolfin, S., Bleeker, M., Johnson, A., Isenberg, E., Lugo-gil, J., \& Ali, M. (2008). Impacts of comprehensive teacher induction: Results from the first year of a randomized controlled study. Washington: U.S. Department of Education.

Gough, D., Thomas, J., \& Oliver, S. (2012). Clarifying differences between review designs and methods. Systematic Reviews, 1(1), 28.

Greenfield, B. (2014). How can teacher resilience be protected and promoted? Educational \& Child Psychology, 32(4), 52-68.

Guarino C. M., Santibanez L., \& Daley G. A. (2006). Teacher recruitment and retention: A review of the recent empirical literature. Review of Educational Research, 76(2), 173-208.

Hall, J. L., Johnson, B., \& Bowman, A. C. (1995). Teacher socialization: A spiral process. Teacher Educator, 30(4), 25-36.

Hobson, A. J., Ashby, P., Malderez, A., \& Tomlinson, P. D. (2009). Mentoring beginning teachers: What we know and what we don't. Teacher and Teacher Education, 25, 207-216.

Holahan, P. J., Jurkat, M. P., \& Friedman, E. A. (2000). Evaluation of a mentor teacher model for enhancing mathematic instruction through the use of computers. Journal of Research on Computing in Education, 32(3), 336-350.

Ingersoll, R., \& Strong, M. (2011). The impact of induction and mentoring programs for beginning teachers: A critical review of the research. Review of Educational Research, 81(2), 201-230.

Johnson, S. M., \& Birkeland, S. E. (2003). Pursuing a "sense of success": New teachers explain their career decisions. American Educational Research Journal, 40(3), 581-617. Retrieved from http://www.gse.harvard.edu/"ngt/JohsonBirkeland_AERjournal_Fallo3.pdf

Kapadia, K., Coca, C., \& Easton, J. Q. (2007). Keeping new teachers: A first look at the influences of induction in the Chicago public schools. Consortium on Chicago School Research. Retrieved from http://ccsr, uchicago.edu/publications/ keeping new teachers 012407 , pdf. 
Kristiansen, H. M., \& Hjørland, B. (2013). Litteratursøgningens metodik. In C. G. Johannsen, \& N. O. Pors (Eds.), Evidens og systematiske reviews: En introduktion (pp. 59-72). Frederiksberg: Samfundslitteratur.

Launs $\varnothing$, L., \& Rieper, O. (2016). Forskning om og med mennesker: Forskningstyper og forskningsmetoder i samfundsforskningen. (3rd ed.) København: Nyt Nordisk Forlag.

Luft, J. A., \& Cox, W. E. (2001). Investing in our future: A survey of support offered to beginning secondary science and mathematics teachers. Science Educator, $10(1), 1-9$.

Odell, S. J., Huling, L., \& Sweeny, B. (1999). Conceptualizing quality mentoring: Background information. In S. J. Odell \& L. Huling (Eds.), Quality mentoring for novice teachers (pp. 8-17). Indianapolis: Kappa Delta Pi.

Rosén, M. (2012). Systematisk litteraturöversikt. In M. Henricson (Ed.). Vetenskaplig teori och metod: Från idé till examination inom omvårdnad. (pp. 429-444).

Stockholm: Studentlitteratur AB.

Schaefer, L., Long, J. S., \& Clandinin, D. J. (2012). Questioning the research on early career teacher attrition and retention. Alberta Journal of Educational Research, 58(1), 106-121.

Shockley, R., Watlington, E., \& Felsher, R. (2013). Out on a limb: The efficacy of teacher induction in secondary schools. NASSP Bulletin, 97, 350-377.

Tanggaard, L. (2015). Kvalitet i kvalitative studier. In S. Brinkmann \& L. Tanggaard (Eds.), Kvalitative metoder: En grundbog (2nd ed.) (pp. 521-531). København: Hans Reitzel.

Thomsen, C., \& Dahlerup, J. F. (2008). Kort indføring i evidens. Projektafdelingen for Det Nye Universitetshospital, Region Midtjylland; Medicinsk afdeling V, Århus.

Walsh, D., \& Downe, S. (2005). Meta-synthesis method for qualitative research: A literature review. Journal of Advanced Nursing, 50(2), 204-211.

Wang, J., \& Odell, S. J. (2002) Mentored learning to teach and standard-based teaching reform: A critical review. Review of Educational Research, 72(3), 481-546.

Wang, J., Odell, S. J., \& Sharon A. S. (2008). Effects of teacher induction on beginning teachers' teaching. Journal of Teacher Education, 59(2), 132-152.

Whatman, J. (2016). Supporting a system-wide shift from advice and guidance to educative mentoring. Wellington: New Zealand Council for Educational Research.

Williams, A., Prestage, S., \& Bedward, L. (2001). Indiviualism to collaboration. The significance of teacher culture to the induction of newly qualified teachers. Journal of Education of Teaching, 27(3), 253-267. 


\title{
The Lack of Induction Programs in Denmark
}

\author{
Lisbeth Lunde Frederiksen \\ VIA University College, Denmark
}

\section{Åse Bonde}

Education Policy Department of the Danish Union of Teachers, Denmark

\begin{abstract}
The purpose of the article is to present the development of induction support for newly qualified teachers in Denmark over the last 10 years. The article underlines that there currently might be incipient shifts in the political ecosystem of education by referring to a teacher commission that was appointed to provide recommendations for rules for new working hours for teachers in Denmark and to the latest recommendations from a commission whose task was to evaluate the Danish Teacher Training Program. Both commissions call attention to newly qualified teachers and to bridging the gap from teacher education to the teaching profession. The article briefly explains the situation today by referring to a nationwide survey study of how schools receive newly qualified teachers. The study was carried out by the Counseling and Mentoring Research Program at VIA University College. One of the research questions was "How and to what extent are newly qualified teachers in Denmark supported during the first year of their professional work?" The study concludes that support of newly qualified teachers is very arbitrary and unsustainable.
\end{abstract}

Keywords: newly qualified teacher, teacher support, teacher induction, mentor, teacher retention

\section{Introduction}

In Denmark, teacher education is a 4 year, 240 ECTS program, including 3 practice modules, each consisting of 10 ECTS, where the student teachers make plans for and carry out teaching in groups of usually 3-4

Citation of this article: Frederiksen, L. L. \& Bonde, Å. (2020). The lack of induction programs in Denmark. In K.-R. Olsen, E. M. Bjerkholt \& H. L. T. Heikkinen (Eds.), New teachers in Nordic countries - ecologies of mentoring and induction (Ch. 3, pp. 71-85). Oslo: Cappelen Damm Akademisk. https://doi.org/10.23865/ noasp.105.ch3 License: CC-BY 4.0. 
fellow students. It is a common expectation of politicans and some school leaders that from day one, a newly qualified teacher should be capable of acting competently as a teacher with reference to the aims of the Danish folkeskole (municipal combined primary and lower secondary school). It is expected from the start that the teacher is able to carry out skilled teaching and perform as a professional teacher.

As a starting point, school principals assign the same tasks to the newly qualified teacher as to very experienced teachers and newly qualified teachers are given full responsibility for their teaching, including the responsibility for what we in Denmark call "class teacher function", which involves responsibility for collaboration between the school and the pupils' parents, and responsibility for the children's well-being at school. In recent years, this understanding has been accentuated by New Public Management affected control concept (Pedersen, 2004), which has meant that teacher education now is governed by fully-specified goals for competence, skills and knowledge for all parts of the education (Børneog Undervisningsministeriet, 2019).

\section{Strong professional identity with capability for professional judgment}

Every day a teacher, individually and in collaboration with colleagues, has to balance their teaching between a variety of demands, wishes and needs in relation to school and to being a teacher. It is a big challenge, not least for a newly qualified teacher, because the teaching profession, among other things, is characterized by working in situations that in many ways are unpredictable and uncertain. To handle that kind of unpredictability implies an ability to carry out professional judgment, which cannot be worked out in terms of clearly-defined rules of what to do or conclude in specific situations. It involves sensitive attention and reflection, experience in distinguishing between essentials and nonessentials, assessment of the consequences of an action, and being able to take necessary measures in difficult situations (Grimen \& Grimen, 2008; Pahuus, 2009). Furthermore, it involves development of a strong professional identity. In other words, it is the way the teacher understands him/herself as a 
professional, i.e. reflections about his/her own characteristics, values and attitudes, ethical guidelines, skills and competencies, that constitutes him/her as a good teacher.

Such skills are developed in close interaction with practice, experiences in practice, and from first-hand experiences acquired after graduation as a teacher. In short, it will shape the process of becoming a professional teacher if the process is supported by reflections and dialogue with experienced professionals in induction programs (a system that uses a variety of coordinated measures tailored to novices and the general educational system) including mentoring during the first years (Tonna, Bjerkholt, \& Holland, 2017).

\section{What is induction?}

Induction can be seen in terms of four broad categories: a process for learning, a particular period of time, a specific phase of teaching and a system (Isenberg et al., 2009).

Most researchers like to call induction a process for learning, not just support and orientation for teachers starting out in the profession, although this could also be a part of induction. But induction is more than personal support, more than socialization into a culture and a system. It is, first of all, a process of continuing professional learning. It is also a particular period early in the teacher's career, and a specific period in the teacher-development continuum. In addition, it is a specific phase in teaching; a phase where the teachers have to make the difficult transition from student to teacher, face concrete challenges in practice, begin to construct a personal practice, and develop a personal professional identity. This phase is strongly connected to what comes before and what comes after. Ingersoll \& Strong describe induction programs as "a bridge from student of teaching to teacher of student” (Ingersoll \& Strong, 2011, p. 203). Furthermore, it should be seen as a system that can be characterized by complexity, interconnectedness, variety, coordination, and dynamics: "A system, that uses a variety of coordinated means, tailored to the novices and the general educational system and that is embedded in social and political cultures of the nations the program inhabits" (Isenberg et al., 2009). 


\section{No national policy}

However, in Denmark, there is neither a system nor a national policy concerning induction. Denmark has a long tradition for local and highly informal support schemes for newly qualified teachers. Both initial teacher education programs and school programs are managed, as mentioned above, by national, centrally-defined measures for quality and objectives described in terms of competence. It is up to the local level, i.e. the municipalities, schools and teacher educators, to take responsibility for fulfilling the defined measures - how to fulfill these at the local level. Central authorities have put in place measures to monitor and evaluate teaching. Hence, education and school (in a way) are, at the same time, managed in a centralized and a decentralized way (cf. Svensson \& Svensson, 2008), which offers both possibilities and challenges. As a consequence, the support for newly qualified teachers is very arbitrary and varies from one municipality to another and even from school to school.

As municipalities rarely choose to form policies on teacher induction for their schools, it is left to the local principals to decide if, and to what extent, they want to provide teacher induction. The current picture is that newly qualified teachers, as mentioned above, get far less support than they need and, furthermore, many also lack a basic formalized introduction, for instance, to the teaching policy of the municipality and the educational focal points of the local school.

When the question about induction programs and mentoring for teachers arises, the following question is often raised among politicians: "Why do teachers need this when, for example, nurses and lawyers don't need it? It must be the teacher education that is not good enough." However, at the same time, the complexity of teacher work seems to be increasing: diversity in the classroom is increasing and teachers experience complex school legislation, such as requirements for registering absenteeism for bilingual students, requirements for use of digital platforms, reports and inclusion. Collaboration with pupils' parents is more complex, perhaps because teachers in some school districts are not as well educated as parents, while in other areas the challenges in families are greater than just a few years ago. Furthermore, there are demands 
and desires for dialogic teaching and a recognizable learning culture, and a demand for varied forms of teaching and for attentive and empathetic teachers with energy.

\section{A short historic view}

During the period 2000-2013, local mentor programs became widespread in several places in the country. Many municipalities had an interest in local teacher induction programs because of a shortage of trained teachers, and various development programs at different levels providing support for newly qualified teachers appeared in a number of municipalities. As a clear sign of this interest, a collective agreement was signed between the Danish Union of Teachers and the public employers' organization, Local Government Denmark (Sørensen, 2008); the agreement entitled all newly qualified teachers to additional time for preparation as part of their employment agreement.

At the same time, a national network was established (Network for Supporting Newly Qualified Teachers), consisting of researchers, municipality and ministry representatives, school leaders, teacher educators, teacher students and teacher union representatives. In this network, new research about induction programs was presented and different ways to support newly qualified teachers, and experiences in relation to this, were discussed. The network still exists, but has been greatly diminished and consists now of very few people: a researcher, teacher union representatives and a few representatives from teacher education - no representatives from local or central authorities.

Unfortunately, as a result of the events that took place in Denmark in 2013, the interest in induction programs and support for newly qualified teachers trickled away from the municipalities in the years that followed.

\section{Lockout of Danish teachers in 2013}

In 2013, all Danish teachers were locked out for almost four weeks. The lockout was the culmination of a long conflict about the fundamental agreements on Danish teachers' working hours. The lockout ended 
with a political intervention and the adoption of a law governing workinghours (Beskæftigelsesministeriet, 2013), with predominant support for the employers' interests. This circumvented all the normal rules of the Danish labor market, and the Danish teachers working hours are, up to the present time, regulated by working hours legislation instead of, as is usual, by a collective agreement between employers and trade unions.

The former central agreement that gave newly qualified teachers extra time for preparation disappeared at the same time, as a result of the working hours law in 2013. This law was followed up by a new school reform, adopted by the Danish Parliament in 2013, that extended the school week considerably for all pupils (Børne- og Undervisningsministeriet, 2019).

As a result of the combination of the working hours legislation and the school reform, the teachers workload increased by 3-4 lessons per week. As an inevitable result of the heavier workload, there was less time for preparation and for cooperation with pupils' parents and colleagues, including less time for cooperation with and informal support of newly qualified teachers.

For the newly qualified teachers, this was an extra heavy burden. The lack of time with their experienced colleagues meant that they now received neither formal nor informal support from their colleagues. Newly qualified teachers experienced a greater pressure of work and a lack of support, and many considered leaving the teaching profession.

In 2017, the Danish Union of Teachers took the initiative to set up a working group with representatives from all major stakeholders (municipalities, school leaders, student teachers, ministries, teacher-training institutions, teacher unions and researchers), to try to formulate a joint recommendation for the support of newly qualified teachers. Until now, the task has not been fulfilled; it appears to be difficult to formulate a concrete joint recommendation in a field where responsibility is distributed among several actors and, in a time of congestion on the educationalpolicy agenda and declining resources, responsibility seems to have a tendency to be shuffled around. 


\section{Analysis of new initiatives for newly qualified teachers}

The collective bargaining negotiations for teachers in the spring of 2018 resulted in the establishment of a Teacher Commission. The Teacher Commission was given the task of providing recommendations for new regulations for teachers' working hours in Denmark. As a part of this, the Teacher Commission also had the task of analyzing initiatives to secure newly qualified teachers a good start to their professional life, including regulations for teachers' work, and estimating the need to adjust teacher education and organization (Kommunernes Landsforening og Forhandlingsfællesskabet, 2018).

\section{Relevant research and evaluations}

In 2015, the VIA Profession and Education Research Center started a research project about induction programs in Denmark, called "Induction and Foothold". The main research question was "How can a teacherinduction system be designed and implemented in a Danish context?" The first step was to investigate "How, and to what extent, are newly qualified teachers in Denmark supported during the first year of their professional work?” (Frederiksen, Krøjgaard \& Paaske, 2017a) It has been examined through a national survey sent out to all newly qualified teachers hired after January 1, 2013. The intention was to identify problems regarding the improvement of mentoring and induction programs for newly qualified teachers in Denmark, in order to have a basis for developing design principles for teacher-induction programs. The intention was also to attract the attention of politicians and school leaders, and to identify if our hypothesis was right that many newly qualified teachers did not receive any kind of induction.

The survey indicated that a large part of the newly qualified teachers generally experience a lack of structure for their debut as teachers; however, this is the case for a significantly smaller share among those with a mentor. The survey showed that less than half of all newly qualified teachers (38\%) answered "yes" to having participated "in a program in 
which an experienced teacher was charged with assisting and supporting - mentor/tutor program". Only $17 \%$ of these mentors (of the $38 \%$ ) had any kind of mentor training. The division of respondents according to their conditions of employment reveals that mentoring programs are offered, to a significantly lesser extent, to newly qualified teachers who are not employed on a permanent, full-time basis. Furthermore, there is a tendency at municipal schools for mentoring programs to be more frequent at schools with classes 8, 9 and 10 (15-17 year-old students). The duration of a mentoring program seems to vary a lot. Of the durations stated, $41 \%$ are 1-6 months, $50 \%$ are 9-12 months, and only very few are more than a year. The fact that a total of $37 \%$ answer "Do not know" when asked about the duration of their program indicates unclear framing of mentoring programs at many schools.

The survey also showed that $60 \%$ of the newly qualified teachers with trained mentors have subject-content dialogues (about the teaching subject, for example mathematics, English, etc.) and $67 \%$ have pedagogicalcontent dialogues (about methods and approaches in general), while this was only the case for respectively $39 \%$ and $45 \%$ of those who had a mentor without any kind of mentor training. The survey also showed that the newly qualified teachers who participated in mentor dialogues that focused on pedagogical-didactical content valued this very much. However, those who did not take part did not find that this kind of dialogue was important. Furthermore, the survey also showed that almost $24 \%$ of all respondents did not expect to be working in Danish municipal primary and lower secondary schools in 3 years' time.

\section{Challenges}

The biggest challenge in Denmark just now is that there is no national organization nor resources for the support of newly qualified teachers. At the same time, schools are challenged by a teacher shortage and an increasing number of newly qualified teachers who have left or are considering leaving the teaching profession. More than 17,000 trained teachers are currently employed outside of primary and lower secondary schools. This is more than every fifth trained Danish teacher 
(Arbejderbevægelsens Erhvervsråd, 2016). Therefore, the most urgent challenge is to put newly qualified teachers on the national school policy agenda - in competition with many other challenges on this agenda.

The Danish Teacher Training Program was formally evaluated in 2018 by a group of experts appointed by the Ministry of Education. The members of the group were Elaine Munthe (Chairman), Professor and Dean of the University of Stavanger and Head of the Norwegian National Council of Teacher Education, Sven-Erik Hansén, PhD, Professor Emeritus, Åbo Akademi, Per B. Christensen, Chairman for the Danish Council of Accreditation, Carsten Aude, Principal of Aarhus Municipality, Lise Tingleff Nielsen, Chief of the Basic School Area at the Danish Institute of Evaluation (EVA), and Inaluk Hede Pedersen, teacher at Bagsværd Skole. The expert group highlighted:

that a high-quality teacher education must necessarily go hand in hand with ongoing professional development. With reference to both the latest TALIS Study 6 and research on the importance of continuing education, the expert group points to two potential areas of action in relation to lifelong learning:

(1) a stronger focus on working systematically with the transition from students to newly educated teachers, e.g. via induction programs, mentor programs and the like, and

(2) the need to continuously build capacity and develop the teacher's competencies as a basis for maintaining and developing the teacher's practice.

The expert group in this context points to the importance of continuous professional development as an instrument for retaining teachers in the teacher profession. (Styrelsen for Forskning og Uddannelse, 2018, p. 17)

The recommendation shows a growing official awareness of the need of support for newly qualified teachers, in order to maintain professional development and maintain and recruit talented, competent, educated teachers in the future.

We know that induction programs with mentoring programs as an element have a positive significance for newly qualified teachers' classroom 
management (Hobson et al., 2009), teaching quality (Hobson et al., 2009; Ingersoll \& Strong, 2011) and pupils' learning outcomes (Ingersoll \& Strong, 2011). See also the article "Support for newly qualified teachers through teacher induction programs - a review of reviews" in this book. Hobson et al. (2009) establish that mentoring programs also reduce the feeling of isolation for newly qualified teachers, and increase self-confidence and self-worth. Furthermore, mentoring can increase the abilities of professional self-reflection and problem solving. Therefore, there is a great need for induction programs in Denmark.

In Denmark, researchers are still collaborating with the national teacher union. Both parties share the same vision that newly qualified teachers should keep up their commitment to being a teacher, stay in the profession, and desire lifelong professional learning. National research develops and tests design principles for induction programs for newly qualified teachers (Frederiksen, Krøjgaard \& Paaske, 2017b; Frederiksen, Paaske, Halse \& Rosholm, 2019), and branches of the Danish Union of Teachers carry out small induction programs outside school time. In addition, the Danish Union of Teachers has arranged workshops for union representatives on the topic of support for newly qualified teachers.

Hopefully, the recommendations from the Teacher Commission will contribute to greater political awareness of teacher induction programs for newly qualified teachers in Denmark in the near future, programs that, to a great extent, have focus on professional development, and not only focus on socialization into underlying cultural teaching practice, the already-existing practice and personal support (cf. SEC, 2010). What is needed is educative mentoring, a kind of mentoring with a developmentoriented mentor approach, with focus on both the newly qualified teachers' professional growth and on development of teaching that promotes the pupils' possibility of learning and well-being (Bradbury, 2010; Langdon \& Ward, 2015).

\section{Need for educated mentors}

However, introduction of national mentor systems or induction programs with mentoring is not enough if it is to result in ongoing professional 
development as the expert group recommends. Becoming a good teacher is not necessarily the same as being a good mentor (Bullough, 2008; Orland, 2001; Wang, Odell, \& Schwille, 2008) as some school leaders think (Frederiksen et al., 2019); there is much more to mentoring than teaching skills. Therefore, mentors have to be trained in mentoring at the same time as they practice mentoring (Brunstad, 2007). If you are going to facilitate ongoing professional development, it requires educated mentors for teachers (Fantilli \& McDougall, 2009). Mentors have to possess analytical skills as well as reflection skills on practice. Mentors have to understand the complexity in teaching situations and be able to initiate dialogues that are equally about new perspectives and different layers of knowledge (Löfström \& Eisenschmidt, 2009). Mentors also have to be able to reflect on and analyze not only mentoring, but also teaching in general, and new teachers' professional development in particular (Aspfors \& Fransson, 2015). Especially, mentors have to be able to analyze and be aware of their own prior assumptions, underlying values and opinions about teaching.

Today, the teacher training programs at the Danish University Colleges offer additional 1o ECTS credit supervisor courses for teachers who have student teachers in teaching practice. The content of the courses is primarily about counseling methods and communication. However, up until now only a very small proportion of teachers have participated in these courses. Different university colleges also offer shorter one-day or halfday courses, which mainly focus on the examination of teacher students and practice as another education arena. Most often, schools only have one qualified supervisor. However, general courses for teachers who need to be mentors for newly qualified teachers do not exist. To be a supervisor for student teachers and to be a mentor for newly qualified teachers is, though similar, not the same task. It demands some different competence to be a mentor to newly qualified teachers (Lejonberg \& Føinum, 2018).

In the above-mentioned national survey, it appeared that only $4 \%$ of the respondents had participated in initiatives where teacher education was involved after graduation. However, $70 \%$ of the respondents wished that teacher education, to some degree, was involved in the transition from education to profession. There could be initiatives in the future to develop induction programs and mentor courses where this is integrated. 


\section{Conclusion}

The biggest challenge in Denmark just now is that there is neither national organization of nor resources for the support of newly qualified teachers. At the same time, schools are challenged by initial teacher shortages and an increasing number of newly qualified teachers who have left or are considering leaving the teaching profession. The responsibility for newly qualified teachers is divided between several levels and stakeholders and, so far, it has been difficult to coordinate efforts to seriously improve the support of newly qualified teachers. From both national and international research, we know what it takes to support newly qualified teachers in the challenges they face in their first years of teaching, which also the expert group that evaluated the Danish Teacher Training Program pointed out as a crucial prerequisite for retaining teachers in the continuous development of teaching. At this moment in time we can observe incipient shifts in the political ecosystem of education (Kemmis, 2014).

Denmark has a teacher shortage. At the same time, the evaluation of Danish teacher education points to the need for working systematically with the transition from students to newly educated teachers, e.g. via induction programs and mentor programs.

On December 16 2019, the Teacher Commission published their report (Christensen, 2019). In the report, the Commission recommends a more systematic reception of newly qualified teachers. The report makes mention of the following, among other things:

- The Commission proposes that all schools have a strategy for how they introduce newly qualified teachers.

- The municipalities must support the schools in close cooperation with the local partners in the school area, including the local teacher union.

- The teacher commission suggests that the central partners in the school take initiative to collect and spread information about good experiences with initiatives that contribute to a good start for newly qualified teachers and carry out experiments preferably in cooperation with the University Colleges (p. 67). 
Furthermore, the Teacher Commission suggests that schools introduce initiatives to mentoring and induction programs, including relevant induction courses (p. 68).

It has to be emphasized that these are not political decisions. They are recommendations. However, these recommendations concern both initiatives for teacher education and initiatives for practice, and point with some weight at a possible realization in the near future of initiatives in both teacher education and school practice. Initiatives that may support and develop self-efficacy, encourage and motivate newly qualified teachers.

Taken together, this point to renewed central and local interest in supporting newly qualified teachers. An interest that creates hope for a step forward for the newly qualified teachers in Denmark.

\section{References}

Aspfors, J., \& Fransson, G. (2015). Att kvalificera sig till mentor - perspektiv på kompetensbehov och utbildning av mentorer för nya lärare. Psykologi $i$ Kommunen, 2.

Arbejderbevægelsens Erhvervsråd (2016). Beskaftigelsespotentiale blandt uddannede loerere

Beskæftigelsesministeriet (2013). Lov nr 409af 26/042013. Lov om forlongelse og fornyelse af kollektive overenskomster og aftaler for visse grupper af ansatte på det offentlige område.

Børne- og Undervisningsministeriet (2019). LBK nr823af 15/08 2019 nit. Bekendtgørelse af lov om folkeskolen.

Bradbury, L. U. (2010). Educative mentoring: Promoting reform-based science teaching through mentoring relationships. Science Education, 94(6), 1049-1071. https://doi.org/10.1002/sce.20393

Brunstad, P. O. (2007). Faglig klokskap. Pacem, 10(2), 59-70.

Bullough, R. (2008). Counter narratives: Studies of teacher education and becoming and being a teacher. Albany: New York State University Press.

Christensen, P. B. (2019). Loererkommissionens rapport.

Fantilli, R. D., \& McDougall, D. E. (2009). A study of novice teachers: Challenges and supports in the first years. Teaching and Teacher Education, 25(6), 814-825. https://doi.org/10.1016/j.tate.2009.02.021

Frederiksen, L. L., Krøjgaard, F., \& Paaske, K. A. (2017a). Lærerstart og fodfæste i et livs-langt karriereforløb.Århus: Danske Professionshøjskoler. 
Frederiksen, L. L., Krøjgaard, F., \& Paaske, K. A. (2017b). Loererstart og fodfoeste i et livslangt karriereforløb. Retrieved from https://www.ucviden.dk/portal/ files/44628052/L_rerstart_og_fodf_ste_m._bilag_1_6.pdf

Frederiksen, L. L., Paaske, K. A., Halse, E., \& Rosholm, K. Lærerstart og fodfæste (2019). Århus:VIA University College.

Grimen, H., \& M. A. (2008). Profesjon og skjønn. In A. og T. L. I. Molander (Eds.), Profesjonsstudier (p. 179). Oslo: Universitetsforlaget.

Ingersoll, R. M., \& Strong, M. (2011). The impact of induction and mentoring programs for beginning teachers: A critical review of the research. Review of Educational Research (Vol. 81). https://doi.org/10.3102/o034654311403323

Isenberg, E., Glazerman, S., Bleeker, M., Johsson, A., Lugo-gil, J., Grider, M., Dolfin, S., Britton, E., \& Ali, M. (2009). Impacts of comprehensive teacher induction: Results from the second year of a randomized controlled study. Development, iii-116. https://doi.org/10.1037/e599012011-001

Kemmis, S. (2014). Changing practices, changing education. Singapore: Springer.

Kommunernes Landsforening og Forhandlingsfællesskabet (2018). Aftale mellem KL og Forhandlingsfoellesskabet om overenskomst-og aftalefornyelsen pr. 1. april 2018 .

Langdon, F., \& Ward, L. (2015). Educative mentoring: A way forward. International Journal of Mentoring and Coaching in Education, 4(4), 240-254. https://doi. org/10.1108/IJMCE-03-2015-0006

Lejonberg, E., \& Føinum, M. (2018). Hva er god veiledning?: En forskningsbasert innføringsbok om veiledning av nye loerere (1st ed.). Bergen: Fagbokforlaget.

Löfström, E., \& Eisenschmidt, E. (2009). Novice teachers' perspectives on mentoring: The case of the Estonian induction year. Teaching and Teacher Education, 25(5), 681-689. https://doi.org/10.1016/j.tate.2008.12.005

Orland, L. (2001). Reading a mentoring situation: One aspect of learning to mentor. Teaching and Teacher Education, 17(1), 75-88. https://doi.org/10.1016/So742051X(00)00039-1

Pahuus, A. M. (2009). Professionel dømmekraft. Gjallerhorn, o8.

Pedersen, D. (2004). Offentlig ledelse i managementstaten (1st ed.). Frederiksberg: Samfundslitteratur.

SEC, E. C. S. W. D. (2010). Developing coherent and system-wide induction programmes for beginning teachers: A handbook for policymakers. Retrieved from http://blaagaard-kdas.ucc.dk/public/dokumenter/Afdelinger/blaagaardkdas/stoettetilnyelarere/Induction Handbook.pdf

Styrelsen for Forskning og Uddannelse. (2018). Kvalitet og relevans i læreruddannelsen: Ekspertgruppens evaluering og vurdering af loereruddannelsen af 2013. Styrelsen for Forskning og Uddannelse. Retrieved from https://ufm.dk/ publikationer/2019/filer/endelig-rapport_evaluering-af-laereruddannelsen.pdf 
Svensson, L. G., \& K. (2008). Profesjoner, kontroll og ansvar. In H., \& M. A. Grimen (Eds.), Profesjonsstudier.

Sørensen, A. 2008. Loereraftalerne 2008, Dafolo.

Tonna, M. A., Bjerkholt, E., \& Holland, E. (2017). Teacher mentoring and the reflective practitioner approach. International Journal of Mentoring and Coaching in Education, 6(3), 210-227.

Wang, J., Odell, S. J., \& Schwille, S. A. (2008). Effects of teacher induction on beginning teachers' teaching: A critical review of the literature. Journal of Teacher Education, $59(2), 132-152$. 



\title{
Induction in Estonia: Over Fifteen Years of Experience - Successes and Struggles
}

\section{Eve Eisenschmidt and Katrin Poom-Valickis}

\section{Tallinn University, Estonia}

\begin{abstract}
This article gives a brief historical perspective of how the induction programme for newly qualified teachers was launched in Estonia. The induction programme was the result of a combined effort from universities, schools and policymakers. A pilot study was carried out in the academic year 2002/2003. The following year, a group of educators and researchers from Tallinn and Tartu Universities analysed the results, improved the implementation model, and in 2004 launched the programme with the support of the Ministry of Education and Research throughout Estonia.

In this paper, we introduce the theoretical framework, the roles of different parties to the induction programme, and analyse the implementation process in order to find answers to the following questions: Firstly, what are the developments and challenges in the Estonian induction programme? Secondly, what are the perspectives for the induction programme in the future? The methodological approach reviewed policy documents, research articles and doctoral dissertations on induction from 2004-2019. The analysis showed that close cooperation between parties was required to achieve a successful launch, but it seems that the main responsibility for implementation was left to the universities, who were seen as a party highly interested in the continuity of teacher education. Moreover, the execution and quality of mentoring varies among the schools, which can be a problem for new teachers.

Based on research evidence and the current situation in teacher education, we will endeavour to give a forward-looking view on how to support beginning teachers in Estonia.
\end{abstract}

Keywords: newly qualified teachers, mentoring, induction programme

Citation of this article: Eisenschmidt, E. \& Poom-Valickis, K. (2020). Induction in Estonia: Over fifteen years of experience - successes and struggles. In K.-R. Olsen, E. M. Bjerkholt \& H. L. T. Heikkinen (Eds.), New teachers in Nordic countries - ecologies of mentoring and induction (Ch. 4, pp. 87-106). Oslo: Cappelen Damm Akademisk. https://doi.org/10.23865/noasp.105.ch4

License: CC-BY 4.0. 


\section{Introduction}

Continuing professional development is an essential part of a teacher's life. In Estonia, preparations for the period between initial teacher education and in-service education - for the induction as the first working year(s) - started in 2001. The universities realised the need to establish a support system for the continuous professional development of graduates.

The Estonian education system had supported beginning teachers at various times in the past. However, the importance of induction came under discussion again during the preparation of the policy document Framework Guidelines for Teacher Education (2000) which highlighted the changes that had taken place in the teaching profession. This document provided the formal criteria for teacher education, such as the level, structure and amount of the study. For instance, initial teacher education for all school levels takes place at universities and must consist of three parts: 1) general studies, focusing on the development of teachers' general cultural, communicative, and social competencies; 2) subject studies, and 3) studies in educational science, psychology and didactics, including practical training at schools. According to requirements, two teacher initial education models are used in Estonian universities: the integrated five-year model, in which subject and educational studies take place concurrently (for class teachers at the primary school level); and the two-phase (or consecutive model), in which students complete their subject studies, a three year Bachelor's level course followed by a two year Master's level course of teacher education (for subject-teachers in lower and upper secondary level). Pre-school teachers and vocational school teachers are prepared at Bachelor's level. This policy also states that every teacher entering the profession must participate in the induction programme. At the same time, the National Teacher Education Development Plan (2003) addressed the three stages of the teachers' professional development: initial education; induction; and continuing professional development. Universities and schools collaborated in preparing and implementing the induction year programme together with policymakers in 2001/2002.

It was agreed that induction in Estonia should aim at: 1) supporting beginning teachers to adjust to the school organisation; 2) developing the basic competencies of new teachers as described in the national teacher standard; and 3) providing support in solving problems that arise in daily teaching. 
The induction system provides opportunities for school development, and also feedback to the institutions for initial teacher education to improve the quality of their curricula (Framework Guidelines for Teacher Education, 2000). At that time, one of the reasons for designing the induction programme for newly qualified teachers was to create a smoother transition from initial education to working life, to diminish the "practice shock" and, on the other hand, to encourage a more collaborative culture at schools.

Since launching the induction programme almost twenty years ago the landscape of teacher education has changed. The Estonian Teacher Education Strategy for 2009-2013 focused on how to ensure the development of teachers' competencies throughout their career, starting with initial teacher education, the induction year and later on in their continuing professional education. In 2013 at the University of Tartu and 2015 at Tallinn University, teacher education underwent major reforms. One of the aims was to offer more flexible ways to acquire teacher education (e.g. short cycles taking into account earlier studies and work experience, designing workplace learning programmes, etc.).

The next milestone, Estonian Lifelong Learning Strategy 2020 (HTM, 2014), addresses the school leader's essential role in initiating changes and developing a leadership style that focuses on the development of students, teachers, and the whole school personnel. It also places more emphasis on the concepts of teachers' workplace learning and collaboration.

However, even after twenty years, some aspects remain the same and are in urgent need of change. A career in teaching is failing to attract younger people. The average age of teachers is quite high (49 years; OECD average is 44); $54 \%$ of teachers in Estonia are aged 50 and above (OECD average $34 \%)(\mathrm{OECD}, 2019)$. The induction policy has been in place in Estonia for fifteen years, yet only $31 \%$ of teachers report having participated in some kind of formal or informal induction. While school principals across the OECD generally consider mentoring to be important for teachers' work and students' performance, Estonian teachers reported that only $17 \%$ had an assigned mentor (OECD, 2019). Although the official policy is in place, the reality is that it is not being implemented. Teacher education is changing, and it is important to analyse the entire process of launching an induction programme and to propose possible ideas for consideration. 
The key questions are:

1. What are the developments and challenges in the Estonian induction programme?

2. What are the perspectives for the induction programme in the future?

\section{Theoretical background and the main parties to the induction programme in Estonia}

The Estonian approach to induction is seen as a period after initial teacher education, when beginning teachers become fully responsible teachers. Induction is a part of a teacher's continuous learning in partnership with teacher education institutions and schools.

\section{Theoretical background of the induction process}

Arising from the theoretical knowledge, and taking into consideration the context of Estonian teacher education, teacher development can be seen in three dimensions: 1) professional knowledge and skills; 2) a social dimension; and 3) a personal dimension (see Figure 3) (Eisenschmidt, 2006). Accordingly, the processes supporting development occur simultaneously in three areas: (1) developing teaching competencies; (2) socialisation in the organisation and professionally; and (3) developing a professional identity.

The development in these dimensions and the corresponding processes take place in the school context and are influenced by the processes within an organisation. The Estonian school system was decentralised when an independent republic was re-established in the early 1990s, and the responsibility for the local school system was devolved to the municipalities (Estonian Parliament, 1992). Estonian school principals have a wide level of autonomy, including the authority to hire and negotiate working conditions and employment contracts for teachers, the allocation of school finances, educational priorities and development plans for the school. Thus, one of the theoretical foundations of the induction year in Estonia was that schools were seen as learning organisations where teachers support each other's professional growth within an organisation (Senge, 1990; 


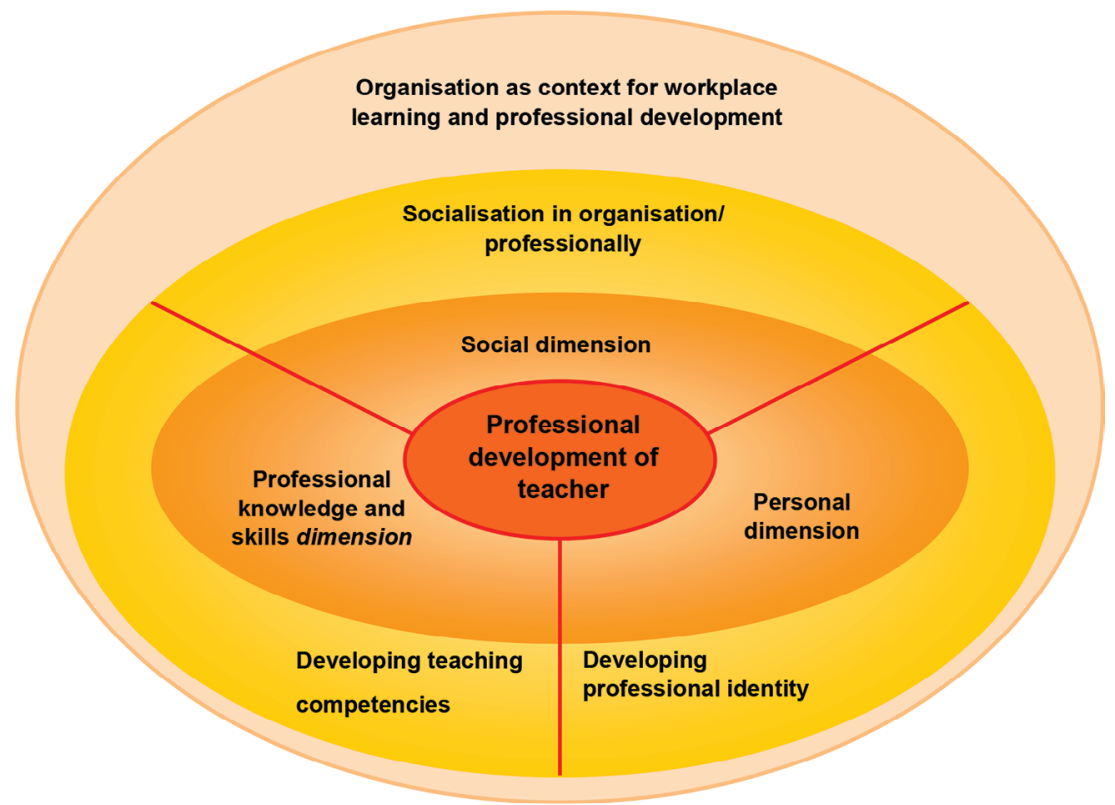

Figure 3. The theoretical foundations of the induction year (Eisenschmidt, 2006).

Fullan, 1991; Harris \& Muijs, 2005). At the same time, the induction year is an opportunity to strengthen the implementation of the professional development of teachers and workplace learning in schools. Developing a mentoring system in schools is seen as an area that increases collaboration among teachers. The relationship between the beginning teacher and mentor is a good example to other teachers of how cooperation with their colleagues can benefit them to develop closer working relationships.

The second facet of the induction period was to look at the newcomers' socialisation process, through which the beginning teacher becomes a member of the wider teaching community - accepting the knowledge, skills, qualities, norms and manners valued in society regarding the particular profession. Two socialisation processes take place simultaneously - socialisation within an organisation and professional socialisation. Professional socialisation is more successful if a person adapts quickly to an organisation; therefore, the focus in the induction year is on recognising schools as organisations and getting to know school culture, the aims of a school and colleagues (Lortie, 1975). It is a social process, where the opinions and attitudes of other teachers have great influence. 
The third essential element of the induction period is the beginning teacher's readiness to develop, analyse and improve their own competencies. In order to ensure the continuity of the professional development of teachers, it is essential to connect the three stages: initial education; induction year; and continuous professional development (FeimanNemser, 2001). During the first working years, the basic competencies are developed, including adopting a suitable teaching style and creating a learning environment, which forms the basis for a professional selfconcept. David Kolb's (1984) model of experiential learning was chosen as the basis for the self-reflection process of a beginning teacher. During the induction year, it is the mentor who supports a beginning teacher in the process of reflection and planning of one's development.

The three theoretical aspects - school as a learning organisation, socialisation both organisationally and professionally, and beginning teachers' readiness for professional development - were followed when planning the content of the induction programme and designing roles and activities for all actors in the process.

\section{Main parties and their roles in the induction programme}

In Estonia, four parties are involved in the induction year programme: (1) school principals, who create the environment that supports the beginner's professional development and appoint mentors; (2) mentors, who are partners for beginning teachers, supporting their professional development and socialisation in a school context; (3) beginning teachers themselves, who are ultimately responsible for their professional development; (4) university induction year centres, where mentor training and support seminars for beginning teachers (10-15 beginning teachers per group) take place (see Figure 4).

The role of the principal is crucial in the development of a school into a learning organisation. Appointing the mentor is the principal's decision and this is critically important, as the mentor, a teacher from the same organisation, is the first contact person between newcomer and organisation. The principal's task is to find teachers who have suitable 


\section{SCHOOL ENVIRONMENT}

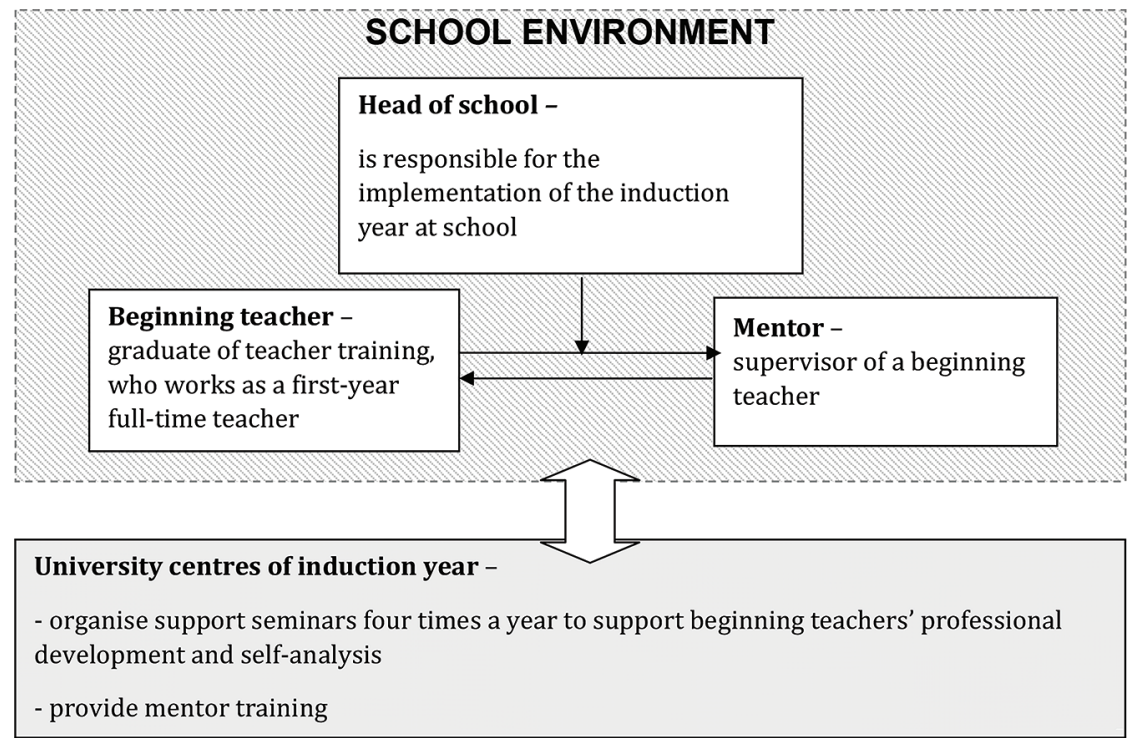

Figure 4. Parties to the induction year (Eisenschmidt, 2006).

qualities to be a mentor - e.g. empathy, willingness to listen and understand other perspectives, but also a readiness to participate in school development and collaborate with other teachers. A mentor should have at least three years of working experience and feel confident enough to share their own experiences and support the new teacher's reflection process.

Theoretically, a mentor has three important tasks in the Estonian induction system: (1) to support the professional development of a beginning teacher; (2) to support the socialisation of a beginning teacher by recognising the school as an organisation; and (3) to participate in the school's development. The primary role of the mentor is to support a beginning teacher's professional development and learning through dialogue and reflection. According to the regulation, all mentors have to pass mentor training at the university. This course, financed by the Ministry of Education and Research, includes the following goals: 1) to facilitate the acquisition of mentoring competencies and attitudes necessary for analysis and development of pedagogical practice; 2) to present skills necessary for supporting teachers' professional growth and promoting a culture of cooperation at school. 
All mentors receive the same training as agreed between all Estonian universities. Mentor training consists of four modules, which are organised as two-day sessions, and take place throughout the duration of one academic year. The first module introduces the concept of mentoring (e.g. mentoring as a professional partnership, the roles of the mentor, the mentor's tasks, beginning teachers' professional development). The second focuses on different competencies for mentoring (e.g. communication skills, such as active listening, giving feedback, etc.) and ethical issues in mentoring. The third module looks at the mentor's activities supporting the professional development of beginning teachers (e.g. classroom observation, reflection process). The final module focuses on mentors' own needs for professional development.

Beginning teachers are responsible for maintaining their relationships with mentors, planning professional conversations, lesson observation, and, based on reflection, improving their own competencies.

The induction programme combines two action environments: (a) learning and development in the school context with mentor support; and (b) the two-day, quarterly peer meetings at the universities. The peer-group meetings take place during the school holidays, as these periods are considered a suitable time for teachers' professional development. This approach is quite unique because of the integration of the two types of mentoring: one-to-one mentoring at school and peer-group mentoring at the universities. The peer-group meetings have similar elements to the peer-group mentoring introduced by Finnish colleagues Heikkinen, Jokinen and Tynjälä (2012). The reasons why the universities organised support seminars for beginning teachers was to: 1) help the initial teacher education institutions understand what problems beginning teachers have, and get feedback about the quality of initial education; 2) discuss problems with their mentor that beginning teachers find uncomfortable to discuss at school; 3) support the development of teachers' reflection skills; 4) allow beginning teachers to share their successes and failures at the group sessions and seek solutions together (Eisenschmidt, 2006). Therefore, the university support seminars created a bridge and continuity between initial education and continuing professional development. 
When preparing and analysing the suitability of the implementation model and developing a programme with several partners, special attention was given to the facilitation of networking throughout the preparation and launch process. At the beginning of the preparation of the induction programme, a group of experts representing the main partners was tasked with the role of leading the design and monitoring process. As well as sharing their ideas and developing a common understanding of the aims of the induction programme, they highlighted the need for cooperation and networking between all parties to be part of the programme (Eisenschmidt \& Niglas, 2014). The main tasks for networking were as follows: (1) universities jointly developed the theoretical model for the induction programme; (2) universities and school representatives designed mentor training and peer-group seminars; (3) ministry and university representatives developed the policy and the evidence-based evaluation of the process; and (4) school and ministry representatives were responsible for the formalisation and implementation of the induction policy into the larger educational system.

\section{The developments and challenges of the Estonian induction programme}

During the first years of implementation, a systematic development of the national programme based on a monitoring system was followed. Two doctoral dissertations (Eisenschmidt, 2006; Poom-Valickis, 2007) as well as research articles were published based on data collected during the implementation of the induction programme.

Results of implementation showed that the first working year for the newcomers was a period of adaptation to the organisation; however, it was doubted whether any organisational learning actually took place. The beginning teachers considered the mentor to be more like the "local guide" (Eisenschmidt, 2006), as collaborative communication was limited in some schools and the mentor was the only link with the teachers (Löfström \& Eisenschmidt, 2009).

Monitoring the development of beginning teachers and their professional learning experiences during the first year of work showed that they 
lack reflection skills, had problems coping with classroom management and difficulties working with parents. The positive observation was the increase in beginning teachers' self-efficacy beliefs at the end of the year (Poom-Valickis, 2007). Beginning teachers' self-efficacy and motivationrelated issues were researched more thoroughly during the implementation process (Meristo \& Eisenschmidt, 2014), which revealed that beginning teachers who enjoyed their work also improved their teaching skills by the end of the first working year. The findings indicated that academic and social growth, cohesiveness and trust in the students were responsible for the self-efficacy beliefs of beginning teachers. Beginning teachers with high motivation and with increased self-efficacy beliefs considered their work to be important. The results indicated that the most important job satisfaction predictor for novice teachers is their sense of community, and a teacher who feels connected to the working environment also has a higher perception of job satisfaction (Meristo, 2016).

At the same time, the feedback on the importance of the induction year among beginning teachers was very divergent, which indicated that the value placed on the induction year varied greatly, probably depending on the assistance received from the mentor, the meaningfulness of the university peer-group seminars and the teacher's own readiness to analyse his/her professional growth (Eisenschmidt, 2006). Analysis of the three years (2004-2007) of monitoring showed that the beginning teachers' readiness for reflection correlated with their perceived meaningfulness of university seminars and with the principals' support (Eisenschmidt, Poom-Valickis, \& Oder, 2008). Also, teachers' evaluations might depend on workplace culture, as it appeared that the school leaders of the organisation with a higher co-operative culture placed more value on the induction year as a learning period for the beginning teacher (Eisenschmidt, 2006) and, thus, paid more attention to creating a favourable atmosphere for mentoring. A supportive teacher community helps to increase the cohesiveness amongst colleagues and newcomers to become members of the school community.

In one study, the correlation between the beginning teachers' involvement in school development, collegial cooperation and supportive school management, were studied longitudinally (Eisenschmidt, Oder \& Reiska, 
2013). School management support perceived by beginning teachers was correlated both with collegial cooperation and involvement into school development, both in the first and fifth year of work. Teachers' readiness to propose an improvement to their work organisation was correlated with involvement in school development and collegial cooperation, and these connections strengthened throughout the years. A teacher's determination to show initiative and improve their work is correlated with their feeling of being fully-fledged members of the organisation and being supported by senior management (Eisenschmidt, Oder \& Reiska, 2013).

Another study investigated beginning teachers' relationships with their mentors as well as the collaboration between beginning teachers and their colleagues after five years of practice (Eisenschmidt \& Oder, 2017). Over half of the beginning teachers continued to collaborate with their mentors during this period, which motivated more cooperation, perceived leadership support and an interest expressed in colleagues' work (Eisenschmidt, Reiska \& Oder, 2015).

Beginning teachers were also asked to analyse peer-group seminars at the university (Lepp, Koni, Kimmel, \& Raam, 2019). The results indicated that beginning teachers wanted to share their experiences and reflect on them, and to have an opportunity to learn from other teachers' experiences. The value of seminars for newly qualified teachers is that it gives them the opportunity to talk about issues that they are unable to confide in with colleagues in the workplace. Also, participants valued the seminars as the possibility of linking theory and practice (scientific reasoning to the questions raised), and as a supportive environment, where they could share their personal problems, and conduct a deep and systematic self-analysis.

The beginning teachers' learning and knowledge-building practices were researched in the extended professional learning community, including both schools and universities (Tammets, Pata, \& Eisenschmidt, 2019). The analysis showed to what extent there are elements of shared practices in the extended professional community, but beginning teachers said that they received little support from other teachers or from the university induction programme group.

Several suggestions to improve and change the induction programme were highlighted during the monitoring of the programme launch 
(Eisenschmidt, Poom-Valickis \& Oder, 2008). Firstly, initial teacher education needed to put more emphasis on the future teachers' professional identities and continuous professional development. The importance of supporting novices' reflection process during initial teacher education should be given more attention, because reflection skills are not selfevident and need to be developed and practised. Reflection seminars were recommended as a means for integrating theoretical courses and school practice experience. Throughout the years of initial teacher education, the future teacher is encouraged to keep a professional development portfolio in various formats, e.g. e-portfolio. This could be considered as continuity between initial education and the induction year programme.

Secondly, mentoring development needs were identified and three main areas were highlighted: 1) the mentoring process itself; 2) the content of mentor training; and 3) mentoring in the school community. The last area includes matters pertaining to socialisation and school leadership (Löfström \& Eisenschmidt, 2009). Mentors' preparation should pay more attention to the mentors' skills and readiness to support the professional growth of the beginning teacher through the process of feedback and reflection in an organisational context. Teacher education institutions should apply a more holistic view of mentoring in mentors' training; mentoring can be seen as a workplace learning approach by strengthening the mentor's role in the school's development and creating a collaborative learning atmosphere for all teachers.

Thirdly, attention was paid to organisational learning as the basis for fostering a teacher's professional development. The changes are more easily achieved in schools which are oriented towards the idea of teachers' professional learning. The new forms of the teachers' continuing professional education address the importance of workplace learning, which is based on collaboration with their colleagues. Therefore, the school environment should become more supportive of teachers' learning and development, and both the teachers as well as school leaders should have the competence to foster organisational learning. It was therefore suggested that mentoring, as a school-based professional learning approach to support beginning teachers, should be an essential part of the principals' leadership training. 
One of the benefits of the model was the partnership of universities and schools in supporting the beginning teachers' professional growth, since this approach creates a strong connection between initial education and their continuous development. Co-operation with schools provides feedback on the quality of initial teacher education and creates opportunities for interconnecting theory and practice. As universities are also the main in-service training providers in Estonia, several topics, e.g. collaborative learning and teachers' self-reflection, were also addressed in the content of other courses offered to teachers and leaders.

In addition, the potential of networking to facilitate policymaking was carefully analysed (Eisenschmidt \& Niglas, 2014). The attempt was to find an approach that could avoid the problems usually faced in topdown reforms. Having the network-based (bottom-up) development of the reform, there is still contradictory evidence about whether launching the induction programme was implemented using a top-down or bottomup approach. The initiators of the programme were university staff members who possess a middle level position between administrators (ministry) and practitioners (schools); all parties were involved in the network and invited to collaborate. Initially, changing from a top-down model was challenging, because many members of the network lacked confidence in their ability or had not had an opportunity to contribute to the process of policy development. A common perception of the practitioners is that policy is formed by "somebody else from somewhere far away" and that is somewhat remote from the realities of everyday life. Even though all the important partners were involved from the beginning and the range of partners expanded during the design and implementation process, it was not possible to ensure the equal participation of all parties. However, the continuous emphasis on networking helped to keep all the partners informed of developments. Furthermore, some positive changes in the attitudes of the members of the network were observed as the process of policy development was becoming more transparent and comprehensible for them, and they gradually started to understand their role and responsibility in the process of designing regulations for reform (Eisenschmidt \& Niglas, 2014). 


\section{Future perspectives for the induction programme}

It would appear that the existing teacher education system has not been responsive enough to guarantee the sustainability of the educational system. The teachers' average age is high and a large number will soon retire ( $54 \%$ of teachers in Estonia are aged 50) (OECD, 2019), there is a lack of new teachers, a growing tendency where a new generation is interested in working as part-time teachers, and career changers who would like to enter the teaching profession. Several changes have been reconsidered in response to the changing situation. On a national level, new regulations regarding the qualification of teachers have been introduced (HTM, 2013). A person with a Master's level of education can develop his/her teachers' competencies in the workplace, analyse themselves against the teacher professional standards and apply for a teacher certificate from the Estonian Teachers' Association. However, so far only $10 \%$ of teachers who enter the profession have used this opportunity (Pedaste, Leijen, Poom-Valickis, \& Eisenschmidt, 2019), and the main way to become a teacher still is through a university teacher education programme. Nevertheless, this is a signal for changes in the educational system to conceptualised teacher preparation and the ways to support teachers' learning in the system. Due to the shortage of new teachers, universities are looking for solutions to make teacher education more flexible and offer opportunities for individualised curricula, as approximately $50 \%$ of teacher education students already work as full-time teachers while they study in university. Therefore, the support programme for the beginning teacher has to accommodate these changes, with the role of the mentor taking on more importance. As initial teacher education moves towards the workplace, more emphasis is placed on beginning teachers' willingness and ability to learn from their own teaching experiences. The design of the current induction programme is changing, with less teachers who need this kind of support after graduation, and more who need this simultaneously with their initial education.

Moreover, to consider both perspectives - entering the profession from other fields (career changes) and simultaneous initial education and working at school - mentoring and workplace learning are becoming more 
important. As mentioned earlier, the Estonian Lifelong Learning Strategy 2020 (Estonian Ministry of Education and Research, 2014) addresses the school leader's essential role of focusing on the development of all learners, including teachers, and developing a school culture where the concept of teachers' workplace learning is strongly emphasised. We have learned during the implementation period that the induction as a short-term (e.g. one or two-year) programme is not relevant in the context of continuous professional development. Research also showed that beginning teachers who have stopped collaborating with mentors value their collaboration with colleagues lower (Eisenschmidt et al., 2013), thus it is important to address the continuous collaboration among colleagues where support for newcomers is of utmost importance. The school leaders' main role is to find ways to strengthen professional learning communities in their organisation, where teachers can collaborate and learn continuously and mentoring becomes natural part of workplace learning.

The aims of induction also need reconsideration as the context, knowledge and concepts of teachers' work and learning constantly develop. Almost twenty years ago, one of the aims of the induction programme was adjustment and socialisation to the system - the organisation and the profession. This aim is giving a more passive role to newcomers, by underestimating their potential and prospective ideas to improve the learning process and organisational development. This kind of limited approach to beginning teachers' individual potential could make teaching a less-attractive proposition. The concept of teacher agency is seen as the potential to act in the interplay between personal capacities and contexts (Priestley, Biesta, \& Robinson, 2015). The teacher agency approach presumes teachers being active in their everyday work, i.e taking responsibility for their pedagogical practices by making decisions about their teaching and school activities. Teacher agency, therefore, refers to the power of teachers (both individually and collectively) to actively and purposefully direct their own working lives within structurally-determined limits (Hilferty, 2008). Recently, the ecological model of teacher agency and how teacher agency could be strengthened was elaborated on and introduced into Estonian teacher education context by Leijen and colleagues (Leijen, Pedaste, \& Lepp, 2019). The model highlights professional 
competence, structural and cultural context, and professional purpose, as the main elements of achieving agency. Authors also emphasise that reflection could be used to strengthen conditions for supporting teacher agency in teacher education, which is also relevant in the context of induction and mentoring of beginning teachers.

Universities are looking for an opportunity to support organisational learning processes and develop new research-based practices in an authentic school context (e.g. Future School Programme, Edulabs, etc.). These programmes strengthen school-university collaboration, taking into account the schools' needs and creating a better understanding of how to develop programmes for teachers. Also, in-service training courses for teachers offered by universities follow more meaningful approaches. The focus is on team-based courses, where a group of teachers from the same school analyses the needs of a particular school and together plan a possible development programme. Teachers work and learn in a team to create new solutions and university academics help to research the impact of new initiatives. The whole process helps to build a learning community where practitioners and teachers work together.

There are now more initiatives to support teachers' professional development at schools. For example, non-governmental organisations seeking opportunities to help schools. An example of this is the network School for New Teachers. They are aiming to develop a learning network of school leaders who are committed to constant improvement of their people-related practices and processes - to make schools better spaces for growth for all. They propose to establish a well-educated mentor community, available to schools seeking qualified mentors.

\section{Conclusion}

We could distinguish three phases in the implementation of the induction programme in Estonia. During the years 2001-2004, the induction programme was prepared. A representative group of experts worked together to solve challenges they faced regarding beginning teachers entering the profession. Universities understood that their graduates needed support, and a smooth transition between initial education and 
continuing education was required. Schools became aware that they needed to develop a new culture where newcomers are supported, and teachers work collaboratively. An implementation model was designed.

During the years 2004-2013, the induction programme was piloted and launched. In the beginning of this programme, extensive monitoring and improvement were carried out, and three cycles of implementation took place (Eisenschmidt et al., 2008). Every academic year, clear development focuses were agreed upon by an expert group of representatives from all parties. After the first year of implementation, universities developed the content of the principal training and mentor education. During the second year, the focus was on the university support seminars and their format, and two universities agreed upon the unification of induction seminars and group mentoring practices. In the third year, the focus was on initial teacher education and the induction year monitoring results; the feedback results were passed on to the university programme designers. The teacher education curricula were analysed and modified based on these findings.

The experts from Tallinn and Tartu Universities met at the universities' induction centres to analyse their work, educate mentors and carry out group mentoring sessions for new teachers. During the programme launch, efforts were made to keep representatives of schools actively involved in the development process to demonstrate that one of the biggest benefits of networking is that it enables access to localised information (Eisenschmidt \& Niglas, 2014). Later, the schools' involvement decreased,leading to a situation where the universities have been the main developers of the programme, which might be the reason why the schools did not feel a sense of responsibility towards developing the mentoring system in the schools.

Seeking alternative ways for induction could be considered as the third phase. Due to changes in the educational system, ways of learning how to become a teacher have been broadening, and considering the emerging professional learning communities at schools, the induction programme for newly qualified teachers needs to respond to these changes. This means that more flexible and individual approaches for induction need to be found. The school culture has a strong impact on newcomers' 
well-being and socialisation. Thus, it is of critical importance to create a collegial working culture, which enables professional development and will, in turn, affirm their staying in the profession. Moreover, it is necessary to support new teachers' agency. For that, we cannot keep considering newcomers to be not experienced enough and think that they only need to focus on classroom teaching. This could lead to a situation where new teachers' potential is underestimated and their prospective ideas to improve the learning process and organisational development are not heard. Therefore, involving them in school development and collegial work is of the ultimate importance. In conclusion, the search for a sustainable model of induction for new teachers will continue as long as the contexts and all actors in the system are in development.

\section{References}

Eesti Õpetajahariduse Strateegia 2009-2013. [Estonian Teacher Education Strategy for 2009-2013]. Retrieved from https://issuu.com/eduko/docs/eesti_opetajahariduse_ strateegia (Accessed o1 January 2020).

Eisenschmidt, E. (2006). Implementation of induction year for novice teachers in Estonia. Doctoral Dissertations on Social Sciences, 25. Tallinn: Tallinn University Press.

Eisenschmidt, E., \& Niglas, K. (2014). Implementing a design research approach and networking in the process of educational change. International Journal of Multiple Research Approaches, 8(2), 221-232.

Eisenschmidt, E., Oder, T., \& Meristo, M. (2010). With five years of teaching experience: Professional aims and tenure. In J. Mikk, M.Veisson, \& P. Luik (Eds.), Teacher's personality and professionalism (pp. 159-174). Estonian studies in education. Frankfurt am Main: Peter Lang Publishers House.

Eisenschmidt, E., Oder, T., \& Reiska, E. (2013). The induction programme - Teachers' experience after five years of practice. Mentoring \& Tutoring: Partnership in Learning, 21, 241-257.

Eisenschmidt, E., \& Oder, T. (2017). Does mentoring matter? On the way to collaborative school culture. Educational Process: International Journal, 1-21.

Eisenschmidt, E., Poom-Valickis, K., \& Oder, T. (2008). Supporting novice teachers' professional development: Monitoring the induction year experience in Estonia. In J. Mikk, M. Veisson, \& P. Luik (Eds.), Reforms and innovations in Estonian education (pp. 77-92). Frankfurt am Main: Peter Lang Publishers House. 
Eisenschmidt, E., Reiska, E., \& Oder, T. (2015). Algajate õpetajate tajutud juhtkonna tugi ning selle seosed kooliarendusse kaasatuse ja õpetajate koostööga. Eesti Haridusteaduste Ajakiri, 3(1), 148-172.

Estonian Parliament (1992). Republic of Estonia Education Act. Retrieved 10 January 2020 from https://www.riigiteataja.ee/en/eli/524042014002/consolide

European Commission (2010). Developing coherent and system-wide induction programmes for beginning teachers: A handbook for policymakers. Brussels: Commission of the European Communities. Retrieved o1 January 2020 from http://www.kslll.net/Documents/Teachers\%20and\%20Trainers\%202010\%20 Policy\%2ohandbook.pdf

Framework Guidelines for Teacher Education [Õpetajate koolituse raamnõuded] (2000). Retrieved o1 January 2020 from https://www.riigiteataja.ee/akt/812791

Feiman-Nemser, S. (2001). Helping novices learn to teach: Lessons from an exemplary support teacher. Journal of Teacher Education, 52(1), 17-30.

Fullan, M. (1991). The new meaning of educational change. New York: Teacher College Press.

Harris, A., \& Muijs, D. (2005). Improving schools through teacher leadership. London: Open University Press.

Heikkinen, H. L. T., Jokinen, H., \& Tynjälä, P. (2012). Peer-group mentoring for teacher development. New York: Routledge.

Hilferty, F. (2008). Theorising teacher professionalism as an enacted discourse of power. British Journal of Sociology of Education, 29, 161-173.

HTM. (2013). Direktori, õppealajuhataja, õpetajate ja tugispetsialistide kvalifikatsiooninõuded [Qualification framework for principals, vice-principals, teachers and support personnel]. Retrieved o1 January 2020 from https://www. riigiteataja.ee/akt/130082013005?leiaKehtiv

HTM. (2014). Estonian Lifelong Learning Strategy 2020. Retrieved o1 January 2020 from: https://www.hm.ee/sites/default/files/estonian_lifelong_strategy.pdf

Kolb, D. A. (1984). Experimental learning: Experience as the source of learning. New York: Jossey-Bass.

Leijen, Ä., Pedaste, M., \& Lepp, L. (2019). Teacher agency following the ecological model: How it is achieved and how it could be strengthened by different types of reflection. British Journal of Educational Studies, 56(1), 39-58.

Lepp, L., Koni, I., Kimmel, M., \& Raam, A. (2019). Induction seminars for newly qualified teachers in Estonia: What NQT-s expect and appreciate? In INTED2019 Proceedings (5697-5703). 13th annual International Technology, Education and Development Conference, Valencia, Spain, 11-13 March, 2019: INTED.

Lortie, D. C. (1975). Schoolteacher: A sociological study. Chicago: The University of Chicago Press. 
Löfström, E., \& Eisenschmidt, E. (2009). Novice teachers' perspectives on mentoring: The case of the Estonian induction year. Teaching and Teacher Education, 25(5), 681-689.

Meristo, M., \& Eisenschmidt, E. (2014). Novice teachers' perceptions of school climate and self-efficacy. International Journal of Educational Research, 67, 1-10.

Meristo, M. (2016). Personal and contextual factors shaping novice teachers' early professional career. Doctoral Dissertations on Social Sciences, 101. Tallinn: Tallinn University Press.

OECD (2019). Volume I: Teachers and school leaders as lifelong learners. TALIS 2018 Country Notes (Estonia), Retrieved o1 January 2020 from http://www.oecd.org/ education/talis/talis-2018-country-notes.htm

Pedaste, M., Leijen, Ä., Poom-Valickis, K., \& Eisenschmidt, E. (2019). Teacher professional standards to support teacher quality and learning in Estonia. European Journal of Education, 54(3), 389-399.

Poom-Valickis, K. (2007). Novice teachers' professional development across their induction year. Doctoral Dissertations on Social Sciences, 33. Tallinn: Tallinn University Press.

Priestley, M., Biesta, G. J. J., \& Robinson, S. (2015). Teacher agency: An ecological approach. London: Bloomsbury Academic.

Senge, P. (1990). The fifth discipline: The art and practice of the learning organisation. New York: Doubleday.

Tammets, K., Pata, K., \& Eisenschmidt, E. (2019). Novice teachers' learning and knowledge building during the induction programme. European Journal of Teacher Education, 42(1), 36-51. 


\title{
A Brief History of the Peer-Group Mentoring Model in Finland: Struggling for Space in a Contested Niche
}

\author{
Hannu L. T. Heikkinen, Matti Pennanen, Ilona Markkanen and \\ Päivi Tynjälä \\ University of Jyväskylä, Finland
}

\begin{abstract}
The aim of this article is to introduce and reflect on the development of mentoring in Finland as implemented in the form of the Peer-Group Mentoring (PGM) model. Firstly, the main characteristics and principles of the PGM model are introduced, after which experiences from implementing the model are analysed based on a literature review. We examine the following research questions: (1) How have the mentoring practices of newly qualified teachers developed towards the PGM model within the educational ecosystem in Finland? (2) How has the PGM model found its relational space ('ecological niche') in this ecosystem? and (3) How has PGM been experienced by mentors and mentees in terms of professional learning and well-being? Theoretically, our examination is based on an ecosystemic view: we see mentoring as an integral element of teachers' professional development, which, in turn, is an integral part of the education ecosystem. Our methodological approach is a systematic review of mentoring research in Finland over the period 2004-2019. The research material consists of policy documents, research reports, peer-reviewed articles and doctoral dissertations. Our research: (1) demonstrates how mentoring has evolved gradually from traditional one-to-one mentoring towards a reciprocal, collegial and dialogic approach; (2) shows how the PGM model has inhabited its niche in the ecosystem of education; and (3) presents how PGM has been experienced by mentors and mentees. The main challenge in applying the model is the lack of national agreement concerning the organisation of mentoring. Applying the concept of learning ecology, mentoring can be seen as
\end{abstract}

Citation of this article: Heikkinen, H. L. T., Pennanen M., Markkanen, I. \& Tynjälä, P. (2020). A brief history of the peer-group mentoring model in Finland: Struggling for space in a contested niche. In K.-R. Olsen, E. M. Bjerkholt \& H. L. T. Heikkinen (Eds.), New teachers in Nordic countries - ecologies of mentoring and induction (Ch. 5, pp. 107-128). Oslo: Cappelen Damm Akademisk. https://doi.org/10.23865/ noasp.105.ch5

License: CC-BY 4.o. 
struggling for a niche within initial teacher education and in-service training. Finding a sustainable solution for mentoring therefore requires developing the ecosystem as a whole and allowing growing space for mentoring as an integral part of the education ecosystem.

Keywords: peer-group mentoring, teacher development, professional learning, professional learning communities, Finland

\section{Introduction}

The aim of this article is to describe the development of mentoring practices in Finland and, through an ecosystemic lens, to examine the main research findings on mentor and mentee experiences of the peer-group mentoring (PGM) model that has been developed in Finland over the past 15 years. Mentoring is a practice that lives (or not) in a given ecological niche. This niche can be understood as a relational space between initial teacher education and a variety of practices of career-long professional development of teachers. In Finland, as in every other country, this niche is formed, enabled and constrained in special ways. On the one hand, the high quality of pre-service teacher education in Finland is widely recognised (e.g. Sahlberg, 2015). On the other hand, challenges with in-service teacher education have been acknowledged, and the need for mentoring and induction has been addressed by a number of researchers (e.g. Almiala, 2008; Aspfors, 2012; Blomberg, 2008; Heikkinen, Swachten, \& Akyol, 2015; Ruohotie-Lyhty, 2011).

No clear explanation for the lack of interest in Finland in developing mentoring has been provided. However, given the high professional status of teachers in Finland and the country's excellent PISA results, there has been little interest in developing teacher induction (Bjerkholt \& Hedegaard, 2008, p. 58). The high status of the teaching profession in Finland has attracted the best of the best students to teacher education, which has also been internationally acknowledged for its high academic standards (e.g. Sahlberg, 2015; Välijärvi \& Heikkinen, 2012). A Master's level degree has been a requirement for teacher qualifications since 1979. Consequently, strong trust in the high level of candidates and the quality of basic teacher education has meant that little attention has been paid to the induction phase. 
There is also a certain strong tradition behind this. Historically, it has not been considered necessary to smooth the path for newcomers. On the contrary, according to the traditional view dating back to the early twentieth century, new teachers had to show obedience, humility and respect for older colleagues (Launonen, 200o). The induction phase was sometimes even associated with a sort of 'newbie' bullying tradition: the newcomer was given the most difficult jobs and the worst-performing pupils. A new teacher was on probation for two years before being formally accepted for the position. It was not until 1985 that the probation years were abolished.

It took a long time before the need for support for new teachers was acknowledged, in the latter part of the twentieth century. To some extent, the introduction of mentoring was promoted by the political initiatives of the European Commission (1995, 2001, 2007 and 2010), with which the discourse on the need for mentoring gradually shifted from Europe to Finland. However, due in part to the fact that there was no shortage of teachers in Finland, the discussion was focused less on mentoring and more on developing teacher education towards career-long professional development. At the beginning of the 20oos, an evaluation of the national teacher education development programme (2002-2005) suggested that a lifelong-learning model should be applied to the development of in-service training for teachers, with different measures at different stages of teachers' careers (Piesanen, Kiviniemi, \& Valkonen, 2007, p. 5). The Trade Union of Education of Finland (OAJ) strongly supported these initiatives. This understanding of teachers' professional development as a lifewide and lifelong mission became one of the guiding principles for the development of teacher education, opening up a niche for mentoring.

In this article, we introduce and reflect on the development of mentoring in Finland during the past 15 years (2005-2020). Our main focus is on the introduction of the Peer-Group Mentoring model (PGM), which was developed through pilot projects in collaboration with the Finnish Institute for Educational Research and a number of municipalities. The PGM model was further developed and disseminated by a national network representing all providers of teacher education in 
Finland (eight universities and five universities of applied sciences). By 2020, approximately 900 mentors were trained in 150 municipalities. It is estimated that 2,00o educational professionals have been involved in PGM on a yearly basis (Tynjälä, Pennanen, Markkanen, \& Heikkinen, 2020).

The key research questions addressed in this article are:

1. How have the mentoring practices of newly qualified teachers developed towards the PGM model within the educational ecosystem in Finland?

2. How has the PGM model found its ecological niche in this ecosystem?

3. How has PGM been experienced by mentors and mentees in terms of professional learning and well-being?

To help the reader understand what is meant by peer-group mentoring in Finland, we must first introduce some of its leading principles. The following sections address each of the research questions, starting with a brief history of mentoring and finally describing teachers' experiences of PGM. In the conclusion section, we reflect on the results and introduce a view of teacher development based on the idea of ecologies of professional learning.

\section{Key features and principles of peer-group mentoring}

Peer-group mentoring differs from the traditional mentoring model in a number of ways. Firstly, in traditional one-to-one mentoring, the basic assumption is that a senior or more-experienced worker transfers knowledge to a younger colleague. However, the research on mentoring shows that often the assumedly-more experienced professionals also learn from their less-experienced counterparts (Geeraerts, Tynjälä, \& Heikkinen, 2018). The PGM model is therefore based on the idea that the mentor-mentee relationship is reciprocal, with each party providing something of value to the other. The PGM model is also deliberately implemented in groups comprising both novice teachers and more-experienced teachers. 
The ideal group size is between five to ten members, which provides a platform where multiple views can be presented but without crowding the discussion. The peer-mentoring group usually meets six to eight times during the academic year, with each meeting lasting around one and a half to two hours. In the first meeting, the group draws up an action plan. The group can decide to devote each PGM session to a specific theme, or choose a common theme for the entire academic year, such as multiculturalism, curriculum work, or teaching method development in a specific discipline, such as the arts, physical education, mathematics, etc. The mentor serves as the facilitator of the group and is responsible for maintaining the group schedule. The mentor also leads the discussion, striving to allot speaking time equally among participants. The mentor can also propose topics and stimulate discussion through different narrative and action-based exercises (Estola, Heikkinen, \& Syrjälä, 2014). Whereas in some international models participation in mentoring is compulsory for new teachers and involves assessment of the mentee, in the Finnish model participation is voluntary and no assessment is involved (Heikkinen, Jokinen, \& Tynjälä, 2012, p. 16).

In its essence, PGM involves teachers in sharing and reflecting on their experiences, discussing the problems and challenges they meet in their work, listening, encouraging one another and, above all, learning together. As this kind of group activity always raises ethical questions, it is important to examine the ethical principles of PGM. The ethical basis of the group is established through collective agreement about its actions. Each PGM group is expected to agree on its own rules of practice, but all agreements must include two basic principles: confidentiality and discussion ethics. The principle of confidentiality means that disclosures made within the group are not shared outside the group, i.e., what is said in the group stays in the group. The ethical discussion principle is that the group's purpose is not to be a rumour mill where other employees' or pupils' personal affairs are debated. The group therefore agrees to avoid mentioning by name or stigmatising in any way people who are not part of the group (Heikkinen et al., 2012, pp. 16-17).

The PGM model is based on the following underlying theoretical principles: 
1. Constructivism

2. Integrative pedagogy

3. Dialogue and narrativity

4. Autonomy

5. Equity

\section{Constructivism}

In traditional mentoring it is assumed that (tacit or explicit) knowledge is transferred from one person to another. This understanding of learning is based on the idea of transmission of knowledge. PGM, instead, relies on the idea of social construction of knowledge. Constructivism maintains that knowledge cannot be transferred between individuals, but that we always interpret new knowledge on the basis of our prior knowledge, conceptions, experiences and beliefs. Thus, the same thing can be interpreted and understood in different ways. Therefore, discussion is an essential element in creating shared understanding. Knowledge is thus not transferred, but rather we each form our own personal conceptions through social interaction. This social construction of knowledge takes place in different settings, not only in schools or educational institutions. As such, learning is not always formally recognised with grades, diplomas or certificates. In other words, human development does not happen only through formal learning. It can also take place through nonformal learning organised outside of the formal educational system, such as in the workplace. Nonformal learning is intentional, but does not lead to formal certification. Often the most neglected form of professional development, however, is informal learning, which is usually unintentional and takes place as a by-product of other activities in everyday settings (Merriam, Caffarella, \& Baumgartner, 2007).

\section{Integrative pedagogy}

Founded on the constructivist perspective, PGM is based on the exchange of ideas and joint knowledge construction in which all parties learn from each other. The principle of integrative pedagogy means that different forms of knowledge are integrated in education to promote learning and 
professional development (Tynjälä, 2008; Heikkinen et al., 2012). The idea of integrative pedagogy is rooted in the common requirement to combine 'theory and practice' in education, but implies a broader combination of forms of knowledge than just 'theory and practice', including:

1) theoretical and conceptual knowledge

2) practical and experiential knowledge

3) self-regulative knowledge

4) socio-cultural knowledge

(1) Theoretical and conceptual knowledge is formal in nature and easy to express explicitly. In everyday terms, this kind of knowledge is often referred to as 'theory'. Theoretical knowledge is propositional and explicit; it is learned, for instance, through texts, figures, discussions or lectures. It is also abstract knowledge evolving as a result of a conscious and conceptual thought process. Theoretical knowledge is important for professional learning, but for deep learning it needs to be complemented with (2) practical and experiential knowledge. This knowledge is often simply referred to in everyday parlance as 'practice'. The terms 'knowhow', 'skills', 'capacities' and 'competencies' are also used to refer to practical and experiential knowledge. Although people commonly talk about 'practice', some form of knowledge is always present in the background. This knowledge is different, however, from the knowledge that can be read in books. It develops through practical experience and, consequently, it often remains intuitive, implicit, tacit and inarticulate. However, through reflective activities, such as journal writing and group discussion, it is possible to explicate and conceptualise experiential knowledge. In addition to these, though, to be able to do their job well, professionals need a third kind of knowledge, (3) self-regulative knowledge. This knowledge encapsulates metacognitive and reflective capacities and skills. To become a skilled professional you need to have the capacity to reflect on the factors behind your behaviour and how they affect your work. A typical feature of high-level expertise is strong self-regulation, i.e., reflective evaluation of your own actions, awareness of your strengths and weaknesses, and development of your competencies. Finally, to become a skilled expert 
you also need (4) socio-cultural knowledge, i.e. the knowledge embedded in social practices and cultures. Every workplace and social community has its own practices and ways of acting that can be learned only by entering in and acting them out. Although these four components of expertise can be analytically distinguished from one another, typical of high-level expertise is that these forms of knowledge are closely integrated with one another. This also applies to mentoring. According to the principle of integrative pedagogy, all of these forms of knowledge are merged in the mentoring process (Heikkinen et al., 2012, pp. 24-27).

\section{Dialogue and narrativity}

The basic principles of constructivism and integrative pedagogy are intertwined with the principle of dialogue and narrativity. This principle is based on a common finding of mentoring research: mentors and mentees both learn in the mentoring process by sharing narratives about their work and life; instead of transferring knowledge, they construct a new understanding that neither of the parties had before (Estola et al., 2014). The dialogical, constructive and interactive character of mentoring is highlighted in terms such as co-mentoring, mutual mentoring, collaborative mentoring, peer collaboration, critical constructivist mentoring, dialogic mentoring, peer mentoring and peergroup mentoring.

According to the dialogic view, mentoring involves a reciprocal exchange of ideas and joint construction of knowledge, from which both parties learn. In a group-mentoring dialogue, all of the group members participate in verbalising their experiences by sharing their stories of what has happened to them in their daily work. In a dialogic relationship, no one has a better or more valid vision of reality - each participant in the discussion understands that their own vision is incomplete. Fundamentally, narrative is the primary mode through which we understand who we are, how we constitute our identities. Consequently, personal identity work is mostly done by constructing life narratives and, similarly, professional identity is achieved through narratives (Heikkinen et al., 2012, pp. 14-15 and 27). 


\section{Autonomy}

The PGM model draws on the idea of professional autonomy, which can be properly understood only in the light of the high level of autonomy of the teaching profession in Finland. Compared to many of their international counterparts, Finnish teachers seem to be more self-directed and less regulated. As the concepts of autonomy and individualism are often misunderstood, it is worth taking a look at the origins of the word. 'Autonomy' literally means operating 'according to laws that one has made for oneself' (Greek auto nomos). As we shall explore, however, a high level of autonomy does not necessarily mean that teachers can do whatever they wish. Etymologically, the concept of autonomy comes from the Greek auto, meaning self, and nomos, meaning law or rules. In ancient Greece this expression was used for a town-state (polis) that constituted its own laws. In an autonomous polis, the laws were discussed and established by the citizens of that particular polis. In the opposite case, a town that was ruled by laws that had been constituted by another polis was described by the words hetero nomos, literally meaning that someone else (another polis) had constituted the laws. This is the origin of the word heteronomy, which is the opposite of autonomy. The concept of autonomy thus emphasises interaction and collective will formation in a social sphere, whereas individualism refers to action based on the will of a particular individual. Finnish peer-group mentoring draws on the idea of professional autonomy as collective will formation instead of individual will formation (Heikkinen et al., 2012, pp. 17-18).

\section{Equity}

Key to peer-group mentoring is the 'peer' concept, which refers to the parity of the parties involved. PGM is based on the presumption that the members of the group are essentially equal participants. But what does this mean, and is it actually possible? And in what sense equal? When examining equity in mentoring, we must ask whether we are referring to equity as associated with: (1) human beings, i.e. existential equity, (2) competence and knowledge, i.e. epistemic equity, or (3) responsibilities and duties, i.e. juridical equity.

Firstly, the dimension of existential equity refers to the human dignity of a person. From a humanistic perspective, each individual's life has equal 
value in its uniqueness. From the existential point of view, we may thus presume that the relationship between participants in a peer-mentoring group is symmetrical. Secondly, epistemic equity refers to knowing something or being capable of doing something. From the epistemic point of view, it is evident that some people have more knowledge, capacities or competencies than others. However, in a mentoring relationship it is essential to understand that some people will have more expertise in some fields than others, but that this disparity evens out as different fields of expertise are presented and explored. In its traditional sense, mentoring is based on an assumption that the more-experienced participant (the mentor) has more knowledge and experience. Today, however, it is understood that younger participants have competence and know-how in different areas of life that can be important contributions to successful teaching. In certain areas of life, such as social media, ICT, or inside experience of the lifeworld of young people, young employees may have superior knowledge than their more experienced co-workers. Epistemic equity thus opens up a variety of options as the relationship can be asymmetric in a variety of ways, in favour of either the mentor or the mentee. Thirdly, by juridical equity we refer to the formallydefined division of responsibilities, duties, and rights in the mentoring process. In formal mentoring relationships, the mentor has to assume more legal responsibility than the mentee. However, if the mentoring relationship is purely informal, juridical responsibility is less key (Heikkinen et al., 2012, pp. 19-22). The above three perspectives of equity are crystallised in the following table.

Table 3. Equity in Peer-Group Mentoring (modified from Heikkinen et al., 2012, pp. 21-22).

\begin{tabular}{|c|c|c|c|}
\hline & $\begin{array}{l}\text { Equity in } \\
\text { terms of }\end{array}$ & $\begin{array}{l}\text { Relationship between } \\
\text { mentor and mentee in } \\
\text { peer-group mentoring }\end{array}$ & $\begin{array}{l}\text { Symbolically illustrated } \\
\text { relationships in PGM: } \\
(\mathrm{M}=\text { mentor, } \mathrm{m}=\text { mentee })\end{array}$ \\
\hline $\begin{array}{l}\text { Existential } \\
\text { equity }\end{array}$ & human dignity & symmetrical & $M=m$ \\
\hline \multirow{2}{*}{$\begin{array}{l}\text { Epistemic } \\
\text { equity }\end{array}$} & \multirow{2}{*}{$\begin{array}{l}\text { knowledge, } \\
\text { capacities and } \\
\text { competency }\end{array}$} & asymmetrical & $M>m$ \\
\hline & & asymmetrical & $M<m$ \\
\hline \multirow[t]{2}{*}{$\begin{array}{l}\text { Juridical } \\
\text { equity }\end{array}$} & \multirow{2}{*}{$\begin{array}{l}\text { responsibilities, } \\
\text { duties, and rights } \\
\text { under law }\end{array}$} & $\begin{array}{l}\text { formal mentoring: } \\
\text { asymmetrical }\end{array}$ & $M>m$ \\
\hline & & $\begin{array}{l}\text { informal mentoring: } \\
\text { symmetrical }\end{array}$ & $M=m$ \\
\hline
\end{tabular}




\section{The historical development of peer-group mentoring in Finland}

One of the key aims of this study is to describe how the mentoring practices of newly qualified teachers have developed in Finland towards the principles of peer-group mentoring described above. As noted, the concept of peer-group mentoring differs in many respects from the traditional concept of mentoring. The history of mentoring of new teachers in Finland starts, however, from a very traditional understanding of mentoring. Triggered by a series of European Commission white papers on teacher education (1995, 2001, 2007 and 2010), concerns were raised in Finland about the need to support new teachers. The Finnish Institute for Educational Research responded to these discussions by launching a set of research and development projects. The development of PGM started in Finland in the beginning of the 2000 under pilot projects funded by the Ministry of Education and Culture, the Academy of Finland and the Finnish Work Environment Fund (Heikkinen, Jokinen, \& Tynjälä, 2008). A brief description of the development of mentoring in Finland is introduced in Table 4 .

Table 4. Development of mentoring in Finland, 2000-2019.

\begin{tabular}{|l|l|l|l|l|l|}
\hline & $\begin{array}{l}\text { One-to-one } \\
\text { mentoring }\end{array}$ & $\begin{array}{l}\text { Group } \\
\text { mentoring }\end{array}$ & $\begin{array}{l}\text { Piloting } \\
\text { Peer-Group } \\
\text { Mentoring } \\
\text { (PGM): Verme }\end{array}$ & $\begin{array}{l}\text { Disseminating } \\
\text { PGM: } \\
\text { Osaava Verme }\end{array}$ & $\begin{array}{l}\text { Trialling PGM } \\
\text { in different } \\
\text { fields: } \text { Verme }^{2}\end{array}$ \\
\hline Years & $2000-2006$ & $2003=>$ & $2006-10$ & $2010-2017$ & $2017-19$ \\
\hline Location & Helsinki & Kokkola & $\begin{array}{l}\text { Jyväskylä } \\
+12 \\
\text { municipalities }\end{array}$ & nationwide & nationwide \\
\hline $\begin{array}{l}\text { Organising } \\
\text { principles }\end{array}$ & $\begin{array}{l}1 \text { texperienced } \\
\text { novice teacher }\end{array}$ & $\begin{array}{l}1 \text { experienced } \\
\text { teacher } \\
+ \text { group } \\
\text { of novice } \\
\text { teachers }\end{array}$ & $\begin{array}{l}\text { 1 experienced } \\
\text { teacher }+ \\
\text { group of } \\
\text { novice and } \\
\text { experienced } \\
\text { teachers }\end{array}$ & $\begin{array}{l}\text { 1experienced } \\
\text { teacher }+ \\
\text { group of } \\
\text { novice and } \\
\text { experienced } \\
\text { teachers }\end{array}$ & $\begin{array}{l}\text { 1 experienced } \\
\text { professional } \\
\text { + novice and } \\
\text { experienced } \\
\text { professionals }\end{array}$ \\
\hline
\end{tabular}

The development of mentoring started with traditional one-to-one teacher mentoring arrangements in Helsinki in the early 2000 s. 
Inspired by international models, some education authorities attempted to provide an experienced mentor for new teachers who were willing to participate in mentoring. However, the mentors were not remunerated or compensated in any way for this work and so, in the absence of proper incentives, it was difficult to find willing mentors. In addition, the organisation of mentoring relied on the individual interests of civil servants with no official structures in place. Consequently, this mentoring model dwindled within a few years. At the same time, mentoring was being piloted on the west coast of Finland in Kokkola. There, as in Helsinki, the first attempt was to introduce the traditional one-toone model. In contrast to Helsinki, though, mentors were paid for their work time, thus encouraging recruitment. Nevertheless, there was a lack of experienced teachers willing to act as mentors. Due to the low availability of mentors, an experimental programme was run in which individual mentors facilitated groups of new teachers. This was done partly for economic reasons, to minimise the cost per person. However, a follow-up study of the pilot revealed other benefits of group mentoring. It was found that the new teachers participating in the group also gained significant support from one another. As a result, the Kokkola programme began developing towards more of a group-mentoring format (Heikkinen et al., 2008).

The group-mentoring approach received further support from other research, which also showed that, in addition to economic benefits, group mentoring provided significant benefits for teachers' professional development as teachers learn professionally from each other by sharing the challenges and experiences that they encounter in their work. This finding was supported by the international research literature on peer-group mentoring and professional learning communities. As a result, the Kokkola model was modified to follow more explicitly a peer-group mentoring approach (Heikkinen et al., 2008).

The peer-group-based model provided a basis for an even more systematic research and development project implemented in 2007-2010 called VERME (an acronym for the Finnish word for peer-group mentoring, 'vertaisryhmämentorointi'). Under that project, a book (Heikkinen, Jokinen, \& Tynjälä, 2010) was published in which the PGM model was 
outlined and empirical experiences of the model were reported. At the same time, a national programme for teacher development called Osaava Ohjelma was launched by the Finnish Ministry of Education with the aim of supporting teacher development as a continuum, from initial teacher training through to induction and continuous in-service training. The programme enabled the PGM model to be scaled throughout Finland through collaboration between the universities providing teacher education and municipalities. This network provided education for mentors (8-15 ECTS credits), which was based on the aforementioned theoretical principles and included mentoring and reflection on personal experiences as a mentor. During an eight-year period, the network, consisting of all teacher education providers in Finland, trained more than 700 mentors. Then, at the beginning of the 2010s, the financial crisis hit the public sector with serious repercussions for the municipal economy. Some municipalities took measures to cut any costs that were not directly justified by law or by binding administrative guidelines. Mentoring had no legal status and was thus often regarded as an extra cost. In some municipalities, however, PGM was implemented as an integral form of in-service education. As a result, mentoring was organised in very different ways in different municipalities.

In 2015, another practice appeared in the ecological niche that proved to be a competitor to the PGM model. This new 'species' evolved within the educational policy of the centre-right coalition government, led by Juha Sipilä. The Sipilä Government brought in a multitude of changes to the educational sector, while simultaneously drastically cutting funding. Criticism has been raised that there was little coordination among the myriad of simultaneous reforms (Tervasmäki \& Tomperi, 2018). The Sipilä Government introduced the idea of the 'digi-leap', which focused on rapid engagement with processes of digitalisation in all areas of society.

To implement the digi-leap policy, a Tutor Teacher Project (TTP), was launched. Despite the different profiles of the TTP and PGM models, in many municipalities the two projects were understood as serving the same purpose: peer learning and teacher mentoring. In certain official documents of the time, the task of the tutor teacher was described in 
very similar terms to the 'mentoring and tutoring' of teachers. While the original principal aim of the TTP was to enhance the 'digi-leap', the aims were later broadened. From an ecosystem perspective, the models were seen as competitors in the same ecological niche from the municipal point of view. However, there was a significant difference in the funding mechanism between the two projects. The state allocated funding to universities ( $€ 1.1 \mathrm{M}$ ) for providing PGM mentor training and developing the model, and it was assumed that the municipalities would finance teachers' participation in PGM locally at their own expense. In contrast, the funding system of the TTP was based on a model where municipalities could apply for state funding, which was directly allocated to TTP activities and covered the majority of expenses, with a total investment of $€ 23 \mathrm{M}$ in the state budget. At the same time, the municipalities were in a difficult financial situation. It was clear that any smart municipal director of education would prioritise the TTP model in order to secure more money from the state, instead of investing the municipality's dwindling financial resources in PGM. As a result, the number of teachers participating in peer-group mentoring decreased significantly after 2015 .

However, the PGM model was still supported by the state through the Teacher Education Development Programme (2017-2020) and was chosen as one of the instruments for developing teachers' professional learning. The model was further developed and applied to other professional fields through the Verme ${ }^{2}$ project, which again involved all of the universities providing teacher education in Finland. The project had two interrelated objectives: (1) to continue the network's previous efforts to develop mentoring for teachers; and (2) to experimentally develop peergroup mentoring for new target groups through new variations of the model. The first objective was achieved by training 138 new mentors over a two-year period and providing support for previously-trained mentors. The second objective, to test different versions of the PGM model, targeted (1) students in the final stage of their teacher studies, (2) managerial staff at educational institutions, (3) professionals in multiprofessional groups, (4) teachers in early-childhood education, basic education and youth workers, (5) teachers providing liberal adult education, (5) experts of 
multicultural education, and (6) teachers in higher education (Pennanen, Markkanen, \& Heikkinen, 2019).

The results of the experimental projects were in line with the findings of earlier research and development work, and PGM was proven as a flexible method that can be used to support professional competence and workplace well-being in various fields. However, finding enough time for PGM amid a busy working life remains a key challenge to members' commitment to PGM group activities. Further issues to be resolved include compensation of employees for their time dedicated to peer-group mentoring and finding financing models to establish the activity on a regular basis. Considering these drawbacks, it is unsurprising that participant numbers declined (Pennanen et al., 2019).

\section{Experiences of the peer-group mentoring model}

In this section, the experiences of mentors and mentees regarding their participation in PGM groups and the administrative arrangements of the PGM model are examined based on a literature review of 193 research publications on PGM produced during 2009-2019. The corpus included seven edited books, 21 articles in peer-reviewed journals, 25 chapters in peer-reviewed edited books (or peer-reviewed conference proceedings), 53 chapters in non-refereed edited books, 21 master's theses, three doctoral dissertations and 69 conference papers or posters. The actual review was focused on 46 peer-reviewed articles and book chapters. The publications were analysed qualitatively. The results of the review have been reported in full detail in a recent peer-reviewed article (Tynjälä et al., 2020). In this section, the main results are summarised (Table 3).

The presented findings cover the following main themes: (1) prerequisites of functional mentoring activities; (2) outcomes, benefits and implications of PGM; and (3) challenges of the model. The findings were grouped into the three categories of relevance: i) individuals and groups; ii) community and organisation; and iii) national issues. 
Table 5. Summary of a review of 46 peer-reviewed studies on the Finnish Peer-Group Mentoring Model (modified from Tynjälä et al., 2020).

\begin{tabular}{|c|c|c|c|}
\hline Main themes & Individual/group level & Organisational level & National level \\
\hline $\begin{array}{l}\text { Prerequisites for } \\
\text { successful PGM } \\
\text { practices }\end{array}$ & $\begin{array}{l}\text { - Open and } \\
\text { confidential } \\
\text { atmosphere } \\
\text { - Methods: rules and } \\
\text { agreements for PGM } \\
\text { group; activating } \\
\text { methods }\end{array}$ & $\begin{array}{l}\text { - Administrative } \\
\text { factors: support from } \\
\text { the management } \\
\text { - Physical factors: time } \\
\text { and place }\end{array}$ & $\begin{array}{l}\text { - National agreements, } \\
\text { funding }\end{array}$ \\
\hline Benefits of PGM & $\begin{array}{l}\text { - A space for sharing } \\
\text { experiences and } \\
\text { reflection } \\
\text { - Empowerment } \\
\text { - Strengthening of } \\
\text { professional identity } \\
\text { - New ideas and views } \\
\text { - Enhanced motivation } \\
\text { and well-being }\end{array}$ & $\begin{array}{l}\text { - Mostly indirect } \\
\text { impact: empowered } \\
\text { teachers as change } \\
\text { agents } \\
\text { - More direct impact } \\
\text { if the teachers } \\
\text { belong to the same } \\
\text { organisation and } \\
\text { PGM is adopted as a } \\
\text { part of the strategy } \\
\text { - A way to support } \\
\text { teachers in the } \\
\text { induction phase }\end{array}$ & $\begin{array}{l}\text { - National network } \\
\text { - Research-based } \\
\text { development of } \\
\text { mentoring }\end{array}$ \\
\hline Challenges & $\begin{array}{l}\text { - Group dynamics } \\
\text { - Time management } \\
\text { - Commitment }\end{array}$ & $\begin{array}{l}\text { - Recognition of } \\
\text { peer learning } \\
\text { as professional } \\
\text { development }\end{array}$ & $\begin{array}{l}\text { - Salary for mentors } \\
\text { - Compensating } \\
\text { participation in PGM } \\
\text { in working hours } \\
\text { - Lack of national } \\
\text { agreement }\end{array}$ \\
\hline
\end{tabular}

With regard to the individual and group level findings, an open and confidential atmosphere was emphasised as a prerequisite for successful peer-group mentoring. The importance of common rules and agreements and activating methods was also revealed. The review showed highly positive results in terms of teacher well-being and professional and identity development. The main challenges identified relate to time management, participant commitment and, in a few cases, relational difficulties arising from group dynamics.

At the organisational level, our review revealed the importance of administrative and organisational support for implementing PGM. In particular, support from the management is a prerequisite for success. Benefits to the organisation were mostly indirect, although there was some evidence that teachers were empowered to act as constructive change 
agents in their schools. The biggest challenge was that peer learning was not always recognised as a form of professional development. Thus, a conceptual change in terms of what is regarded as professional development is needed.

At the national level, we observed that without legislation or a national collective agreement about the principles and conditions of its activities, PGM does not have an officially-recognised status in the education system. This has made it possible for municipalities to cut spending on PGM in economically-challenging times, which is reflected in the low proportion of teachers participating in mentoring. However, a promising network has developed around the PGM model, which has not only organised mentoring and education for mentors but also produced a remarkable body of research-based knowledge about the PGM model. Altogether, research on the Finnish model of peer-group mentoring has provided a rich knowledge base on the implementation of the model and on the experiences of participants and stakeholders, which has also been widely internationally peer reviewed and published in a number of journals and presented at conferences (Tynjälä et al., 2020).

\section{Conclusions}

One of the key concepts of this study is the ecological niche of mentoring. In ecology, the niche concept refers to the relational position or function of an organism in an ecosystem of plants and animals and their nonliving environment. The ecological niche describes how an organism or population responds to the distribution of resources and competitors and how it, in turn, alters those same factors. Likewise, there are niches for a variety of educational practices, like mentoring, within other educational practices (Kemmis \& Heikkinen, 2012).

The ecological niche of mentoring can be determined in a number of ways. Firstly, it can be understood as a liminal space or zone, or a 'liminal tunnel' (Savin-Baden, 2020), between initial teacher education and the induction phase, where a student teacher achieves a new identity as a qualified teacher. Secondly, the niche of mentoring can be defined in administrative terms as a zone between universities and municipalities. 
From this perspective, mentoring remains in a niche where responsibility for the professional development of teachers is administratively shifted from universities to municipalities. As in many other countries, mentoring in Finland seems to inhabit a contested niche between universities and municipalities. This niche even seems to provide 'hostile and nourishing ecological conditions' (Godfrey \& Brown, 2019, p. 17). Thirdly, in terms of the different forms of learning, this niche of mentoring can be interpreted as an intermediate state that intervenes between formal, non-formal and informal learning. From this perspective, the Finnish model of peer-group mentoring has deliberately merged these different types of learning and can be described as a kind of dialectical circle of formalisation and informalisation of learning (Heikkinen et al., 2012, p. 7). The strength of this is the seamless integration of different forms of learning. Its weakness, however, is that the formal institutions of learning do not always recognise such a form of learning as a proper method of professional development, which makes it difficult to allocate funding and resources to it.

Our goal in this article has been to study how mentoring has evolved in the Finnish education ecosystem, how it has come to inhabit its ecological niche and lived and developed there, how teachers have experienced it, and how it has been administratively established. Based on our literature review, the Finnish model of PGM has proven to be a highly promising innovation in the field of professional development. However, it has been challenging to get the model to take root in most municipalities. One explanation given for this difficulty is that a new 'species', the TTP model, appeared in the same ecological niche. It has been suggested that instead of competing in the same ecological niche, these projects should be combined (Pennanen et al., 2019). More generally, there seems to be an urgent need to orchestrate projects for teacher development at a national level.

The research shows that the challenge of providing mentoring for new teachers is far from solved. The need to develop mentoring of new teachers has been addressed in the Teaching and Learning International Survey (TALIS, 2018). Finland stands out clearly from other TALIS countries in terms of the low availability of mentoring programmes 
(Taajamo \& Puhakka, 2019, p. 6). The TALIS survey concludes that a national solution is needed in Finland to organise induction and mentoring for new teachers and that in order to achieve a national agreement on mentoring in Finland the responsibilities of the stakeholders (municipality employers, schools, teachers' union, universities providing teacher education) have to be clarified (Taajamo \& Puhakka, 2019, pp. 90-92). Similar recommendations were also made by the report on development of the attraction of teacher education in Finland (Heikkinen et al., 2020) as well as by the teacher educators who were involved in the PGM model (Pennanen et al., 2019, pp. 7-8): that broad-based social deliberation is needed to find the best ways to develop the induction of new teachers in the Finnish ecosystem of education. A sustainable solution can only be found through developing the ecosystem as a whole, and mentoring needs to be seen as an integral part of the education ecosystem.

\section{References}

Almiala, M. (2008). Mieli paloi muualle: Opettajan työuran muutos ja ammatillisen identiteetin rakentuminen [I had a burning desire to get elsewhere: A change in a teacher's career and the construction of a professional identity]. [Doctoral dissertation. University of Joensuu, Joensuu, Finland].

Aspfors, J. (2012). Induction practices: Experiences of newly qualified teachers [Doctoral dissertation, Åbo Akademi, Åbo, Finland].

Bjerkholt, E., \& Hedegaard, E. (2008). Systems promoting new teachers' professional development. In G. Fransson \& C. Gustafsson (Eds.), Newly qualified teachers in Northern Europe: Comparative perspectives on promoting professional development (Research publication: Teacher education No. 4, pp. 45-75). University of Gävle, Gävle, Sweden.

Blomberg, S. (2008). Noviisiopettajana peruskoulussa: Aloittelevien opettajien autenttisia kokemuksia ensimmäisestä opettajavuodesta [As a novice teacher in elementary school: Authentic experiences for beginner teachers from the first year of teaching] [Doctoral dissertation, University of Helsinki, Helsinki, Finland].

Estola, E., Heikkinen, H. L. T., \& Syrjälä, L. (2014). Narrative pedagogies for peer groups. In C. J. Craig \& L. Orland-Barak (Eds.), International teacher education: Promising pedagogies (Part A) (Advances in Research on Teaching, Vol. 22, pp. 155-172). Bingley, England: Emerald Group Publishing Limited. 
European Commission (1995). White paper on education and training: Teaching and learning: Towards the learning society. Brussels, Belgium: Author. Retrieved from http://aei.pitt.edu/1132/1/education_train_wp_COM_95_590.pdf

European Commission (2001). Making a European area of lifelong learning a reality. Brussels, Belgium: Author. Retrieved from https://epale.ec.europa.eu/ en/resource-centre/content/making-european-area-lifelong-learning-realitycommunication-commission-com

European Commission (2007). Improving the quality of teacher education. Brussels, Belgium: Author. Retrieved from https://eur-lex.europa.eu/legal-content/EN/ TXT/PDF/?uri=CELEX:52007DC0392\&from=EN

European Commission (2010). Developing coherent and system-wide induction programmes for beginning teachers: A handbook for policymakers. Brussels, Belgium: Author. Retrieved from https://ec.europa.eu/assets/eac/education/ policy/school/doc/handbooko410_en.pdf

Geeraerts, K., Tynjälä, P., \& Heikkinen, H. L. T. (2018). Inter-generational learning of teachers: What and how do teachers learn from older and younger colleagues? European Journal of Teacher Education, 41(4), 479-495.

Godfrey, D., \& Brown, C. (Eds.) (2019). An ecosystem for research-engaged schools: Reforming education through research. Abingdon, England: Routledge.

Heikkinen, H. L. T., Jokinen, H., \& Tynjälä, P. (2008). Reconceptualising mentoring as a dialogue. In G. Fransson \& C. Gustafsson (Eds.), Newly qualified teachers in Northern Europe: Comparative perspectives on promoting professional development (Research publication: Teacher education No. 4, pp. 107-124). University of Gävle, Sweden.

Heikkinen, H. L. T., Jokinen, H., \& Tynjälä, P. (Eds.) (2010). Verme: Vertaismentorointi työssä oppimisen tukena [Verme: Peer-group mentoring for promoting learning at work]. Helsinki, Finland: Tammi.

Heikkinen, H. L. T., Jokinen, H. \&. Tynjälä, P. (Eds.) (2012). Peer-group mentoring for teacher development. Abingdon, England: Routledge.

Heikkinen, H. L. T., Utriainen, J. Markkanen, I., Pennanen, M., Taajamo, M., \& Tynjälä, P. (2020). Opettajankoulutuksen vetovoima [Attractivity of teacher education]. Helsinki: Publications of the Finnish Ministry of Education and Culture.

Heikkinen, H. L. T., Swachten, L., \& Akyol, H. (Eds.) (2015). Bridge over troubled water: New perspectives on teacher induction. Ankara, Turkey: Pegem Academi.

Kemmis, S., \& Heikkinen, H. L. T. (2012). Future perspectives: Peer-group mentoring and international practices for teacher development. In: H. L. T. Heikkinen, H. Jokinen \& P. Tynjälä (Eds.), Peer-group mentoring for teacher development (pp. 144-170). Abingdon, England: Routledge. 
Launonen, L. (2000). Eettinen kasvatusajattelu suomalaisen koulun pedagogisissa teksteissä 1860-luvulta 1990-luvulle [Ethical educational thinking in the pedagogical texts of a Finnish school from the 1860 s to the 1990s]. [Doctoral dissertation, University of Jyväskylä, Jyväskylä, Finland].

Merriam, S., Caffarella, R. S., \& Baumgartner, L. M. (2007). Learning in adulthood: A comprehensive guide (3rd ed.). San Francisco, CA: Wiley.

Pennanen, M., Markkanen, I., \& Heikkinen, H. L. T. (Eds.) (2019). Verme2 testaa: Kokemuksia vertaisryhmämentoroinnin soveltamisesta [Vermez testing: Experiences in applying peer mentoring]. Jyväskylä, Finland: Finnish Institute for Educational Research.

Piesanen, E., Kiviniemi, U., \& Valkonen, S. (2007). Opettajankoulutuksen kehittämisohjelman seuranta ja arviointi. [Monitoring and evaluating the teacher education development programme] (Tutkimusselosteita/Koulutuksen tutkimuslaitos No. 38). Jyväskylä, Finland: Finnish Institute for Educational Research.

Ruohotie-Lyhty, M. (2011). Opettajuuden alkutaival: Vastavalmistuneen vieraan kielen opettajan toimijuus ja ammatillinen kehittyminen [First steps on the path of teacherhood: Newly qualified foreign language teachers' agency and professional development]. [Doctoral dissertation, University of Jyväskylä, Jyväskylä, Finland].

Sahlberg, P. (2015). Finnish lessons 2.o: What can the world learn from educational change in Finland? (2nd ed.). New York, NY: Teachers College Press.

Savin-Baden, M. (2020). Learning ecologies: Liminal states and student transformation. In R. Barnett \& N. Jackson (Eds.), Ecologies for learning and practice: Emerging ideas, sightings, and possibilities (pp. 46-60). Abingdon, England: Routledge.

Taajamo, M., \& Puhakka, E. (2019). Opetuksen ja oppimisen kansainvälinen tutkimus TALIS 2018: Perusopetuksen vuosiluokkien 7-9 ensituloksia, osa 1 [International research in teaching and learning TALIS 2018: First results of basic education grades 7-9, part 1] (Raportit ja selvitykset No. 8). Helsinki, Finland: Opetushallitus. Retrieved from https://www.oph.fi/fi/tilastot-jajulkaisut/julkaisut/opetuksen-ja-oppimisen-kansainvalinen-tutkimustalis-2018

Tervasmäki, T., \& Tomperi, T. (2018). Koulutuspolitiikan arvovalinnat ja suunta satavuotiaassa Suomessa. [Value choices and the direction of education policy in 100-year-old Finland.] niin \& näin 2/2018, 164-200.

Tynjälä, P. (2008). Perspectives into learning at the workplace. Educational Research Review, 3, 130-154. https://doi.org/10.1016/j.edurev.2007.12.001.

Tynjälä, P., Pennanen, M., Markkanen, I., \& Heikkinen, H. L. T. (2020). Finnish model of peer-group mentoring: Review of research. Annals of the New York 
Academy of Sciences (Special issue "Mentoring: Theoretical Background, Empirical Findings, and Practical Applications.”), 1-16. https://doi.org/10.1111/ nyas.14296

Välijärvi, J., \& Heikkinen, H. L. T. (2012). Peer-group mentoring and the culture of teacher education in Finland. In H. L. T. Heikkinen, H. Jokinen, \& P. Tynjälä (Eds.), Peer-group mentoring for teacher development (pp. 31-40). Abingdon, England: Routledge.

Wenger-Trayner, E., \& Wenger-Trayner, B. (2011). Communities of practice: A brief introduction. Retrieved from https://wenger-trayner.com/wp-content/ uploads/2015/o4/o7-Brief-introduction-to-communities-of-practice.pdf 


\title{
Mentoring in Iceland: An Integral Part of Professional Development?
}

\author{
Birna Svanbjörnsdóttir
}

University of Akureyri, Iceland

Hildur Hauksdóttir

Akureyri Junior College, Iceland

\section{Maria Steingrímsdóttir}

University of Akureyri, Iceland

\begin{abstract}
The main aim of this article is to give an overview of the development of mentoring for newly qualified teachers (NQTs) in Iceland and to shed light on the outcome of a mentoring education program developed by the University of Akureyri.
\end{abstract}

Over the past few years, mentoring and induction have gained momentum in research and scholarly writings in Iceland. Teacher dropout rates, teacher shortages and occupational stress have highlighted the importance of induction plans and mentoring for NQTs (Bjarnadóttir, 2005; Bjarnadóttir, 2015; Steingrímsdóttir \& Engilbertsson, 2018).

As of 2013, the Department of Education at the University of Akureyri has offered an education program (30 ECTS credits) with a focus on mentoring. An evaluation of this program was conducted in order to assess the learning outcomes and the structure of the program, focusing on the following research question: How have the teachers who have completed the mentoring program at the University of Akureyri experienced it in terms of their professional development and work as mentors? Also, we wanted to find out if a "third space" had been realized, where teacher educators, local authorities and practicing teachers come together and learn from each other on the premise of professional improvement. Data was collected through focus-group interviews, self-evaluation and action research of participants in the mentoring program.

Our findings imply that the teachers involved found themselves to be more competent after completing the mentoring program, with deeper understanding of the

Citation of this article: Svanbjörnsdóttir, B., Hauksdóttir, H. \& Steingrímsdóttir, M. (2020). Mentoring in Iceland: An integral part of professional development? In K.-R. Olsen, E. M. Bjerkholt \& H. L. T. Heikkinen (Eds.), New teachers in Nordic countries - ecologies of mentoring and induction (Ch. 6, pp. 129-149). Oslo: Cappelen Damm Akademisk. https://doi.org/10.23865/noasp.105.ch6

License: CC-BY 4.0. 
theories behind mentoring which was reflected in their increased engagement in school improvement.

Keywords: mentor education, induction, NQTs, professional development, third space

\section{Introduction: Teacher education and mentoring in Iceland}

Here we will address teacher shortages and teacher education in Iceland, and mentoring and induction in the Icelandic context, to give an insight into the background of the mentoring program and the research we based it upon. Also, we will describe the 30 ECTS credit mentoring education program this article revolves around.

\section{Teacher shortage}

In Iceland, according to the Teaching and Learning International Survey (TALIS) (OECD, 2014), the average age of the teaching profession is getting higher and in order to avoid teacher shortages, ensure teacher retention, as well as boosting the number of teachers, it is important to support NQTs. The results of TALIS reveal that the average age of Icelandic teachers has gone up since their previous report in 2008. Also, the report shows that teachers below the age of 30 made up $6 \%$ of the teaching profession in 2014 , compared to 2008 when the ratio was $13 \%$. Also, the number of teachers about to retire is growing.

More factors may play a role in the Icelandic context when it comes to foreseeable teacher shortages. Following the enactment of a new law on education, which introduced a five-year program in teacher education (law no. 87/2008), fewer teachers have graduated than before the law came into effect. Admissions to teacher education (for preschool, primary and lower secondary school teachers) have decreased by $40 \%$ since 2008 . The universities educating teachers do not pass enough graduate teachers to meet the demands of recruitment: 270 new teachers are needed every year, but on average, only 90 students graduate. There is a significant dropout rate among NQTs, especially in the first three years (Ministry 
of Education, Science and Culture, 2019). Recent research indicates that teacher recruitment will not meet demand, since such a large number of teachers are about to retire. Therefore, it is urgent to explore how NQTs can be supported and find out what kind of support leads to teacher retention (Eyjólfsson \& Jónsson, 2017).

\section{Teacher education}

In 2008, a law (no. 87/2008) was passed by the Icelandic Parliament in which a new education policy was presented for all school levels in Iceland, as well as teacher recruitment and education. As of 2008, teacher education in Iceland is a five-year program at Master's level for preschool, primary school, lower secondary and upper secondary school teachers. That is, a three-year B.Ed., BA or BS degree without a teaching license, followed by a two-year M.Ed. degree leading to a teaching license for one specific school level. Worth noting is that the upper secondary school level is financed by the state while the municipalities finance preschools, primary and lower secondary schools (Government of Iceland, 2019).

To respond to foreseeable teacher shortages, a new law on teacher education and teacher competency was enacted in 2019 (law no. 95/2019). The section about teacher education remained more or less the same, that is, a five-year program is required. Teacher students will continue to specialize in one school level, but the new law allows for more mobility of the profession between different school levels due to one teaching license for all. Students that start their teaching education in 2021-2022 will graduate in accordance with the new laws. By implementing this law, the government's goal is to:

- increase the flow of teachers between different school levels and promote the professionalism of teachers in diverse educational systems,

- encourage consistent professional development and acknowledge specialization at different school levels,

- prevent teacher shortages since teachers have credentials and can secure employment at all school levels, as well as increase the number of new teachers (law no. 95/2019). 
Teacher students can take different modules according to which school level they have chosen for their career and have priority when it comes to relevant teaching positions available. However, they can also specialize for other levels assessed by a national teaching council based on a qualification framework. The Ministry of Education appoints the council of 11 delegates representing different stakeholders in the education system (law no. 95/2019).

The new law also allows teacher education institutes to offer a more practice-based teacher education, without a research project or with a research project of less than 30 ECTS credits. Those students receive a MT degree (Master of Teaching) but cannot commence a $\mathrm{PhD}$ course unless they add a 30 ECTS credit research project (law no. 95/2019).

The details of the one teacher license (as opposed to three) remain to be seen but it needs to be taken into consideration that teacher education is still structured according to previous law, and curricula based on the new law will not be adopted in full until the fall of 2021. Thus, some time is allowed for adjustment.

There are some structural differences between universities that offer teacher education when it comes to field practice, but in total the amount of time is similar. For those studying to be preschool, primary or lower secondary teachers, about 42 ECTS credits in practical training are required, while those studying to become upper secondary school teachers are required to take 1o ECTS credits (University of Akureyri, 2020a, 2020b \& 2020c). Most field practice takes place during the students' last year. Those studying to be preschool, primary or lower secondary teachers can now choose a paid induction year while simultaneously writing an M.Ed. thesis (Ministry of Education, Science and Culture, 2019). This induction year includes a 50\% position at a school and the student fulfills all duties entailed in the position. This is only available in areas where there is a teacher shortage, since no positions are designated specifically for teacher students (Ministry of Education, Science and Culture, 2019). A student can also take a different route and split her/his fifth year between field work and teacher training (30 ECTS credits) in the fall semester and then write her/his M.Ed. thesis (3o ECTS credits) in the spring semester without pay. 


\section{Induction and mentoring}

In Iceland, no national policy concerning induction or mentoring of new teachers has existed, which is in contrast to many other European countries (European Commission, 2010). No laws or regulations in Iceland ensure support for new teachers from mentors when they start working, and thus no tradition has been developed for professional guidance or systematic induction to the teaching profession.

Yet the need for support for NQTs has been acknowledged to a certain extent, and some schools have developed support for newcomers, but it has been highly informal and unsystematic. Thus, induction is dependent on the school administrators and the financial situation of the school (Steingrímsdóttir, 2007). In fact, NQTs' need for mentoring and induction was very little discussed until around the turn of the 21st century, with the emergence of the first scholarly writings in Icelandic on NQTs based on Icelandic research (Bjarnadóttir, 2005; Steingrímsdóttir, 2007).

During the last few years in Iceland, as in other countries, mentoring and induction has become more prominent in the discussion as one of the factors to prevent beginning teachers from failing and leaving the profession. The teachers' unions and universities providing teacher education in Iceland have been advocates of support for new teachers. Their objective has been to develop mentoring as a sustainable part of schoolwork (Bjarnadóttir, 2015; Hauksdóttir, 2016; OECD, 2014; Steingrímsdóttir, 2010).

Icelandic research on new teachers (Steingrímsdóttir, 2007, 2010; Steingrímsdóttir \& Engilbertsson, 2018) has highlighted the urgent need for induction and mentoring. Also, the researchers imply that although some new teachers are being provided with mentoring, it is neither systematic nor formal. Based on these research studies, although no laws or regulations stipulate that new teachers must receive mentoring, 40-50\% of first-year teachers are provided with mentors. The mentoring NQTs receive is mostly focused on practical aspects of their schoolwork. The focus is not on theoretical or professional support, although research confirms that they also need this. Steingrímsdóttir and Engilbertsson's research (2018) indicated that a large group of the newcomers rarely met their mentor and were not assigned mentors with the same subject or in the 
same field as the new teacher. That particular group of new teachers valued the mentoring/support much less than the group that met their mentors more often and had a mentor that had the same or a similar teaching field. This correlates with other studies (e.g. Desimone et al., 2014). The frequency of formal meetings with mentors and the professional background of mentors were the variables that had the strongest connection to job satisfaction and the experience of support for schoolwork.

This Icelandic research (Steingrímsdóttir \& Engilbertsson, 2018) gives an indication that emphasis should be placed on creating time and space for mentors to do their work, and mentoring should not be an addition to a full workload. Also, even though NQTs were assigned mentors, it differed whether these mentors complied with their assigned task. In some cases, mentees never met their mentor (ibid). Therefore, it is of importance to ensure that those who are assigned as mentors know their role and that their work is knowledge-based. They should be able to support those beginning their careers and have a constructive effect on their work and attitude, so that NQTs can better cope with and stay in their chosen career instead of leaving the profession. Also, mentors must value the knowledge and past experiences that new teachers bring to the profession, as has been pointed out in other scholarly writings (Ingersoll, 2012; Hong \& Matsko, 2019).

It may be noted that in Iceland the percentage of teachers who did not take part in formal or informal induction activities is above the OECD average, but is not statistically different from the OECD average concerning assigned mentors at the current school (OECD, 2020).

\section{Putting mentoring on the agenda}

In spring 2018, the Minister of Education appointed a group of educational experts from universities with a teacher education program, the teachers' unions and municipalities. This group was to put forth proposals of actions to increase the recruitment of teachers and counteract the dropout rate in teacher education. For example, the group proposed three measures that included formal mentoring and induction for new teachers. The first deals with targeted mentoring for NQTs in all schools. The 
second deals with formal training and specialization in mentoring for experienced teachers who oversee the induction of new teachers and student teachers. The third measure concerns an induction year for teacher students - the fifth year - which has been mentioned previously in this article. In 2019, the Ministry of Education launched an initiative that includes formal mentoring for new teachers, and more emphasis on mentoring education for experienced teachers to support and mentor student teachers and NQTs. The Ministry will finance mentor education for experienced teachers for the next five years. Also, new teachers will receive formal and systematic mentoring during their first three years in the profession, and will have a reduced workload assigned to them (Ministry of Education, Science and Culture, 2019). This is an explicit acknowledgement of the importance of mentoring and support of NQTs.

When reviewing the results of Icelandic research, it becomes clear that mentoring in Iceland needs more discussion in order to further develop and improve. For example, there is hardly any, or at least very little, mentoring culture in the Icelandic context, such as peer mentoring and other formal measures that encourage experienced teachers to support newcomers (Steingrímsdóttir, 2007, 2010).

An important milestone in Icelandic mentoring history was reached when the universities with teacher education departments started to offer a 30 ECTS credit mentor program in 2013. The aim of the program is to strengthen mentoring as a niche within the school culture so that it becomes an ecological entity. The mentoring education program at the University of Akureyri (UNAK) is part of its graduate program, where professional development of mentors is put at the forefront of its programs, as well as efforts to promote peer mentoring which again could contribute to creating a spirit of the third space, which aims at more systematic collaboration between different stakeholders (teacher educators, local authorities and practicing teachers), as explained by Zeichner (2010). This corresponds with the Ministry of Education's initiative mentioned above, which aims at putting mentoring on the agenda. The mentoring education program consists of three courses, taught consecutively over three semesters: mentoring in the field; professional development and school community; and mentoring - a part of teachers' professional 
education. Each course is based upon learning outcomes that focus on the role of mentoring NQTs (University of Akureyri, 202od).

In the light of current discussions about NQTs and the Ministry's initiative of boosting mentoring and induction, we felt it necessary to review and evaluate the mentoring education program at the University of Akureyri to see whether it yielded the professional development hoped for, as well as contributing to a process where mentoring becomes a sustainable and integral part of the school community. To assess the outcome of this initiative we conducted an evaluation based on interviews of the participants that completed the mentoring education program in 2018.

The structure of the mentoring education program and its learning outcomes are based on international and Icelandic research highlighted in the following article, followed by our research question:

How have the teachers who have completed the mentoring program at the University of Akureyri experienced it in terms of their professional development and work as mentors?

\section{Laying the groundwork for the mentoring program}

According to research, it is unequivocal that supporting teachers who are developing professionally is an important part of their learning process (Fullan, 2007; Ingersoll \& Strong, 2011). Such support can be on a personal level or a team level and revolve around reflection (Smith, 2015). Constructing and integrating comprehensive induction and formal support for NQTs can be a challenge (OECD, 2020). Different approaches to mentoring subsequently lead to different kinds of learning, and therefore many variations of methods and actions of mentors (OECD, 2019). According to Kemmis, Heikkinen, Fransson, Aspfors, and EdwardsGroves (2014) mentoring might include support and/or collaborative self-development, while Fransson and Gustafsson (2008) discuss the importance of balancing evaluation on the one hand and promotion of professional development on the other. In a recent OECD report (2019), the authors point out that it is also a challenge to extend and maintain mentoring schemes, as well as training experienced teachers to become 
effective mentors. Not only do mentors have heavy workloads, but also there is a lack of recognition of their work, which again can hinder the improvement and quality of mentoring.

Significant social changes over the past few years have had an impact on education and, consequently, teachers and their work (DarlingHammond, Wei, Andree, Richardson, \& Orpjanos, 2009; OECD, 2014). Darling-Hammond et al. (2009) point out that the teaching profession is no longer limited to work inside the classroom. It also requires collaboration with colleagues and other specialists, parents, students and, last but not least, reflection on the work itself as well as professional development. Therefore, teachers need to develop lifelong learning skills (Heikkinen, Joikinen, \& Tynjälä, 2012).

Research, both international and Icelandic, has shown that many NQTs find the transition from teacher education to the field challenging, both professionally and personally, and they need support at the beginning of their career (European Commission, 2010; Hauksdóttir, 2016; OECD, 2014; Steingrímsdóttir, 2007, 2010; Ulvik, Smith, \& Helleve, 2009). Thus, recent research on NQTs has focused more on what kind of support they need at the beginning of their career and the most efficient ways to provide the mentoring and induction they need. The goal and purpose of such support is to facilitate NQTs' assimilation into the profession and the school community so that they become more successful and more capable, thereby reducing the number of teachers who drop out in the first few years (Bartell, 2005; Darling-Hammond, 2006; European Commission, 2010).

It has also been argued that teacher education must focus more on introducing teacher students to different practices, such as providing constructive feedback and cooperative learning, at the expense of too much emphasis on a theoretical and methodological approach. Also it should lead the way in terms of professional development (Grossman, Hammerness, \& McDonald, 2009).

For mentoring to be as effective as possible, Smith (2015) points out that those responsible for mentoring need to be trained in its basic factors, since there are indications that there is a difference between those who have had such training and those who have not (Helleve, Danielsen, $\&$ Smith, 2015). The difference is most apparent when it comes to those 
who are well prepared and know how and why certain factors need to be emphasized. Mentoring should facilitate reflection and ensure that mentors are conscious of their responsibility for teachers' professional development. Thus, their approach aims at leadership in change as explained by Fullan (2007). Various scholars have pointed out the misconception that teacher induction fixes problems when, in fact, teacher induction is reciprocal - a learning process for experienced teachers as well as NQTs (Bartell, 2005; Tolhurst, 2010; Van Esch \& Tillema, 2015).

Tolhurst (2010) concludes that it is necessary for mentors to be able to analyze what kind of support is needed in every case. He emphasizes the importance of NQTs receiving constructive feedback on their work based on dialogue. This means that teachers receive help to reflect on their work, how effective it is and learn from it. Also Tolhurst explains that mentoring requires a certain balance of support for personal style and practice, as well as promoting understanding of what effective teaching is. This is in accordance with Van Esch and Tillema (2015), who believe dialogue between parties needs to be demanding, supportive and solution orientated.

Effective leadership must not be underestimated in induction and mentoring. According to research, principal leadership is one of the most significant factors of teachers' commitment to the profession (Hong \& Matsko, 2019). In terms of mentoring, it seems that more emphasis is now placed on the cooperation and co-responsibility of teacher educators, and field experiences based on academic research pertaining to quality teacher education. Thus, it cannot be realized without a meaningful and extensive partnership of schools and universities (Bjarnadóttir, 2015; Darling-Hammond, 2006; Zeichner, 2010).

The third space, as explained by Zeichner (2010), aims at a more systematic approach and collaboration between universities and schools in order to make teacher education more seamless, where different stakeholders meet in a partnership and all voices are of equal value (Bjarnadóttir, 2015). Also there is a consensus that everyone is a learner, but their expertise is based on different experiences. An example of such partnership is found in Finland: Verme, a Finnish network for peer-group mentoring. Its main goal is to develop and disseminate the peer-group mentoring model (PGM) to support professionals in the educational field. There are 
some similarities between this Finnish approach and the mentoring program at the University of Akureyri that is discussed in this article. In Iceland, teacher education has been reorganized in the light of this, where mentoring is more prominent than before (Bjarnadóttir, 2015).

Since more emphasis is placed now on mentoring and induction of NQTs, we decided to evaluate the mentoring program and its impact on the professional development of the teachers involved. As has been pointed out, it is important to conduct more small-scale studies to understand the processes in question better (Simmie, de Paor, Liston \& O’Shea, 2017).

\section{Method}

The evaluation of the mentoring program is based on two focus-group interviews conducted in January 2019, self-evaluation of participants in the 30 ECTS credit program, and an action-research project (Mills, 2017) which the participants completed in the last course of the program. In order to get a dynamic discussion of the program we chose focus-group interviews to collect data rather than individual interviews. The selfevaluation was based on a critical reflection of teachers on their own participation and contribution to different aspects of the program. The participants supported their reflections using examples and with references to the proposed learning outcomes of the program. The final course of the mentoring education revolved around an action-research project, which focused on mentoring and participants carried out in the field. The action research followed a plan where participants defined the subject, developed a research question, defined a sample, collected data, connected their analysis with the results of the research and mapped out a plan for improvement. Students then presented the outcome on the Internet as well as in seminars. Their grade was based on peer assessment in the seminars.

There were nine participants who all had five-twenty years of teaching experience. One focus-group included five teachers, the other one four. Participants were working in pre-schools, primary schools and upper secondary schools and had completed a 30 ECTS credit mentoring education program at the University of Akureyri. Each interview was semi-structured and lasted about an hour. The interviews were 
then transcribed, and thematic analysis was applied (Cohen, Manion, \& Morrison, 2000).

An evaluation is specifically designed to provide information for decision making, and the findings cannot be generalized (Gall, Borg, \& Gall, 1996). The objective of this evaluation was to provide information about teachers' experiences of the mentor program and to assess its quality and need for future improvements. Also, to find out how it impacted upon participants' professional development.

\section{Ethical considerations and limitations}

All students who completed the mentoring program in December 2018 received an invitation to participate in the evaluation. They all accepted and consequently gave informed consent to taking part in a focus group and allowing the use of their data for the evaluation. Those carrying out the evaluation were aware of their ethical responsibility, since the evaluation was aimed at the courses and students they taught and knew and could, therefore, bias the results even though systematic, ethical and reflective processes were used (Davíðsdóttir, 2013; Mills, 2017). All conditions concerning validity for this type of evaluation were met (McNiff \& Whitehead, 2010). The objective of the evaluation was clear; it was based on a systematic plan and yielded practical results.

\section{Outcomes}

The objective of the evaluation was to explore how the participants experienced the effect that the mentor program had on their work as mentors and their professional development. To shed further light on this we focused on the structure of the mentoring program and the impact of its learning outcomes on participants.

Thematic analysis yielded three main themes: Firstly, practical implications regarding content and structure of the course; secondly new approaches in mentoring and commitment to the role of a mentor; and thirdly mentoring as a contributing factor to professional development of teachers and the importance of creating a third space. 


\section{Practical implications}

Regarding the overall evaluation of the program, new knowledge and structure were frequently mentioned by participants. They found the structure of the mentoring program to be logical and with a clear reference and relation to field work, and one of them described its benefits as follows: "It is like my battery has been recharged."

The participants found the build-up between the courses to be logical; the first course focused on the theoretical framework, the second course on the school community and, finally, the third course required action research and a comprehensive approach to cooperation. One participant commented on the action research in the final course:

I felt liberated, wow, this is great, this was awesome ... I found it [action research] to be such a powerful tool. You had heard about it before and people were talking about this. I am all for having this as a part of my job.

The participants' self-evaluation and action research revealed that they had learned and adopted academic vocabulary and ways of thinking, and now regarded mentoring as a reciprocal process and a challenge for the school community as a whole. The following comment exemplifies this:

I had no theoretical background to rely on when working as a mentor. Did the best as I could but always based on my own practices and worked according to that. Now, I have so much more knowledge because I have read so much.

Another said:

This opened my mind in so many ways. I loved studying scholarly articles and theoretical frameworks.

The participants were generally satisfied with the content and the structure of the courses. A stronger knowledge base, constant self-reflection, cooperation and action research were mentioned by participants. Factors were also mentioned that promoted professional development, changed their practices and yielded stronger commitment to providing mentoring to all co-workers, not just pre-service teachers and NQTs. They also considered themselves more capable of mentoring their co-teachers. One said: 
My emphasis went from practical things, checklists and box ticking to deeper discussions with him [mentee] to make him reflect more on what he was doing, and why, and you just went deeper.

The participants observed a clear connection between the courses and their experience in practice. Thus, one said:

Yes! ... You sort of knew; you had dealt with lots of things but now you knew they actually had a name.

Another said:

... I am just one of those who has not sat down and read scholarly articles for years. I found it to be incredibly rewarding.

They believed now that they were more aware of the importance of active listening and being there, not only for NQTs but also other colleagues. They allowed themselves more time to pinpoint challenges in discussions with other teachers and believed they were more apt at problem-solving as equals. They also thought they now had a deeper understanding of co-workers' feelings and challenges in practice.

\section{New approach and commitment to the role of mentoring}

In regard to Theme 2, the participants considered the knowledge of mentoring of NQTs as very important within the school. The role of mentors is still rather undefined in Icelandic schools, so classroom teachers did not necessarily assume responsibility for mentoring. The participants stressed that the responsibility of induction and mentoring should not be assigned to just one teacher or leader but rather be regarded as a collaboration of the school as a whole. Delegating roles is therefore important. Participants pointed out that generally speaking, induction was not prioritized in the field, and there was a strong tendency to assign the responsibility of induction to one person only. According to the participants, they felt that this was ingrained in the school culture. 
One said:

It is more about working conditions ... or the culture of that school ... how important the administrators are.

Another said:

I started thinking about what kind of teacher I wanted to be, both in regard to students and NQTs etc. Then when we reflected on our practice ... I realized: this is who I am [as a professional].

A third one described the order of importance this way:

$\ldots$ if there is conflict about whether to attend a team meeting or [a mentor meeting], then the team meeting comes first. If there is a need for a teacher substitute, that comes first; it [mentoring] is not considered more important than that. Which is maybe normal considering how busy things are, but still ...

In a few of the participants' schools, induction plans had been implemented for some time, but they were further developed during the participants' time doing the courses and after they had completed the mentoring program. Other schools started to write induction plans while the teachers were taking the mentoring program and, in yet more schools, efforts were made to create such induction plans. Those teachers who had taken the mentoring program often took responsibility for such work.

\section{Professional development of teachers and the importance of creating a third space}

A third theme the participants expressed was the need for a clear and formal vision on the school leaders' behalf when it came to induction and mentoring of NQTs. Generally, they believed mentoring was not regarded as part of school culture. Participants in the mentoring program realized that peer support is of importance, especially to promote mentoring and professional development. They also mentioned the importance of principals and local municipalities getting involved in policymaking and implementation. Their voices needed to be heard and they needed to be introduced to different methods and theory. One said: 
This needs to be presented to ... all the staff. That is our plan in our next staff meeting, then I will present my action research and its background. This is exactly what I mean by everyone taking part, induction is not a private issue ... which is what I experienced in the beginning: She is learning about mentoring and induction! She will shoulder the responsibility! [opinion expressed by the teachers' colleagues]. But that is not good enough, we need to work together so things are done properly.

Participants voiced their will to find a platform where NQTs and even pre-service teachers, experienced teachers and teacher educators could actively participate in a formal discussion and referred to Verme (http:// osaavaverme.wixsite.com/verme/en), which they had learnt about in the mentoring program. Such a platform could create a connection between the theoretical framework and those working in the field, in preschools, primary schools and upper secondary schools, and serving as professional development.

They said:

It would be beneficial to both teacher students and experienced teachers to meet and have a dialogue. Not necessarily listening to lectures. It is about dialogue ... there is such a wide gap between the theory and practice. This is what I felt was needed for teacher students beginning their studies [teacher education], a little bit of a reality check.

Aiming at bridging the gap between theory and practice and to build and improve a mentoring culture, they discussed if it was possible to have a formal discussion group including mentoring teachers, NQTs, as well as teacher educators, meeting regularly over the school year.

\section{Indications}

In this evaluation, we searched for an answer to the following question: How have the teachers who have completed the mentoring program at the University of Akureyri experienced it in terms of their professional development and work as mentors?

Our findings seem to indicate that the mentoring education program promoted professional development and peer support for the participants, 
as well as a deeper understanding of the need for implementing dynamic collaboration. Also, there was a deeper understanding of the importance of induction and mentoring for NQTs and the learning process involving all teachers in the school. The mentoring program seemed to have changed the practices of participants in such a way that it promoted professional work and targeted academic discourse.

When reading theories behind induction and mentoring practices in the first course, the participants realized that the framework of that part of teacher's practice was supported by theories and research. That gave them self-confidence in the practice as Bartell (2005) claims, and they became more fluent in the relevant professional discourse of induction and mentoring. Participants said they had gained a new perspective on the role of mentors. Instead of regarding it as a one-way street, they now believe mentoring should be an integral part of the school culture. That included reflection, critical thinking, problem-solving, peer support and commitment-not only for the NQTs but all teachers-disregarding teaching experience as is stated in the Finnish model of Verme, as Heikkinen et al. (2012) highlight. Therefore, mentoring seems to be a factor that potentially can support professional development for all, and with the intention and opportunity to create a third space where all stakeholders take part. Many scholars have pinpointed this as instrumental for improving mentoring and teacher education (i.e. Darling-Hammond et al., 2009; Grossman et al., 2009; Smith, 2015; Zeichner, 2010). In our evaluation, we noticed that in schools induction and mentoring were not a priority, which implies that school principals did not lead the way when it came to this important part of NQTs' first year. These findings are in conflict with those showing effective leadership being instrumental in induction and mentoring (Hong \& Matsko, 2019).

The Icelandic educational system has been undergoing significant changes recently, and it is still too early to make definite conclusions about improvements, for example, regarding induction and mentoring. However, we can assume from the conclusions of our evaluation that the mentoring program motivated experienced teachers to seek further professional development, or as one participant said: "It's like someone recharged your battery." From our evaluation, we see that the mentoring 
program and its learning outcomes are consistent with the proposal and objectives of the Ministry of Education (Ministry of Education, Culture and Science, 2019). We cannot make any assumptions about the perspective of mentees since it has not been the subject of evaluation yet.

Following this evaluation, it would be of interest and importance to delve into what the induction meant for the NQTs, and its implications for their professional development. Also, it remains to be seen what changes the Ministry's initiative will have on the sustainability of induction and mentoring in the Icelandic education ecosystem. The third space may not be realized unless different stakeholders, including teacher educators, school leaders, experienced teachers, local authorities and policymakers, become partners sharing this common goal. Ultimately, this evaluation further supports our notion that the mentor program yields the results hoped for and possibly further reveals the importance of dynamic collaboration towards the third space.

\section{References}

Bartell, C. (2005). Cultivating high-quality teaching through induction and mentoring. Thousand Oaks: Corwin Press.

Bjarnadóttir, R. (2005). Hvernig styður Kennaraháskóli Íslands við starfshæfni kennaranema? Icelandic Journal of Education, 14(1), 29-48. Retrieved from https://timarit.is/view_page_init.jsp?pageId=5009280

Bjarnadóttir, R. (2015). Leiðsögn. Lykill að starfsmenntun og skólapróun. Reykjavík: Háskólaútgáfan.

Cohen, L., Manion, L., \& Morrison, K. (2000). Research methods in education. (5th edition). London: Routledge Falmer.

Darling-Hammond, L. (2006). Constructing 21st-century teacher education. Journal of Teacher Education, 57(3), 300-314. https://doi.org/10.1177/0022487105285962

Darling-Hammond, L., Wei, R. C. Andree, A. Richardson, N., \& Orpjanos, S. (2009). Professional learning in the learning profession: A status report on teacher development in the United States and abroad. Stanford, CA: National Staff Development Council and the School Redesign Network at Stanford University.

Davíðsdóttir, S. (2013). Mat á skólastarfi. Handbók um matsfræði. (2nd edition). Reykjavík: Bókaútgáfan Hólar.

Desimone, M., Hochberg, E., Porter, A., Polikoff, M., Schwarz, R., \& Johnson, L. (2014). Formal and informal mentoring: Complementary, compensatory, or consistent? Journal of Teacher Education, 65(2), 88-110. 
Eyjólfsson, H. E., \& Jónsson, S. H. (2017). Skýrsla til starfshóps um nýliðun og bott starfsumhverfi grunnskólakennara í Reykjavík KÖNNUN Á MEĐAL ÚTSKRIFTAÁRGANGA ÚR KENNARANÁMI HÍ/KHÍ OG HA ÁRIN 200o-2012. Reykjavík: Háskóli Îslands.

European Commission. (2010). Developing coherent and system-wide induction programmes for beginning teachers: A handbook for policymakers. Brussel: Author.

Fransson, G., \& Gustafsson, C. (Eds.). (2008). Newly qualified teachers in northern Europe. Comparative perspectives on promoting professional development. Gävle: University of Gävle.

Fullan, M. (2007). The new meaning of educational change. (4th edition). London: Teacher College Press.

Gall, M., Borg, W., \& Gall, J. (1996). Educational research - An introduction. (6th edition). White Plains: Longman Publishers.

Government of Iceland. (2019). Retrieved from https://www.stjornarradid.is/ verkefni/menntamal/

Grossman, P., Hammerness, K., \& McDonald, M. (2009). Redefining teaching, reimagining teacher education. Teacher and Teaching: Theory and Practice, 15(2), 273-289. http://dx.doi.org/10.1080/13540600902875340

Hauksdóttir, H. (2016). Allir á hlaupum. Upplifun nýliða í stétt framhaldsskólakennara [unpublished M. Ed. thesis]. Háskólinn á Akureyri.

Heikkinen, H. L. T., Joikinen, H., \& Tynjälä, P. (Eds.). (2012). Peer-group mentoring for teacher development. London: Routledge.

Helleve, I., Danielsen, A., \& Smith, K. (2015). Does mentor education make a difference? In H. Tillema, G. van der Wetahuizen \& K. Smith (Eds.), Mentoring for learning. "Climbing the mountain" (pp. 313-332). Rotterdam: Sense Publishers.

Hong, Y., \& Matsko, K. (2019). Looking inside and outside of mentoring: Effects on new teachers' organizational commitment. American Educational Research Journal, 56(6), 2068-2407.

Ingersoll, R. M., \& Strong, M. (2011). The impact of induction and mentoring programs for beginning teachers: A critical review of the research. Review of Educational Research, 81(2), 201-233. https://doi.org/10.3102/0034654311403323

Ingersoll, R. (2012). Beginning teacher induction: What the data tell us. Phi Delta Kappan, 93(8), 47-57.

Kemmis, S., Heikkinen, H. L. T., Fransson, G., Aspfors, J., \& Edwards-Groves, C. (2014). Mentoring of new teachers as a contested practice: Supervision, support and collaborative self-development. Teaching and Teacher Education, 43, 154-64. http://dx.doi.org/10.1016/J.TATE.2014.07.001

Law no. 87/2008. Act on the education and recruitment of teachers and administrators of preschools, compulsory schools and upper secondary school. Retrieved from: https://www.althingi.is/lagas/nuna/2008087.html 
Law no. 95/2019. The act on the education, competency and recruitment of teachers and administrators of preschools, compulsory schools and upper secondary schools. Retrieved from: https://www.althingi.is/altext/pdf/149/s/1942.pdf

McNiff, J., \& Whitehead, J. (2010). You and your action research. London: Sage.

Mills, G. (2017). Action research: A guide for the teacher researcher. (6th edition). New York: Pearson.

Ministry of Education, Science and Culture. (2019). Fjölgum kennurum: aðgerðir í menntamálum. Retrieved from: https://www.stjornarradid.is/verkefni/ menntamal/adgerdir-i-menntamalum/fjolgum-kennurum-adgerdir-imenntamalum/

OECD (European Commission). (2014). The OECD teaching and learning international survey (TALIS). https://doi.org/10.1787/9789264196261

OECD. (2019). A flying start: Improving initial teacher preparation systems. Paris: OECD Publishing. https://doi.org/10.1787/cf74e549-en

OECD. (2020). TALIS 2018 Results (Volume II): Teachers and school leaders as values professionals. Retrieved from https://www.oecd-ilibrary.org/education/ talis-2018-results-volume-ii_19cfo8df-en

Simmie, G., de Paor, C., Liston, J., \& O'Shea, J. (2017). Discursive positioning of beginning teachers' professional learning during induction: A critical literature review from 2004 to 2014. Asia-Pacific Journal of Teacher Education. https://doi.or g/10.1080/1359866X.2017.1280598

Smith, K. (2015). Mentoring: A profession within a profession. In H. Tillema, G. J. van der Westhuizen \& K. Smith (Eds.), Mentoring for learning: "Climbing the mountain" (pp. 283-288). Rotterdam: Sense Publishers.

Steingrímsdóttir, M. (2007). Ofsalega erfitt og rosalega gaman. Reynsla nýbrautskráðra kennara af fyrsta starfsári. Icelandic Journal of Education, 16(2), 9-27.

Steingrímsdóttir, M. (2010). „Nú veit maður ef til vill út á hvað starfið gengur“: Hvað segja kennarar eftir fimm ár í starfi? Icelandic Journal of Education, 19(1-2), 71-88.

Steingrímsdóttir, M., \& Engilbertsson, G. (2018). Mat nýliða á gagnsemi leiðsagnar í starfi kennara. Netla - Online Journal of Pedagogy and Education. Retrieved from http://netla.hi.is/2018/ryno3

Tolhurst, J. (2010). The essential guide to coaching and mentoring. (2nd edition). London: Pearson Education.

Ulvik, M., Smith, K., \& Helleve, I. (2009). Novice in secondary school - the coin has two sides. Teaching and Teacher Education, 25(6), 835-842. https://doi. org/10.1016/j.tate.2009.01.003

University of Akureyri. (2020a). Educational studies, B. Ed. 180 ECTS (Curriculum). Retrieved from https://ugla.unak.is/kennsluskra/index. php?tab=nam\&chapter $=$ namsleid $\&$ id $=640014 \_20206 \&$ lina $=402 \&$ namskra $=1$ \&kennsluar $=2020$ 
University of Akureyri. (2020b). Educational studies, M.Ed. 120 ECTS

(Curriculum). Retrieved from https://ugla.unak.is/kennsluskra/index.

php?tab $=$ nam \&chapter $=$ namsleid $\&$ id $=640078 \_20206 \&$ lina $=407 \&$ namskra $=1 \&$ kennsluar $=2020$

University of Akureyri. (2020c). Educational studies, postgraduate diploma, 60 ECTS. Retrieved from https://ugla.unak.is/kennsluskra/index.php?tab=nam\&chapter= namsleid\&id=640081_20186\&kennsluar $=2018$

University of Akureyri. (2020d). Mentoring for practicing teachers, postgraduate diploma, 30 ECTS (Curriculum). Retrieved from https://ugla.unak.is/kennsluskra/ index.php?tab=nam\&chapter $=$ namsleid $\&$ id $=640153 \_20206 \&$ namskra $=1 \&$ kennsluar $=2020$

Van Esch, G., \& Tillema, H. (2015). The learning potential of mentoring conversation. In H. Tillema, G. J. van der Westhuizen \& K. Smith (Eds.), Mentoring for learning: "Climbing the mountain" (pp. 155-179). Rotterdam: Sense Publishers.

Zeichner, K. (2010). Rethinking the connection between campus courses and field experiences in college and university-based teacher education. Journal of Teacher Education, 61(1-2), 89-99. 



\title{
Induction and Mentoring of Newly Qualified Teachers in Kindergartens and Schools in Norway
}

\author{
Eva M. Bjerkholt and Knut-Rune Olsen \\ University of South-Eastern Norway, Norway
}

\begin{abstract}
This article presents the main features of, and analyzes the work on, facilitating induction and mentoring for newly qualified teachers (NQTs) in Norway. The methodological approach is a review of a variety of sources of political, scientific and professional nature.

The article addresses the following research questions: What characterizes the different milestones in the history of induction and mentoring in Norway? Which stakeholders have been active partners in the policymaking, and how has this contributed to changing and developing the national program for induction and mentoring for NQTs in Norway?

The narrative on induction and mentoring in Norway can be divided into four periods, or as we have chosen to call them, milestones. Although each milestone has distinct developmental traits and challenges, our analysis shows some pervasive features that have characterized the work throughout the whole history of induction and mentoring for NQTs in Norway. First, state authorities, represented by the Ministry of Education and Research and the Directorate of Education and Training, have played a key role in leading and facilitating cooperation between the stakeholders. Furthermore, there has been a clear distribution of roles and responsibilities between employee organizations, regional authorities and teacher education institutions.

The history of induction and mentoring in Norway is one of many examples where education, research and politics are intertwined. In 2021, the results of a comprehensive national survey will be published and discussed between the stakeholders before further policy decisions are made.
\end{abstract}

Keywords: newly qualified teachers (NQTs), white papers, stakeholders, national framework

Citation of this article: Bjerkholt, E. M. \& Olsen, K.-R. (2020). Induction and mentoring of newly qualified teachers in kindergartens and schools in Norway. In K.-R. Olsen, E. M. Bjerkholt \& H. L. T. Heikkinen (Eds.), New teachers in Nordic countries - ecologies of mentoring and induction (Ch. 7, pp. 151-176). Oslo: Cappelen Damm Akademisk. https://doi.org/10.23865/noasp.105.ch7

License: CC-BY 4.0. 


\section{Introduction}

In the spring of 2017, the Norwegian Parliament (in Norwegian Stortinget) made the following unanimous decision:

The Storting asks the Government, in collaboration with the stakeholders, to design a national framework for a mentoring system which ensures that all newly qualified teachers are covered by the national framework, and which allows for local adjustments. (Kunnskapsdepartementet, 2017, translated from Norwegian by the authors)

Based on this decision, the Ministry of Education and Research established a working group consisting of representatives from the teacher organizations, employers' interest organizations, state authorities and teacher education programs. After one year of work, these stakeholders signed an agreement that included principles for mentoring of NQTs in kindergarten, primary, lower secondary and upper secondary schools. The principles pointed out the guidelines for induction and mentoring based on teacher education as a continuum of professional learning into the teaching profession. The agreement also specified the roles and obligations of the various stakeholders. In addition, the Ministry of Education and Research commissioned the Directorate of Education and Training to implement four measures that were intended to facilitate the implementation of the national framework (Kunnskapsdepartementet/ Ministry of Education and Research, 2018b):

The Directorate of Education and Training should:

1. Prepare guidelines to support school and kindergarten owners who, according to the Working Environment Act, have the primary responsibility for implementing all types of further education for their employees - i.e. also mentoring newly qualified teachers based on the principles.

2. Develop a national framework for a master's degree program (30 ECTS) as a formal education for experienced teachers who would like to be mentors for NQTs. 
3. Announce assignments to the university and university college sector to offer this education in line with the adopted framework for the education program.

4. Conduct a national evaluation to identify the extent to which the implementation of the new agreement meets the Parliament's stated goal of the program including all NQTs.

\section{The methodological approach}

In this article, we are studying the history of induction and mentoring in Norway. Our research questions are: What characterizes the different milestones in the history of induction and mentoring in Norway? Which stakeholders have been active partners in the policymaking, and how has this contributed to changing and developing the national program for induction and mentoring for NQTs in Norway?

The methodological approach is based on reviews of mainly four types of documents. These are policy documents such as white papers related to reforms in teacher education and the transition from being a student to becoming a teacher in kindergartens and schools. Furthermore, we present and discuss results from national surveys and evaluations on induction and mentoring. The data also includes scientific articles, books, reports and Norwegian dissertations focusing on induction and mentoring for NQTs. Documents from the Norwegian Network for Mentoring of NQTs, ${ }^{1}$ such as annual reports (2004-2020), reports from meetings, seminars and conferences, and research presentations and discussions in the network, also provide parts of the data.

We have chosen to organize our article mainly based on a linear historical and narrative form of presentation divided into four main periods. The first period extends from about 1980 up to 2002. During this period, we find the first traces of issues related to induction and mentoring for NQTs being discussed in academic and political contexts in Norway. In

1 https://www.nyutdannede.no/en 
1998 two local pilot projects were launched in which different types of measures aimed at NQTs were tested.

The next period extends from 2003 to 2008. In 2003, a national project aimed at induction and mentoring was initiated, which gradually included all groups of NQTs in kindergartens, primary schools and lower and higher secondary education. The project immediately received strong support from teacher education institutions in Norway, and a national network was established in which all these institutions were represented. This network's main tasks were to offer mentor education and collaborate with local authorities in order to increase the scope of mentoring aimed at NQTs.

In the period from 2009-2016 the national program changed character, from being time-limited projects to becoming a more permanent program financed through annual allocations in the state budget. National surveys showed that more and more NQTs were included in the program, and the mentor education was strengthened and expanded. The first formal agreement between state authorities and key stakeholders was signed in 2009 to secure NQTs access to mentoring.

The fourth period covers the years from 2016 to the present. In 2016 a national survey showed that about $40 \%$ of all NQTs were still without any form of mentoring. This triggered the former mentioned a unanimous decision in the Norwegian Parliament in 2017. Based on the decision, state authorities worked out-in collaboration with stakeholders-national guidelines intended to secure all new teachers mentoring during the first two years of work after graduating from initial teacher education. A new national curriculum for a master's level mentoring program (30 ECTS) was also implemented.

As is evident from the discussion of the term "induction" in the introductory article of this book, what we refer to as mentoring is just one of several possible measures in a comprehensive strategy to support NQTs. A special feature of the Norwegian induction program is however that mentoring in the form of targeted and formalized conversations between professionals, often referred to in English as guidance, counseling or coaching (in Norwegian veiledning), has played a crucial role in the programs. The most important reason for this is probably that since the 1980 os competence and school development has been a 
priority and mandatory task for all schools in Norway. The NQTs are, of course, included in this and, in many cases, the content of the development work addresses subjects and didactic challenges that they are well acquainted with from their updated initial teacher education. The main challenges of the NQTs are therefore not primarily related to the content of school subjects or curriculum development and implementation, but rather to the lack of professional experience as catalysts to transform theory and theoretical knowledge into practical skills. In the Norwegian tradition reflective mentoring in the form of peer mentoring has been a central part of all development and implementation work in kindergartens and schools over the last 40 years (Handal \& Lauvås, 1983; Lauvås \& Handal, 2014). This might also explain why mentoring as a reflective strategy for development and learning (Schön, 1987) has had such a wide place in induction in Norway.

\section{The first milestone: Pilot projects and their background (1982-2002)}

Following a commission from the previously named Ministry of Church-, Education and Research, Karl Øyvind Jordell conducted a survey of NQTs in 1982 (Jordell, 1982). He concluded that there was a need to implement special measures aimed at NQTs' professional development. He emphasized, among other things, the special responsibility of school leaders to make the best possible arrangements for new teachers. Jordell also proposed starting testing of different models for mentoring, and the allocation of funding to reduce working hours for both NQTs and mentors as compensation for the extra work involved. Furthermore, he suggested that cooperation should be arranged between schools and teacher education in order to establish induction programs (Jordell, 1982, pp. 450-451).

Jordell's report was not followed up politically. The question was not put on the political agenda before the OECD in 1990 called for a more effective and systematic system of mentoring for new teachers in Norway (NOU:22, 1996). As a response to this, the Ministry proposed to introduce a candidate year with certification for students after completing initial 
teacher education (Kirke-, utdannings- og forskningsdepartementet/ Ministry of Church, Education and Research, 1997a). This year should mainly consist of regular teaching work in a school, but should also include both mentoring and assessment before the candidate received his/ her formal teaching diploma. In the discussion that followed, the suggestion received strong criticism, and mentoring programs for NQTs gained support as an alternative. The proposal for a candidate year with certification was therefore set aside, but was relaunched in the White Paper no. 11 (Kunnskapsdepartementet/Ministry of Education and Research, 2009) with reference to Sweden, where similar measures were being discussed (cf. Fransson's article in this anthology). However, the proposal was rejected again, partly because of opposition from the teacher organizations in Norway, and has not been a topic of political discussion since.

Based on the objections to a candidate year, the Ministry of Church, Education and Research in 1997 instead invited teacher-education programs to seek funding for projects including mentoring for NQTs. Teacher education institutions were to be responsible for the projects, but was to be carried out in close collaboration with schools and kindergartens, school and kindergarten owners, regional authorities and teacher organizations (Kirke-, utdannings- og forskningsdepartementet/Ministry of Church, Education and Research, 1997b).

With this announcement, important educational policy decisions were made that would prove to be of great importance for the further development of mentoring for NQTs in Norway (Bjerkholt, 1999, 2002, 2004, 2013; Skagen, 2011). In the announcement text for the project funds, the following three principles were highlighted: The first principle was that teacher education should motivate and initiate the work on developing mentoring programs. This principle expanded the teacher education area of responsibility from mainly relating to the education of teacher students, to including measures aimed at NQTs. Secondly, the programs should be developed in collaboration with regional and local authorities. The third principle was that the projects should be a collaborative area for the development of quality in both teacher education and in kindergartens and schools in general. 
It was also pointed out that mentoring should be offered individually and in groups as a key strategy. This mentoring should be based on the experiences and needs of the individual NQTs, not on predetermined themes provided by the local school or authority. The Ministry's announcement referred to the dominant approach of the time in the field of mentoring in teacher education (Skagen, 2011; Sundli, 2001), the strategy "Action and Reflection" (Handal \& Lauvås, 1983; Lauvås \& Handal, 1990, 2000, 2014; Olsen, 2013a, 2013b, 2015). This approach is characterized by mentoring based on the needs of the individual mentee, intended to contribute to learning through reflection on action (Schön, 1983, 1987). This form of mentoring is in line with an "educational approach" (Richter et al., 2013). This clearly differs from an approach where the mentor is the expert and the mentee is the submissive learner (Cochran-Smith \& Paris, 1995; Feiman-Nemser, 1998, 2001). The strategy represents a decisive emphasis on the interaction between the mentor and the mentee, to be carried out according to dialogic principles. The purpose is that through this the NQTs can receive support to reflect on experiences and challenges in their daily work guided by a formally qualified and experienced colleague, where they both can develop and learn. Thus, mentoring becomes an important supplement to other types of learning activities the NQT participates in, for example, through collaboration with colleagues and in courses and formal training (Eraut, 2004, 2010).

During the period from 1998-2002, the Ministry funded two pilot projects on mentoring of NQTs, both individually and in groups. Eva M. Bjerkholt at Telemark University College was responsible for the project on mentoring NQTs in primary and secondary schools, and Sidsel Hauge at the Oslo University College was responsible for the project on mentoring newly qualified kindergarten teachers.

Both projects (Bjerkholt, 1999, 2002; Hauge, 2001) were considered successful (Utdannings- og forskningsdepartementet/Ministry of Education and Research, 2002a), and formed the basis for starting a national project of mentoring for NQTs in kindergartens and schools (Utdannings- og forskningsdepartementet/Ministry of Education and 
Research, 2002a) which, in principle, has been continued as a national program until today.

\section{The second milestone: National projects and a national network (2003-2008)}

Based on the positive outcomes of the two pilot projects, mentoring of NQTs was launched as a national project in 2003 . It was financed by state funding, which allowed more universities and university colleges with teacher education programs to join the project.

The response from the teacher education programs was overwhelming, and already from 2004, the initiative included 27 teacher education institutions and covered most of Norway. At this stage, NQTs in upper secondary schools were also included (Bjerkholt, 2004).

The national project was initially planned to be limited to the period 2003-2007, but a national evaluation report published in 2006 (Dahl, Buland, Finne, \& Havn, 2006) showed very positive effects of the measures implemented. The survey documented that a large majority of the NQTs, leaders in kindergartens and schools, and the local mentors, thought that mentoring had made the NQTs:

- Better with regard to reflecting on their own practice and what leads to a good learning environment in classes

- Believe in their own abilities

- Better at handling and mastering class leadership

- Better at handling and mastering their whole work situation (Dahl et al., 2006 p. iii)

Furthermore, in 2003 the Ministry established a national "Network for mentoring of newly qualified teachers" in kindergartens, schools and upper secondary schools. The network's main task was to coordinate and develop the quality of teacher education institutions' work with mentoring programs. The members of the network were professional key personnel at the universities and university colleges participating in the work nationally. This network has been financed ever since by the Directorate 
of Education and Training and has to date been an important partner for the state authorities in promoting induction and mentoring for NQTs in Norway.

The national network was also intended to serve as an arena for sharing experiences and promoting quality in development of induction and mentoring of NQTs. The 2006 evaluation report (Dahl et al., 2006) highlighted the importance of the network as a professional forum in the wider sense. The report emphasized that the network, which included both teacher educators and researchers, had published several research reports and articles focusing on mentoring NQTs. The network was "thus developing a special field of knowledge and research on NQTs" (Dahl et al., 2006, p. 24).

National and international research (Flokenes \& Mæhle, 1981; Gold, 1996; Hubermann, 1993; Jordell, 1982, 1986; Strømnes, 1979) had shown that the development in schools and society as a whole up to the turn of the millennium had brought a number of new challenges and tasks to teachers in schools and kindergartens. In 1992 teacher education for classes 1-10 was extended to four years, but it was predominantly theoretical and subject oriented. Pedagogy and practice constituted only a minor part of the educational process (Nilssen, 2007). This underlined the need for induction and mentoring, but the 2006 evaluation report showed that only a few of the NQTs were covered by the program. In 2005, a little over 300 NQTs were participating, of which 100 were kindergarten teachers, 150 teachers in primary and secondary schools and about 60 teachers in upper secondary schools (Dahl et al., 2006, p. 24). One obvious reason for the limited participation was that many employers, from both custom and tradition, believed the NQTs did not need any form of support or mentoring (Bjerkholt, 1999).

The broad support from teacher education on the other hand, can be seen as an expression of concern and familiarity with the challenges facing NQTs. White papers and publications from the turn of the millennium onwards show increased attention to national and international research that supported such a view (Bjerkholt, 2013). Gradually, Slettes it was recognized that the knowledge and specialized skills required of professional practitioners could not be adequately learned during initial 
teacher education. What is taught in teacher education represents primarily a starting point and must be developed through targeted and systematic training and continuing education in the profession (Bjerkholt, 2013; Eik, 2014; Eraut, 2004, 2010; Grimen, 2008; Ødegård, 2011; Østrem, 2008).

Another factor that affected employers' limited interest in acting was of an economic nature. For teacher education, participation in the mentoring programs entailed new tasks and was therefore financed through earmarked government grants. However, regarding the financing of the specific measures aimed at the NQTs, it was argued by the national authorities that this was a voluntary program provided for through the annual framework grants for operating schools and kindergartens. This meant that measures aimed at mentoring NQTs had to be financed locally, and thus prioritized in competition with other types of continuing education for all teacher groups. We shall return to the consequences this Slettes may have had for the further development of induction and mentoring for NQTs in Norway.

\section{The third milestone: Further national surveys and formal agreements between stakeholders (2009-2016)}

White Paper no. 11: "The teacher. The role and education" (Kunnskapsdepartementet/Ministry of Education and Research, 2009), stated that the Norwegian Government wanted to further develop the system of mentoring for NQTs as a national program (Bjerkholt, 2013, p. 20). The political debate following the report showed that there was broad agreement on this. No significant changes were made regarding financing, but the need to coordinate and strengthen cooperation between the stakeholders was highlighted.

Following up this White Paper, a letter of intent was signed by the Ministry of Education and research and The Norwegian Association of Local and Regional Authorities (KS), ${ }^{2}$ which aimed to increase the num-

2 https://www.ks.no/om-ks/ks-in-english/ 
ber of NQTs receiving mentoring (Kunnskapsdepartementet/Ministry of Education and Research \& KS, 2009). Formal national and regional collaborative forums were also set up with representatives from employers, teachers' organizations, teacher education and political authorities to coordinate the work.

Since the 1970s, teacher education had offered continuing education in mentoring for practice teachers for student teachers in kindergartens and schools. With the extension of the mentoring programs for NQTs, there was a need to strengthen the education of mentors (Bjerkholt, 2002, 2013; Bullough, 2012; McNally, 2016). A working group was therefore appointed to develop new national guidelines for a continuing mentoring education program (30 ECTS) (Kunnskapsdepartementet/Ministry of Education and Research \& KS, 2009). With minor adjustments, these guidelines were in effect up until 2019 (Kunnskapsdepartementet/Ministry of Education and Research, 2010a, 2010b).

In this period three national surveys were carried out to measure the effect of the mentoring programs. Two of these were financed by state funds and carried out by external consultancy agencies (Kunnskapsdepartementet/Ministry of Education and Research, 2011, 2012). The third study was conducted under the auspices of the largest teachers' organization in Norway (Fladmoe \& Karterud, 2012). While the two state-initiated surveys mainly obtained data from NQTs and leaders in schools and kindergartens, the survey conducted by the teachers' organization also included data from the mentors. This survey found that the most important success factors for establishing sustainable mentoring programs were: a) commitment from the leaders in kindergartens and schools; b) time allocated to mentoring for both NQTs and mentors; and c) contact with teacher education (Fladmoe \& Karterud, 2012).

In short, the surveys showed that all parties directly involved considered the effect of the mentoring programs as consistently positive. At the same time, it was revealed that about $40 \%$ of the NQTs were not included in any formal mentoring programs.

In the period from 2014-2016, a further comprehensive national evaluation was carried out. The purpose was to answer two main questions: 
1. Do the mentoring programs help to ensure a good transition between initial teacher education and the professional work as a teacher, and to recruit, develop and retain skillful NQTs in schools and kindergartens?

2. Does mentor education provide the competence and skills needed for good practice as mentors?

The evaluation was based on document studies and case studies of selected municipalities that could document good results in their work with mentoring for NQTs. The case studies also targeted teacher education as providers of mentor education, kindergarten and school owners, leaders in kindergartens and schools, mentors and NQTs.

The second main question, regarding the quality of the mentoring programs, was approached through interviews with, and questionnaires for, teachers who had completed mentor education.

The results of the study were presented in the form of two reports (Rambøll, 2015, 2016). The first of these, from 2015, was mainly comprised of qualitative data, while the second also presented the results of the quantitative section with data obtained via questionnaires. As in earlier studies, the survey showed several positive effects of the measures:

- The NQTs who received mentoring felt more secure and more aware of the significance of their own competence.

- They seemed more confident in sharing the competencies they had acquired during their teacher education with their more experienced colleagues.

- The NQTs experienced mentoring as important for their development as teachers.

- NQTs who participated in mentoring were more positive in their assessments of their first year as teachers.

- The mentors' competence was useful in school and kindergarten development.

- The mentor education offered new career paths for teachers. (Rambøll, 2015). 
The survey aimed at the quality of mentor education showed that the students were very satisfied with the education, but that the programs were quite different in form and content. There were also differences between regions in terms of the extent of the education. In some regions, most students completed only the first half of the education (15 ECTS), as this was the minimum required for practice teachers, while in other regions mentors with 30 ECTS were most common.

However, the quantitative part of the survey (Rambøll, 2016) showed that about $40 \%$ of NQTs still did not receive any formal mentoring. Furthermore, among the $60 \%$ who had received mentoring, there were large variations in the scope, content, frequency, structure and quality of the mentoring programs. Nearly half of this group had received mentoring only once a month or less. The survey also showed that about $50 \%$ of the mentors had no formal education in mentoring.

The results from the evaluation study on the extent and quality of mentoring were regarded as somewhat disappointing. The Union of Education in Norway's ${ }^{3}$ student organization, "Pedagogstudentene", ${ }^{4}$ was particularly active in its efforts to draw political attention to the matter. Excerpts from the debate in the Norwegian Parliament show that the organization's efforts were one of the reasons why the debate resulted in a unanimous decision, in spring 2017, to implement measures aimed at ensuring that all NQTs would be offered mentoring.

\section{The fourth milestone: Agreement on a comprehensive national program}

The unanimous decision in the Norwegian Parliament in 2017 testifies to the political recognition of the importance of mentoring for NQTs. It can also be understood as a signal to the stakeholders that greater determination and results that are more positive are expected.

\footnotetext{
https://www.utdanningsforbundet.no/om-utdanningsforbundet/english/ https://www.pedagogstudentene.no/

https://www.utdanningsnytt.no/arbeidsmiljo-laereryrket-skoleutvikling/na-blir-det-nasjonalerammer-for-veiledning-av-nyutdannede-laerere/179812
} 
The group of stakeholders appointed in 2017 based much of its work on recent research on induction and mentoring, as well as the evaluation report from 2016. Representatives from the Ministry of Education and Research led work in the group. Teacher education participated with representatives from Universities Norway, ${ }^{6}$ which is a cooperative body for universities and university colleges offering teacher education in Norway. Their main concern was to establish a connection between the professional qualification that takes place in teacher education and the further professionalization that occurs within the profession.

The employers were represented by the Norwegian Association of Local and Regional Authorities ${ }^{7}-\mathrm{KS}$, which is an organization for all local governments in Norway, and by representatives from various private organizations. Teachers' unions were represented by the Union of Education in Norway, which is the largest teachers' union with about 180,00o members, the Norwegian Union of School Employees, ${ }^{8}$ the Association of School Leaders, ${ }^{9}$ and "Norsk Lektorlag", ${ }^{10}$ which is a union for university and college-educated lecturers and other academics with similar education. In addition, "Pedagogstudentene" was represented. The National Network for Mentoring of NQTs participated as an observer, giving research-based information and answering questions from the stakeholders in work on the agreement.

Completing a formal agreement proved to be demanding and took about one year. Although the stakeholders agreed with the main objective of the Norwegian Parliament, there was disagreement about how comprehensive the measures should be and how they should be financed. These issues were particularly important to the Norwegian Association of Local and Regional Authorities. They were also an issue for the Private Kindergartens' Associations, ${ }^{11}$ which represent the owners of about half of the kindergartens in Norway. This is related to the fact that virtually all schools and kindergartens (private and municipal) in Norway are financed by government

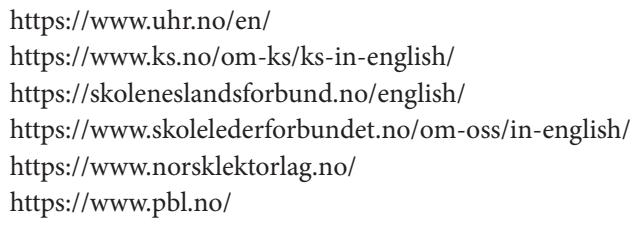


grants and tax revenues. This funding is expected to cover expenses not only for kindergartens and schools, but also other municipal responsibilities ranging from road construction to centers for the elderly. This means that all municipal and county activities are subject to political priorities that require negotiations about the distribution of limited resources among a wide variety of recipients. Although the municipal and private owners at the national level committed themselves to the agreement, they knew it would still be challenging to follow up on the agreement locally.

The main obligation of the municipalities' interest organization (KS) is therefore to look after the interests of its member counties and local municipalities in the best possible way. This means that if Norwegian Government authorities impose new tasks on counties and municipalities, it is the role of KS to demand that this should be financed through increased government grants. Regarding induction and mentoring for NQTs it has, as mentioned, been an overriding principle that kindergarten and school owners must cover expenses from within their own budgets. This means that although $\mathrm{KS}$ as an organization, on a professional basis, is positive to mentoring NQTs, it is of little importance for an interest organization to assign tasks that will result in a significant increase in expenses for its members. In the final agreement this is expressed in the proviso that the scope and organization of the measures must be adapted to local conditions. This is also probably the most important reason for the large local variations in the quality and scope of mentoring, and for the fact that around $40 \%$ of NQTs in 2016 were still without any formal mentoring program.

The teacher organizations, for their part, were concerned with the mentors being compensated for the responsibility and extra work they undertake, and that the NQTs are allocated time in their work plans for participating in mentoring.

Despite these obvious conflicts of interest, all the stakeholders with the exception of the Norwegian Union of School Employees ${ }^{12}$ reached an agreement that was intended to "... contribute to the implementation of mentoring through anchoring in their own organization, implementation

12 The main reason was that the financial compensation of the employees was not sufficient as they perceived it. 
of measures related to their own areas of responsibility and dialogue between the parties" (Kunnskapsdepartementet/Ministry of Education and Research, 2018b).

The national agreement ${ }^{13}$ included a section with concept clarifications related to the definition of key concepts, such as newly qualified teacher, qualified mentor and mentoring. Among other things, it states that a teacher in Norway is perceived as an NQT during the first two years of work after completing initial teacher education (Bjerkholt, 2013; Britton, Paine, Pimm, \& Raizen, 2003; Jakhelln, 2011). A qualified mentor is required to have formal mentor education (30 ECTS) and a minimum of three years of professional experience as a teacher. The term mentoring is defined as "a planned, systematic and structured process that is carried out individually and in groups" (Kunnskapsdepartementet/Ministry of Education and Research, 2018b, p. 6).

The agreement between the stakeholders, furthermore, states that mentoring must have a frequency and scope that provides the basis for expecting that it will contribute significantly to learning and development for NQTs (Ingersoll \& Strong, 2011; Parker, Ndoye, \& Imig, 2009). This can be seen in relation to the results of the national evaluation in 2014-2016, which documented that there were large variations in the frequency and scope of mentoring, and that many mentors lacked formal qualifications. The report stated that this variation meant that they could not conclude that mentoring for NQTs always had a positive impact on the learning and development of the new teachers (Rambøll, 2016). This is the reason why the agreement underlines that mentoring should preferably be conducted by qualified mentors who are academically up to date, and that the mentor should, in principle, not be in a leadership relationship with the NQT. This was important to prevent that conflicting roles in any way might decrease mutual confidence and hamper the effect of mentoring.

The national agreement also states that mentoring should be based on research and experience-based knowledge. Furthermore, it is intended to establish a good connection between the professional qualification in

13 https://www.nyutdannede.no/media/1240/veiledning-av-nyutdannede-nytilsatte-larere-i-barnehage-og-skole-6.pdf 
teacher education and further professional development in the profession (Mausethagen \& Smeby, 2017). The agreement strongly advocates the importance of collaboration between teacher education, employers and teacher organizations.

In addition to the formal agreement, a digital guide ${ }^{14}$ providing examples and advice regarding how employers can follow up on the principles and obligations, has been compiled. The Directorate for Education and Training has, in collaboration with the National network for mentoring of newly qualified teachers, also developed new national frameworks for a combined further education in mentoring (30 ECTS). These frameworks are based on the national principles and are intended to establish a common mentoring education offered at the universities and university colleges. The mentoring education is at master's level and consists of a common basic module of 15 ECTS and a supplementary module of 15 ECTS with two alternatives. One is aimed at mentoring teacher students and NQTs, and the other focuses on colleague or process mentoring for quality development in kindergartens and schools. Teachers in schools' grade 1-10 can apply for scholarships or reduced reading time during the study period, which usually extends over one academic year.

The agreement is valid for the period 10.09.2018 until 31.07.2021. During this period, work on the implementation of the agreement will be followed up with an extensive national evaluation. A final report will be available in February 2021, well in advance of the end of the contract period.

\section{Future challenges and opportunities}

In the work to come, there are many challenges for the stakeholders related to following up the national agreement. These are linked to financial conditions, collaborative structures and the need to increase the number of qualified mentors. 
In recent years, teacher education in Norway for primary and secondary schools has undergone major reforms and is now a five-year master's degree program. These graduating teachers will have an education that in many ways differs from their colleagues. They have fewer subjects in their subject portfolio and can be expected to have a more research-based approach to teaching and learning than previous generations of teachers. The amount of practice within the program, however, is almost the same.

The kindergarten and school owners need to have knowledge about today's teacher education and what they can expect of the NQTs in order to follow up on the ambitious principles in the national agreement. This requires that kindergarten and school leaders have insight into what is emphasized in the new teacher education as a basis for following up the principles and facilitating mentoring in a way that both supports and challenges the NQTs. Mentoring should not only be perceived as support but must also highlight the fact that NQTs represent competence that can be of benefit to their colleagues and further school-based development (Olsen \& Wølner, 2017).

As stated above, the question of who should fund induction and mentoring of NQTs, represents what we might call the Gordian knot in the Norwegian narrative. It is therefore very positive that the Norwegian Government, in the state budgets for 2019 and 2020, chose to allocate NOK 60 million and invite employers to apply for financial support for mentoring of NQTs in primary and secondary schools. However, in the case of NQTs in kindergartens and upper secondary schools, the Government has not provided such financial support.

\section{Conclusions}

This article addresses the research questions: What characterizes the different milestones in the history of induction and mentoring in Norway? Which stakeholders have been active partners in the policymaking, and how has this contributed to changing and developing the national program for induction and mentoring for NQTs in Norway?

The narrative of what characterizes the different milestones illustrates a chronological and political agreement line of facilitating induction and 
mentoring for NQTs in Norway since 1998. It started with two projects aimed at kindergarten, primary and secondary school teachers. NQTs in upper secondary schools were included in 2004. The first national letter of intent between state authorities and employers' representatives was signed in 2009 (Kunnskapsdepartementet/Ministry of Education and Research \& KS, 2009). This agreement was renewed in 2014. In 2018, an agreement was signed between the stakeholders aimed at ensuring that all NQTs in kindergartens, primary, secondary and upper-secondary schools would be offered mentoring during the first two years of work after completing initial teacher education.

Throughout the periods, state authorities represented by the Ministry of Education and Research and the Directorate of Education and Training, have led and financed the part of the measures that the teacher education institutions have been responsible for. This applies primarily to the education of mentors and cooperation on the employer side. The National network for mentoring of newly qualified teachers has played a key role in the sharing of experiences and quality development of the national program since 2003. Representatives from the network have also carried out research and development projects in the field.

Induction and mentoring for NQTs in Norway has not been authorized by law or other formal regulations. Consequently, participation in the program is voluntary and is the responsibility of the local employers.

A comprehensive national evaluation conducted in the period from 2014-2016 showed that 40\% of NQTs were still not included in any form of formal mentoring, and that the support given to the remaining $60 \%$, in many cases was of varying quality and frequency. The evaluation also showed that there was a significant lack of mentors with formal competence for this role. This triggered a unanimous decision in the Norwegian Parliament which aimed at ensuring that all NQTs in kindergartens, primary, lower and upper secondary schools would be offered mentoring in the first two years of work after completing initial teacher education. Implementation of the measures related to the decision is ongoing and is being followed up by a comprehensive evaluation to measure the impact. The results of the evaluation are expected to be published in 2021. 
As in most other countries, the purpose of induction and mentoring for NQTs has, to some extent, been financially motivated with a view to strengthening the recruitment to teacher education and retaining as many NQTs as possible in the profession. However, the measures in Norway have also, to a large extent, been justified based on research and experience. Mentoring is regarded as important in a national strategy for quality development and more learning for children and young people in kindergartens and schools. This is reflected in the national agreements concluded between the parties, in white papers and official reports. We also refer to the introductory article, where we discuss the strategy of OECD countries in this area.

The history of induction and mentoring in Norway is one of many examples where education, research and politics are intertwined. Politics is, by definition, about the premises of how limited financial resources can be managed in the best possible way. Which measures have the greatest impact can, in most cases, be difficult to document empirically. Therefore, decisions are often made more on a political rather than a scientific and research-basis.

The evaluation report expected to be published in 2021 will give us some indication of what effects the measures that were implemented after 2017 have had. This can be expected to generate a new discussion on the matter, both between the stakeholders and in the Norwegian Parliament.

\section{References}

Bjerkholt, E. (1999). Nasjonalt pilotprosjekt veiledning av nyutdanna allmennloerere i Telemark. Delrapport I, 1998-1999. [National pilot project - Mentoring newly qualified teachers, Report I, 1998-1999]. Notodden: Telemark Lærerhøgskole. Bjerkholt, E. (2002). Veiledning av nyutdanna allmennloerere 1998-2001. Sluttrapport.

[Mentoring newly qualified teachers 1998-2001. Final report]. Notodden:

Høgskolen i Telemark, avd. for estetiske fag, folkekultur og lærerutdanning.

Bjerkholt, E. (2004). Statusrapport nettverk veiledning for nyutdannede loerere 2003 handlingsplan 2004. (Vol. 1). [Status report Netwerk for mentoring of newly qualified teachers 2003 - action plan 2004]. Notodden: Høgskolen i Telemark. Bjerkholt, E. (2011). Statusrapport Nettverk for veiledning av nyutdannede loerere 2010 handlingsplan 2011. (Vol. 8). [Status report Netwerk for mentoring of newly qualified teachers 2010 - action plan 2011]. Notodden: Høgskolen i Telemark. 
Bjerkholt, E. (2013). Åpning av lukkede rom: En kvalitativ studie av innholdet og dialogene $i$ veiledningssamtaler mellom nyutdannede loerere og lokale veiledere. [Opening closed rooms: A qualitative study of the content and dialogues in mentoring newly qualified teachers and their local mentors]. ( $\mathrm{PhD}$ monography, no. 168), Det utdanningsvitenskapelige fakultetet, Universitetet i Oslo, Oslo.

Britton, E., Paine, L., Pimm, D., \& Raizen, S. (2003). Comprehensive teacher induction. Dordrecht/Boston/London: Kluwer Academic Publishers.

Bullough, R. (2012). Against best practice: Uncertainty, outliers and local studies in educational research. Journal of Education for Teachers, 38(3), 343-357. doi: $10.1080 / 02607476.2012 .668335$

Cochran-Smith, M., \& Paris, P. (1995). Mentor and mentoring: Did Homer have it? In J. Smith (Ed.), Critical discourses on teacher development (pp. 181-202). London: Cassel.

Dahl, T., Buland, T., Finne, H., \& Havn, V. (2006). Hjelp til praksisspranget - Evaluering av veiledning av nyutdannede loerere. [Help with the leap from teacher training. Evaluation report on mentoring newly qualified teachers]. Retrieved from https://www.regjeringen.no/globalassets/upload/kilde/kd/rap/2006/ooo4/ddd/ pdfv/280075-sluttrapport_med_vedlegg_veiledning_av_nyutdannede.pdf

Eik, L. T. (2014). Ny i profesjonen: En observasjons- og intervjustudie av førskoleloereres videre kvalifisering det første året $i$ yrket. [New in the profession: An observations and interview study of pre-school teachers further qualification in the profession]. (PhD monografi, no. 192), Det utdanningsvitenskapelige fakultetet, Universitetet $\mathrm{i}$ Oslo, Oslo.

Eraut, M. (2004). Informal learning in the workplace. Studies in Continuing Education, 26(2). https://doi.org/10.1080/158037042000225245

Eraut, M. (2010). Knowledge, working, practices, and learning. In S. Billett (Ed.), Learning through practice (pp. 37-58). Dordrecht: Springer.

Feiman-Nemser, S. (1998). Teachers as teacher educators. European Journal of Teacher Education 21(1), 63-74. Retrieved from https://doi.org/10.1080/0261976980210107. doi:10.1080/0261976980210107

Feiman-Nemser, S. (2001). From preparation to practice: Designing a continuum to strengthen and sustain teaching. Teacher College Record, 103, 1013-1055. Retrieved from https://www.brandeis.edu/mandel/questcase/Documents/Readings/Feiman_ Nemser.pdf

Fladmoe, A., \& Karterud, T. (2012). Veiledningsordningen for nytilsatte nyutdannede loerere og førskoleloerere. Resultat fra kartlegging vinteren 2012. [Mentoring newly qualified teachers and pre-school teachers]. Retrieved from https:// www.regjeringen.no/globalassets/upload/kd/vedlegg/grunnskole/gnist/ veiledningsordningen_rapport_2012.pdf 
Flokenes, J., \& Mæhle, A. B. (1981). Samarbeidsprosjektet unge loerarar. [Collaboration project - young teachers]. Stord: Stord Lærarskule.

Gold, Y. (1996). Beginning teacher support: Attrition, mentoring, and induction. In J. Sikula (Ed.), Handbook of research on teacher education (pp. 548-594). New York: Macmillan.

Grimen, H. (2008). Profesjon og profesjonsmoral. [Profession and professional ethics.] In A. Molander \& L. I. Terum (Eds.), Profesjonsstudier (Professional studies) (pp. 144-16o). Oslo: Universitetsforlaget.

Handal, G., \& Lauvås, P.(1983). På egne vilkår. En strategi for veiledning med loerere. [On your own terms. A strategy for mentoring teachers]. Oslo: Cappelen forlag. Hauge, S. (2001). "Man må ta så mange avgjørelser hele tiden ...": Rapport fra pilotprosjekt om veiledning av nyutdannede førskoleloerere. [ «You have to make so many decisions all the time ...»: Report from a pilot project on mentoring of newly qualified pre-school teachers]. Oslo: Høgskolen i Oslo.

Hubermann, M. (1993). The lives of teachers. New York: Teachers College Press Columbia University.

Ingersoll, R. M., \& Strong, M. (2011). The impact of induction and mentoring. Programs for beginning teachers: A critical review of the research. Review of Educational Research, 81(2), 201-233. https://doi.org/10.3102/0034654311403323. Retrieved from https://repository.upenn.edu/gse_pubs/127/?utm_source= repository.upenn.edu\%2Fgse_pubs\%2F127\&utm_medium=PDF\&utm_ campaign $=$ PDFCoverPages

Jakhelln, R. (2011). Alene-sammen. Nyutdannede loereres profesjonsloering i kollegial samhandling. [Alone-together. Newly qualified teachers professional learning in collective interaction]. (PhD. thesis) Fakultetet for Humaniora, Samfunnsvitenskap og Lærerutdanning, Universitet i Tromsø, Tromsø.

Jordell, K. Ø. (1982). Det første året som loerer. En spørreskjemaundersøkelse. 1. hovedrapport. [The first year as a teacher. A questionnaire, main report]. Tromsø: Univsitetet i Tromsø.

Jordell, K. Ø. (1986). Fra pult til kateter: Om sosialisering til loereryrket: En teoretisk studie. [From student's desk to teacher's desk: About socialization to the teaching profession: A theoretical study]. (PhD monography) Universitetet i Tromsø, Tromsø.

Kirke-, utdannings og forskningsdepartementet. (1997a). Om loererutdanning. (Meld. St. nr. 48 (1996-1997) [About teacher education, Minister of Church, Education and Research, White paper 48 (1996-1997)]. Oslo: Kirke- utdannings- og forskningsdepartementet. Retrieved from https://www.regjeringen.no/no/ dokumenter/st-meld-nr-48_1996-97/id191285/

Kirke- utdannings- og forskningsdepartementet. (1997b). Invitasjon til deltakelse $i$ pilotprosjekt om veiledning til nyutdannede loerere 1998-2001. [Minister of Church, 
Education and Research, Announcement for pilot project on mentoring newly qualified teachers 1998-2001]. Oslo: Kunnskapsdepartementet.

Kirke-, utdannings- og forskningsdepartementet (2001). Kvalitetsreformen Mangfold krevende - relevant. (Meld. St. nr. 16, 2000-2001). [Quality reform Diversity demanding - relevant. Ministry of Church, Education and Research, White paper no. 16, 2000-2001]. Oslo: Kirke- utdannings- og forskningsdepartementet. Retrieved from http://www.regjeringen.no/nb/dep/kd/dok/regpubl/stmeld/ 20012002/stmeld-nr-16-2001-2002-.html?id=195517

Kirke-, utdannings- og forskningskomiteen (2017). Innst. 182 S (2016-2017), 14.02.2017. [Church, Education and Research Committee, setting $182 \mathrm{~S}$ ]. Retrieved from https://www.stortinget.no/no/Saker-og-publikasjoner/Publikasjoner/Innstillinger/ Stortinget/2016-2017/inns-201617-182s/?all=true

Kunnskapsdepartementet. (2009a). Lareren rollen og utdanningen. (Meld. St. nr. 11 (2008-2009) [The teacher role and education, Ministry of Education and Research, White paper no. 11. 2008-2009]. Retrieved from https://www. regjeringen.no/contentassets/dceo159eo67d445aacc82c55e364ce83/no/pdfs/ stm20082009001100odddpdfs.pdf

Kunnskapsdepartementet. (2009b). Oppdragsbrev 33-09: Utdanning av veiledere for nyutdannede loerere - forvaltning av midler. [Ministry of Education and Research, Mission letter 33-09 Training of supervisors for NQTs - management of funds]. Retrieved from www.regjeringen.no

Kunnskapsdepartementet. (2009c). GNIST - partnerskap for en helhetlig loerersatsing. [Ministry of Education and Research, GNIST - Partnership for comprehensive teacher engagement]. Oslo: Kunnskapsdepartementet. Retrieved from https://www. regjeringen.no/globalassets/upload/kd/vedlegg/udir_gnist_avtale_msign.pdf

Kunnskapsdepartementet. (2018a). Oppdragsbrev 26-18 Veiledning av nyutdannede nytilsatte loerere $i$ barnehage og skole. [Ministry of Education and Research, Letter of assignment 26-18, Mentoring newly qualified teachers, newly appointed teachers in kindergarten and school]. Oslo: Kunnskapsdepartementet.

Kunnskapsdepartementet. (2018b). Veiledning av nyutdannede nytilsatte loerere $i$ barnehage og skole, avtale 09/2018. [Ministry of Education and Research, Mentoring newly qualified, and newly appointed teachers in kindergarten and school, National agreement between stakeholders]. Oslo: Kunnskapdepartementet. Retrieved from https://www.regjeringen.no/contentassets/oo81e41fad994cfdbb 4eo364a2eb8f65/veiledning-av-nyutdannede-nytilsatte-larere-i-barnehage-og-s kole.pdf

Kunnskapsdepartementet \& KS. (2009). Avtale mellom Kunnskapsdepartementet og KS om veiledning av nytilsatte nyutdannede pedagoger $i$ barnehagen og skolen. [Agreement between the Minister of Education and Research and The Norwegian Association of Local and Regional Authorities (KS) on mentoring newly qualified teachers in kindergartens and schools]. Oslo: Kunnskapsdepartementet. 
Kunnskapsdepartementet \& KS. (2011). Innføring av veiledningsordning for nytilsatte nyutdannede loerere. Resultater fra kartleggingen høsten 2010. [Ministry of Education and Research and KS, Introduction of mentoring program for newly hired, newly qualified teachers. Results from the survey in autumn 2010]. Retrieved from http://www.regjeringen.no/upload/KD/Vedlegg/Kompetanse/Rapport_ veiledningsordning_nytilsatte_nyutdannede_laerere.pdf

Kunnskapsdepartementet \& KS. (2012). Innføring av veiledningsordning for nytilsatte nyutdannede loerere. Resultater fra kartleggingen høsten 2011. [Ministry of Education and Research and KS, Introduction of mentoring program for newly hired, newly qualified teachers. Results from the survey in autumn 2010]. Retrieved from https://www.regjeringen.no/globalassets/upload/kd/vedlegg/kompetanse/rapport_ veiledningsordning_nytilsatte_nyutdannede_laerere.pdf

Kunnskapsdepartementet (2018). Veiledning av nyutdannede nytilsatte loerere $i$ barnehage og skole. [Ministry of Education and Research, Mentoring newly qualified teachers in kindergarten and school]. Retrieved from: https:/www.regjeringen.no/ contentassets/oo81e41fad994cfdbb4e0364a2eb8f65/veiledning-av-nyutdannedenytilsatte-larere-i-barnehage-og-skole.pdf

Lauvås, P., \& Handal, G. (1990). Veiledning og praktisk yrkesteori. [Guidance and practical professional theory]. Oslo: Cappelens Pedagogikkbøker.

Lauvås, P., \& Handal, G. (2000). Veiledning og praktisk yrkesteori. (2. utgave). [Guidance and practical professional theory ( $2^{\text {nd }}$ ed.)]. Oslo: Cappelen Akademisk.

Lauvås, P., \& Handal, G. (2014). Veiledning og praktisk yrkesteori. (3. utgave). [Guidance and practical professional theory ( $3^{\text {nd }}$ ed.)]. Oslo: Cappelen Damm Akademisk.

Mausethagen, S., \& Smeby, J.-C. (Eds.) (2017). Kvalifisering til profesjonell yrkesutøvelse. [Qualification for professional practice]. Oslo: Universitetsforlaget.

McNally, J. C. (2016). Learning from one's own teaching: New science teachers analyzing their practice through classroom observation cycles. Journal of Research in Science Teaching, 53(3), 473-501.

Nilssen, V. (2007). Seeing the kids, seeing the student teachers, dealing with two arenas the whole way: A case study of a cooperating teacher mentoring first-year student teachers' mathematics teaching. ( $\mathrm{PhD}$, monography). Norges TekniskNaturvitenskapelige Universitet, NTHU, Trondheim.

NOU 1996:22 (1996). Lorerutdanning: Mellom krav og ideal. [Teacher education: Between requirements and ideals]. Oslo: Kirke-, utdannings- og forskningsdepartementet.

OECD. (1990). Reviews of national policies for education. Norway. Retrived from https://www.oecd.org/education/school/48297989.pdf

Olsen, K.-R. (2013a). Veiledning og praksislærerrollen i lærerutdanning - mester eller reflekterende samtalepartner? [Guidance and the role of teacher in teacher 
education - master or reflective interlocutor?]. In L. G. Lingås \& K.-R. Olsen (Eds.), Pedagogisk veiledning. [Educational guidance]. Oslo: Gyldendal Akademisk.

Olsen, K.-R. (2013b). Veiledning av nyutdannede lærere. Resultater og utfordringer. [Mentoring newly qualified teachers: results and challenges]. In L. G. Lingås \& K.-R. Olsen (Eds.), Pedagogisk veiledning. [Educational guidance]. Oslo: Gyldendal Akademisk.

Olsen, K.-R. (2015). Praksislærerrollen, mester eller kritisk venn. [The practice teacher role, master or critical friend]. In E. K. Høihilder (Ed.). Praksisboka for loererutdanning. [The practice book for teacher education], pp. 55-66. Oslo: Gyldendal Akademisk

Olsen, K.-R., \& Wølner, T. A. (2017). Lesson study og loereres loering. [Lesson study and teacher learning]. Oslo: Gyldendal Akademisk

Parker, M. A., Ndoye, A., \& Imig, S. R. (2009). Keeping our teachers! Investigating mentoring practices to support and retain novice educators. Mentoring \& Tutoring: Partnership in Learning, 17(4), 329-341. https://doi.org/10.1080/13611260903391500

Rambøll. (2015). Evaluering av veiledningsordningen for nyutdannede pedagoger $i$ barnehage og skole. Delrapport. [Evaluation of the mentoring program for newly qualified teachers in kindergarten and school.] Retriewed from https://www. udir.no/globalassets/filer/tall-og-forskning/forskningsrapporter/ny-delrapportevaluering-av-veiledningsordningen-for-nyutdannede-pedagoger-i-barnehage-ogskole-vedlegg-inkl.pdf

Rambøll. (2016). Veiledning av nyutdannede barnehagelorere og loerere: En evaluering av veiledningsordningen og veilederutdanningen. [Evaluation of the mentoring program for newly qualified teachers in kindergarten and school]. Retrieved from https://www.udir.no/tall-og-forskning/finn-forskning/rapporter/veiledning-avnyutdannede-larere-og-barnehagelarere/

Richter, D., Kunter, M., Ludtke, O., Klusmann, U., Anders, Y., \& Baumkert, J. (2013). How different mentoring approaches affect beginning teachers' development in the first years of practice. Teacher and Teacher Education, 36, 166-177. Retrieved from http://s3.amazonaws.com/academia.edu.documents/38325593/2013_Richter_et_ al._TATE.pdf?AWSAccessKeyId=AKIAJ56TQJRTWSMTNPEA\&Expires $=146952$ 6688\&Signature $=$ QmZEck2YLtZAIzfHYLtzK\%2BckdbE\%3D\&response-contentdisposition=inline\%3B\%2ofilename\%3DHow_different_mentoring_approaches_ affec.pdf.

Schön, D. (1983). The reflective practitioner: How professionals think in action. San Francisco: Jossey-Bass.

Schön, D. (1987). Educating the reflective practitioner. San Francisco: Jossey-Bass. Skagen, K. (Ed.). (2011). Kunnskap og handling i pedagogisk veiledning. (2. utgave). [Knowledge and action in educational guidance $\left(2^{\text {nd }}\right.$ ed. $\left.)\right]$. Bergen: Fagbokforlaget. 
Strømnes, Å. L. (1979). Starten i loereryrket. [The start of the teaching profession]. Oslo: Universitetsforlaget.

Sundli, L. (2001). Veiledning i loererutdanningens praksis: Mellom refleksjon og kontroll. [Mentoring in teacher education training: Between reflection and control.] ( $\mathrm{PhD}$ monography). Oslo: Høgskolen i Oslo.

Utdannings- og Forskningsdepartementet. (2002). Veiledning av nyutdannede loerere invitasjon til søknad om midler for 2003. [Mentoring newly qualified teachers invitation to apply for funds, Ministry of Education and Research]. Oslo: Utdannings- og Forskningsdepartementet.

Utdannings- og Forskningsdepartementet. (2016). Kvalitetsreformen Om ny loererutdanning Mangfoldig - krevende - relevant. (Meld. St. nr. 16 (2001-2002). [Quality reform About new teacher education Diverse - demanding - relevant, Ministry of Education and Research, White paper no. 16 (2001-2002)]. Retrieved from https://www.regjeringen.no/contentassets/ae31935c94ff4c169cc1c378e4arbe1d/ no/pdfa/stm200120020016ooodddpdfa.pdf

Utdanningsdirektoratet. (2010a). Rapport: Innføring av veiledning for alle nyutdannede nyansatte loerere. [Directorate of Education and Training, Report: Introduction of mentoring for all newly qualified teachers]. Oslo: Utdanningsdirektoratet. Retrieved from http://www.regjeringen.no/upload/KD/Vedlegg/UH/Gnist/ veilederutdanning_arbeidsgrupperapport.pdf

Utdanningsdirektoratet. (2010b). Rapport: Veilederutdanning av mentorer for nyutdannede loerere - forslag til rammer for utdanningen. [Directorate of Education and Training, Report: Supervision of mentors for newly qualified teachers proposal for a framework for education. Directorate of Education and Training]. Retrieved from http://www.regjeringen.no/upload/KD/Vedlegg/UH/Gnist/ veilederutdanning_arbeidsgrupperapport.pdf

Ødegård, E. (2011). Nyutdannedes pedagogiske lederes mestring og appropriering av barnehagens kulturelle redskaper. En kvalitativ studie av nyutdannede førskoleloreres kompetansebygging det første året $i$ yrket. (no. 145). [Newly qualified pre-school teacher leaders' mastery and appropriation of kindergarten's cultural tools]. ( $\mathrm{PhD}$, monography. Oslo: Universitetet i Oslo.

Østrem, S. (2008). En umulig utdanning til et umulig yrke? Om allmennloererutdanning og yrkesutøvelse. [An impossible education for an impossible profession?] ( $\mathrm{PhD}$, monography). Roskilde: Roskilde Universitetscenter. 


\title{
Mentoring for Newly Qualified Teachers in Sweden: Reforms and Challenges
}

\author{
Göran Fransson \\ University of Gävle, Sweden
}

\begin{abstract}
This article focuses on the mentoring of newly qualified teachers (NQT) in Sweden and gives a brief historical overview of how mentoring has appeared on the educational agenda in Sweden and how its focus has changed over time. The research questions that guide this study are: (a) what major key events and reforms can be identified in relation to implementing mentoring of NQTs in Sweden, and how have these efforts turned out; (b) what is the state at present; (c) how is the issue of education and training dealt with; and (d) what key players and initiatives for the future can be identified? The methodological approach is a systematic review of policy documents and research on mentoring in Sweden from 1970-2019, as well as analyses of key actors web pages. Two important reforms are identified: (1) the national agreement (ÖLA, 2000) in 1995 between the Swedish Association of Local Authorities (SALAR), the National Union of Teachers in Sweden (Lärarnas Riksförbund) and the Swedish Teachers' Union (Lärarförbundet), giving NQTs the right to be supported by a mentor and to participate in an induction programme; and (2) the parliamentary decision in 2011 to introduce a reform package which included teacher registration with a probationary year, evaluations of NQTs and a mentoring system. The probationary year and principals' evaluations of NQTs were discontinued in 2014. A side effect of this was that mentoring became downplayed, which led to new initiatives to get mentoring back on the educational agenda. A professional programme with four levels of proficiency has been identified as a key reform that, if implemented, could put mentoring and the professional development of NQTs back on the educational agenda.

The current situation in Sweden is that some legislation and regulations related to the mentoring of NQTs are in place, although recent data shows that induction and mentoring are not as widespread as might be expected. Major stakeholders such as the two teacher unions, the Swedish National Agency for Education and
\end{abstract}

Citation of this article: Fransson, G. (2020). Mentoring for newly qualified teachers in Sweden: Reforms and challenges. In K.-R. Olsen, E. M. Bjerkholt \& H. L. T. Heikkinen (Eds.), New teachers in Nordic countries - ecologies of mentoring and induction (Ch. 8, pp. 177-197). Oslo: Cappelen Damm Akademisk. https://doi.org/10.23865/noasp.105.ch8

License: CC-BY 4.0. 
the Swedish Educational Broadcasting Company (UR) are identified as providers of web-based materials supporting NQTs.

Keywords: induction, mentoring, probationary year, Sweden, teacher registration reform

\section{Introduction}

The Swedish Education Act (2014), Chapter 2, \$22a, states that:

A local authority that has employed a teacher or preschool teacher with the relevant teaching qualifications shall ensure that at the start of their employment the teacher or preschool teacher will undergo a period of induction that in the main corresponds to the teacher's or preschool teacher's competence, unless the teacher or preschool teacher has not already undergone such an induction period. (Translated from Swedish)

The above paragraph constitutes the legal basis for the mentoring of newly qualified teachers (NQTs) and preschool teachers in Sweden. However, putting this Act in place has been challenging (Utbildningsdepartementet, 2013), and the extent to which it has been realised could also be questioned. The guiding research questions for this study are: (a) what major key events and reforms can be identified in relation to implementing mentoring of NQTs in Sweden, and how have these efforts turned out; (b) what is the state at present; (c) how is the issue of education and training dealt with; and (d) what key players and initiatives for the future can be identified? A systematic review of relevant policy documents and research on mentoring, teaching induction and teacher registration in Sweden from 1970-2019 has been carried out. In this, key actors have been identified and the web pages of these organisations have been analysed.

The chapter begins with a brief overview of the teacher education programmes that are available in Sweden, showing how mentoring has appeared on the educational agenda and describing how the focus has changed over time. In the main, the chapter focuses on the status and provision of mentoring in recent years and indicates what might happen in the future. 


\section{Teacher education programmes in Sweden}

In Sweden some 240,000 teachers work in preschools, leisure-time centres, primary schools and upper secondary schools. Around 8,0oo new teachers graduate each year from the teacher education programmes (TEPs) offered by universities in Sweden. In the academic year of 2017/18, a total of 8,360 teachers graduated from TEPs. These included 2,660 preschool teachers, 910 F-3 teachers (that is: preschool class and years 1-3), 570 teachers of years $4-6,550$ leisure-time teachers, 660 subject teachers in years 7-9, 1,430 subject teachers for the upper secondary school and 550 vocational teachers (Universitetskanslerämbetet, 2019). One thousand and sixty graduated from supplementary teacher education programmes, that is: a programme for people already working 'as teachers' but who have no formal teaching qualifications, who may, after validation of job experience and university courses, attend individually-designed courses to attain a formal teacher qualification. There is currently a shortage of teaching graduates and registered teachers in Sweden, and it is estimated that by 2035 this number will have increased to 79,000 .

In Sweden, preschool teacher education programmes consist of 210 ECTS credits. Three different academic degrees are available for teachers in the nine-year compulsory school system: one for the preschool class and years 1-3 (consisting of 240 ECTS credits), another for years 4-6 (consisting of 240 ECTS credits) and a third for school-based leisure-time centres (consisting of 180 ECTS credits). Two other kinds of degrees focus on subject teachers and are directed at work in years 7-9 in the compulsory school (consisting of 240 ECTS credits) and in the upper secondary school (consisting of 300 ECTS credits). All the teacher education programmes include studies in specific subject matter, didactics, pedagogy and a minimum of 30 ECTS credits in teaching practice in schools. The main way of becoming a teacher is through a teacher education programme.

There is also a shorter route into teaching, which is to first take a subject degree and then follow a short 9o ECTS credit programme, (the supplementary teacher education programme), although the number of students taking this route amounts to about a couple of hundred each year. In this teacher education programme structure every student teacher has to have a teaching practice placement before they are able to enter the 
teaching profession as NQTs, where they are then regarded as inexperienced yet qualified teachers.

\section{Mentoring in Sweden - some historical notes}

In 1978, when it was investigated how a new teacher education could be organised and implemented, it was suggested that NQTs should work as teachers for at least two years and then return to a teacher training institution for an additional six months of in-service training (30 ECTS credits) (SOU 1978:86). If this proposal had been implemented, it would have been a way of supporting new teachers early on in their careers, by offering opportunities for reflection, learning and recovery from teaching. In the same investigation, seven and a half pages of the Commission's 495 page report dealt with the induction of NQTs and provided good examples of support and induction, both in Great Britain and in Sweden. The report noted that:

Many teachers experience during their first job such difficulties and such inadequacy that they leave the profession. Already today, there are strong reasons to give the newly qualified teachers better support in their work ... the period immediately after the professional debut must be considered as crucial for the new teacher's continuing attitude to their profession, especially for their willingness to change their own and the school's approach. (SOU 1978:86, p. 248, 250)

The report suggested 'acclimatisation measures', with induction programmes, reduced service and contact teachers (equivalent to mentors) who could provide guidance. However, this proposal was not approved and, thus, not implemented.

Formalised mentoring for NQTs was not a priority during the 1980s, although it is likely that new teachers were informally supported by more-experienced colleagues - a phenomenon that has, to some extent, always existed between teachers.

Sweden experienced many educational reforms at the end of the 1980 s and beginning of the 1990s. The government's responsibility for schools was decentralised to the local education authorities in the municipalities (today there are 290 municipalities in Sweden). The detailed regulations 
for the education system were reduced, and a goal-oriented governance system was introduced. A new curriculum was implemented in 1994, which involved setting achievement goals for students and enabling teachers to select suitable educational content and methods. The education sector was also opened up for private alternatives and profit organisations, and profiling and competitions between schools were encouraged. Thus, in a relatively short period of time, the Swedish education system has changed from being highly centralised to one of the most decentralised and market-oriented in the western world (Lundahl, 2016).

In the early 1990s, the rhetoric emanating from politicians and the teacher unions was that it was time to rely on teachers' professionalism to develop the education system and its results. In this context, the National Union of Teachers in Sweden (Lärarnas Riksförbund) made an important decision in May 1992 to work towards the implementation of teacher registration, that is: a certification that only teachers who graduated from teacher education institutions could get, giving exclusive rights to teach (cf. Frelin \& Fransson, 2019). As this union mainly organises teachers who are subject specialists in upper secondary schools and at the senior level of the nine-year compulsory school, the union saw benefits for their members in being positioned as registered teachers. However, it was to take almost 20 years before the decision to introduce teacher registration became a reality. It was during this time that mentoring for NQTs became an issue on the educational agenda.

\section{The 1995 national agreement between teacher unions and local authorities}

The restructuring of the education system in the late 1980 and early 1990 as described above enabled the teacher unions to take more responsibility for the development of the education system and position themselves as professional and responsible parties. Thus, in 1995, a national agreement (ÖLA, 200o) was reached, between the Swedish Association of Local Authorities (SALAR), the National Union of Teachers in Sweden and the Swedish Teachers' Union, emphasising school development. One component in this agreement was that it gave new teachers the right to 
be supported by a mentor and to participate in an induction programme during a probationary year.

As the Swedish way of governance had become highly decentralised due to reforms, the task of implementing this agreement and developing local initiatives was handed over to the country's 290 municipalities. This often involved renegotiation with teachers' unions at the local level in order to find suitable forms and conditions for the induction programme and for mentors and mentees. In some municipalities, carefully-prepared induction systems emerged, while other municipalities devised more ad hoc solutions. In some municipalities very little, if anything, happened. In the later rounds of negotiations, the national agreement was not renewed and, since 31 March 2005, no national agreement has been in place, although some local agreements do still exist at municipal level. In the autumn of 2004, $59 \%$ of all NQTs employed on a probationary basis were allocated a mentor by the school in which they worked, and $63 \%$ thought that they received the help they needed as new teachers (Lärarnas Riksförbund, 2005). Note that employment on a probationary basis gave the right to a mentor, but obviously that was not working out as intended.

\section{Teacher registration, probationary year and teacher induction (2006-2017)}

The decision taken by the National Union of Teachers in Sweden (Lärarnas Riksförbund) in May 1992 to work towards the implementation of teacher registration resulted in early 2006 in an official government inquiry initiated by the Social Democratic Government (SOU 2008:52). As the inquiry was initiated at the beginning of the 2006 General Election campaign, it can be understood as a way of moving the issue of teacher registration away from the political agenda (Gustafsson \& Fransson, 2012, p. 25). The Government was under pressure from an opposition with a highly offensive political manifesto in the area of education. However, despite the political initiative to initiate the inquiry, the Social Democrats lost power and a centre-right coalition government was formed.

The official government inquiry, entitled 'Registration and stricter qualifying rules' (SOU 2008:52), was held in May 2008. On 2 March 2011, 
the government bill based on this inquiry was adopted by the Swedish Parliament (Proposition 2010/11:20), and the implementation of three closely-linked reforms was initiated. First, teacher registration linked to the subjects and grades that teachers were trained for was implemented. Second, a probationary year with evaluations was added for new teachers before teacher registration could be granted. During the probationary year it was compulsory for school principals to evaluate NQTs in relation to the teaching standards that had been developed by the Swedish National Agency for Education (Skolverket), and it was left to the principals to decide whether or not to recommend registration. Third, during the probationary year an NQT was also expected to have a mentor assigned to them to support their professional development but not one who was expected to be involved in their evaluations.

However, the implementation of these reforms was not smooth. Teacher registration became especially problematic when the NQTs who were already working had to be registered in accordance with the grades and subjects of their teacher education. It took a long time to review all the documentation and decide whether teacher registration should be granted and, in many cases, matching subjects and grades with a specific teacher education proved challenging (Frostenson, 2014). It also turned out that many older and experienced teachers were teaching year levels and subjects that they had not been trained for, which led to them not being granted registration for their present teaching position. Needless to say, this led to a number of adjustments to the legislation. One of the most recent policy adjustments was that from 1 July 2019, which now means that leisure-time teachers need a specific teacher registration to be able to teach and be responsible for a school's leisure-time activities.

The evaluations carried out by the principals were also questioned, and research showed variation in the quality of the evaluations (Fransson, Frelin, \& Grannäs, 2017; Gerrevall, 2017). Evaluation was also a complicated practice, and there were fears that if NQTs were not offered probationary placements and evaluated for teacher registration it would make a teaching career less attractive (Utbildningsdepartementet, 2013). Thus, in July 2014, the probationary year and principals' evaluations of NQTs were discontinued and teacher registration was earned by graduating from teacher education. 
When these parts of the reform package were discontinued in July 2014, a side effect was that mentoring also became downplayed. This could be understood as the issue of mentoring being buried under other 'more important' issues that were vying for attention. This led to the Swedish Teachers' Union, the National Union of Teachers in Sweden and the Swedish Association of Local Authorities and Regions (SALAR) making a joint effort during 2016-2017 to revive the issue of induction and mentoring, albeit with limited effect. However, it did result in some workshops and web-based materials, including a film about research highlighting the importance of mentoring and ways of organising and carrying it out. Further, in August 2017, a letter was sent to the government calling for mentor education and an information campaign about the induction period.

\section{Mentoring - the current situation}

The current situation in Sweden is that some legislation and regulations pertain to the mentoring of NQTs. As noted at the very beginning of the chapter, the Swedish Education Act, Chapter 2. $\$ 22 \mathrm{a}$, states that the employer 'shall ensure that at the start of their employment the teacher or preschool teacher will undergo a period of induction'. This is further elaborated on by legislation adopted on 26 June 2014, '.. regarding the induction period for teachers and preschool teachers' (SKOLFS 2014:44):

The principal shall design the induction period so that the teacher is given the opportunity to carry out as many of the profession's tasks as possible. Different methods for the planning and implementing of the teaching, development conversations, assessment and documentation and, where applicable, individual development plans and grading should be included. Furthermore, the induction period will deal with questions about the treatment of students, teachers' leadership and teachers' interactions with students, colleagues, parents and guardians. (SKOLFS 2014:44, $\$ 7$, translated from Swedish)

Although these regulations are now in place, it is important to understand how they play out in practice. For instance, the TALIS survey from 2018 (OECD, 2019) shows that in Sweden 30 \% of the lower secondary 
school teachers participating in the study reported that they took part in some kind of formal or informal induction when they began work at their current school, compared to an average of $42 \%$ of the teachers in the other countries participating in the same survey.

When it comes to mentoring in Sweden, $17 \%$ of the teachers with up to five years of teaching experience were reported to have been assigned a mentor, compared to an average of $22 \%$ among the other participating countries (OECD, 2019, Table I.5.10). Notably, in Argentina, Chile, Italy, Finland, Lithuania, Slovenia and Spain, only 5-10 \% of the NQTs reported having a mentor, while more than $50 \%$ reported having a mentor in Kazakhstan, New Zealand, Shanghai and Singapore. Compared with TALIS 2013 Sweden is among the four countries that have slightly increased the numbers of NQTs being mentored.

Further, in May 2019 the Swedish Teachers' Union conducted a survey covering $99 \%$ of the municipalities $(n=287)$, which showed that only $5 \%$ of the municipalities 'always' offered an induction period to NQTs while $20 \%$ 'never' did. Thirteen percent offered this 'often', $31 \%$ 'seldom' and $31 \%$ offered it 'sometimes' (Lärarförbundet, 2019).

In September and October 2019, another survey was sent to 3,228 of the NQTs belonging to the Swedish Teachers' Union and who had graduated in spring 2019. Eight hundred and ninety NQTs responded, yielding a response rate of $31 \%$. This survey showed that $41 \%$ of the NQTs were in an induction period and had a mentor, while $59 \%$ were not. However, an analysis of the different categories of teachers shows that these figures mainly refer to teachers of years F-3 and 4-9 in the nine-year compulsory school and at upper secondary school, and involve induction activities and mentoring. For preschool teachers and leisure-time teachers the percentages were $32 \%$ and $23 \%$ respectively (Figure 5).

Among the $59 \%$ who were not involved in an induction period and did not have a mentor $(n=496), 24 \%$ claimed that they had been offered a mentor and $76 \%$ said that they had not. In the latter group $(\mathrm{n}=369), 74 \%$ stated that they would like to have had a mentor.

Among the teachers with an induction period and a mentor $(\mathrm{n}=338)$, $13 \%$ claimed that they had reduced duties in class in order to have time to meet with their mentors. 


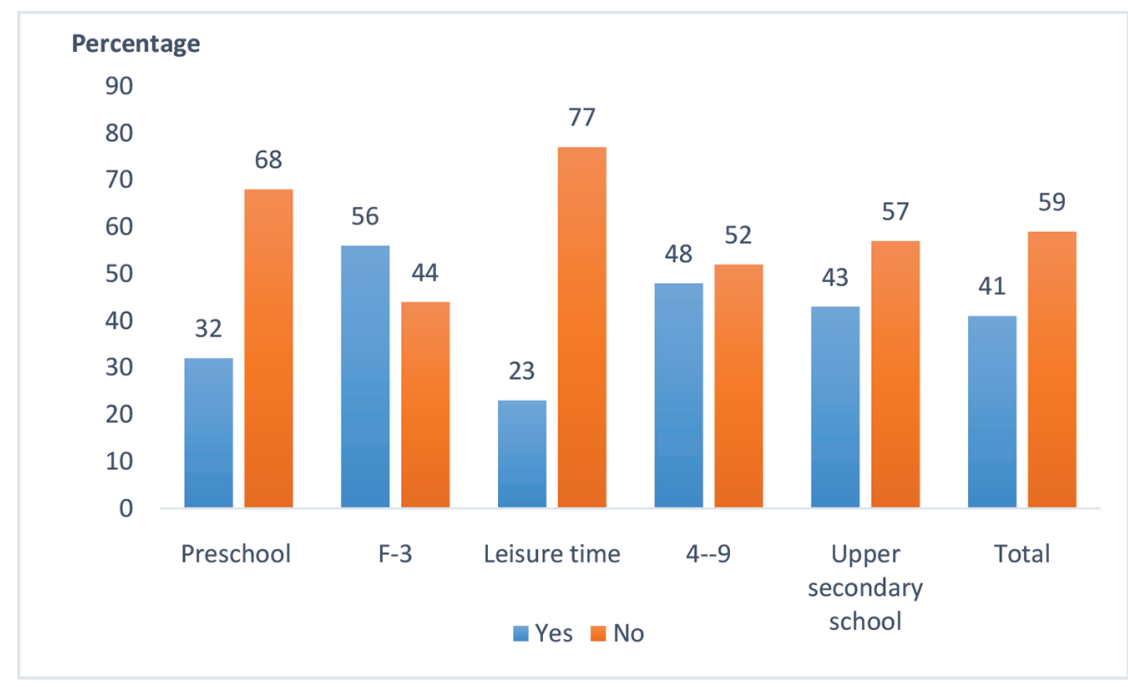

Figure 5. Percentage of NQTs in an induction period with mentors. $(n=988)$. (Lärarförbundet, 2019).

This shows that more effort is needed to organise induction systems and offer NQTs induction activities and mentoring.

In the following, the extent to which NQTs are involved in mentoring activities and mentoring will be discussed. Here the focus is on the principals and a government inquiry proposing a 'professional programme and education for mentors'.

\section{Principals as important key actors - who are also busy and moving around}

Research has shown that principals are important for the well-being, professional development and resilience of NQTs (Bickmore \& Bickmore, 2010; Buchanan et al., 2013; Peters \& Pearce, 2012). For instance, Peters and Pearce (2012) found that relationships between NQTs and principals were important for the resilience and well-being of the former. Similarly, Tiplic, Lejonberg and Elstad (2016) showed that trusting relationships between principals and NQTs reduced teachers' turnover intentions. In a study of Californian principals, Wood (2005) identified five important roles that principals played in the induction of NQTs: '(a) culture builder, (b) instructional leader, (c) coordinator/facilitator 
of mentors, (d) novice teacher recruiter and (e) a novice teacher advocate/retainer' (p. 39). Thus, principals play an important role for NQTs in a number of ways - from a direct one-to-one relation to how they influence and develop a school's culture.

Against this backdrop, it is disadvantageous for NQTs when principals only stay in a position for a short period and then move on to other schools. For instance, the 2013 TALIS study showed that Swedish principals were less experienced than their counterparts in other Nordic countries - both as principals and regarding time in service at their present school - and changed schools to a greater extent (Skolverket, 2015a). Denmark has the highest proportion of experienced principals. Additionally, in Sweden $51 \%$ of the principals have worked for less than three years at their present school, compared with approximately $30 \%$ in Iceland and Finland, and $20 \%$ in Denmark.

The Swedish Schools Inspectorate (Skolinspektionen, 2019) has recently acknowledged that this situation negatively influences the ability to organise induction programmes or mentoring for NQTs, which principals are largely responsible for organising and involved in. The processes, routines and initiatives that are involved in organising these kinds of activities are slowed down, downsized or even neglected, as are activities like cooperative assessments of national tests and the structured work of supporting pupils with special needs.

Thus, the principals' working conditions and organisational structures within the education system negatively affect the possibility of organising systematic and structured induction and mentoring for NQTs in Sweden. This shows the complexity of the educational ecosystem and how circumstances are interrelated. It also shows that support for NQTs is not just a matter of moving induction and mentoring higher up the educational agenda, but also means making sure that NQTs, mentors, principals and the entire education system are catered for in the best possible way.

The shortcomings in supporting NQTs and in giving them a good start and successful professional development in their first year of teaching may be symptomatic of greater challenges in the Swedish educational system. 


\section{Waiting for the 'professional programme' - a 2018 reform proposal put on hold}

The issue of NQTs' professional development and the provision of mentors has also been highlighted in a recent official government inquiry aimed at strengthening the teaching profession and teaching in order to 'strengthen the pupils' learning and development of knowledge and values' (SOU 2018:17, p. 96). The inquiry's focus is colourfully illustrated and manifested in the title: With teaching skills in focus - A framework for the professional development of teachers and principals.

The main proposal in the inquiry is the implementation of a professional programme (Professionsprogram) offering systematic opportunities for professional development. Linked to this programme is the implementation of a professional framework with four levels of proficiency: registered teachers, experienced teachers, merited teachers and especially merited teachers. Corresponding levels are proposed for preschool teachers. For principals two levels are suggested - principal and merited principal. The first level - registered teacher - addresses the professional development of NQTs and their participation in induction programmes and mentoring activities with a view to becoming registered teachers. Mentors for NQTs are expected to be experienced teachers who have undergone mentor education.

This government inquiry was delivered in March 2018 and, since then, has been on the government's table for decision and further action. At the time of writing this article (January 2020), the educational sector in Sweden is still waiting to see what the outcome of this proposal will be.

The inquiry highlights the issue of education for mentors of NQTs. An education of 7.5 ECTS credits is proposed. The suggestion is that mentors need to 'develop a professional approach in the role as mentor and develop their knowledge about for instance professional ethics, adult education and conversational methodology' (p. 260). In the inquiry, the issue of mentor education is assessed as being of 'immediate interest', and it is proposed to be implemented already 'in 2019'. However, as yet, nothing has been decided or implemented. 
Although this proposal has not yet become a reality, it is interesting to analyse the extent to which mentor education is provided in Sweden today at universities. This is covered in the next section.

\section{Education and training for mentors - state of the actual}

The education and training of mentors is closely related to the mentoring of NQTs. Becoming a mentor implies a transition from experienced teacher to mentor and the need to master both teaching and mentor practices (Aspfors \& Fransson, 2015a). Orland-Barak (2001) claims that learning to be a mentor involves similar developmental stages to those experienced by NQTs in their first years of teaching. Here, mentors' professional development can be of two kinds: informal learning based on experiences during the mentoring process, or more formalised in terms of mentor education courses. In research, mentors' professional competence has been found to be highly practice-oriented (Clarke, Killeavy, \& Moloney, 2013; Ulvik \& Langørgen, 2012; Ulvik \& Sunde, 2013).

When it comes to formalised mentor education, it has been claimed that the education of mentors is important. For instance, the New Teacher Project in California, USA, claimed that mentor education was the key to the success of a sustainable induction programme (Moir, 2009).

But how is mentor education regarded and acknowledged in Sweden? The Government Bill (Proposition 2010/11:20) proposing the reform package of teacher registration, probationary year and induction system touched on the issue of mentor education in the following way:

It is certainly also an advantage if the mentor has some form of supervisor or mentor qualification. Several consultative bodies point out that this should be compulsory, although the value of this is questioned by the Government. Södertörn University suggested that the educational institutions that organise teacher training should also offer mentor education. The Government regards this as a valuable point of view, but leaves it to the higher education institutions themselves to decide whether to introduce and organise such education. (Proposition 2010/11:20, p. 38, translated from Swedish) 
When the Bill was adopted by Parliament on 2 March 2011, the reform process was accelerated to the extent that already in autumn of 2011 NQTs were required to have a formal probationary year and a mentor. By the spring of 2014, only five out of 18 surveyed universities offering teacher education provided some kind of education for mentors of NQTs (7.5 ECTS credits and five weeks of study) (Aspfors \& Fransson, 2015b). When the probationary year and principals' evaluations of NQTs were discontinued in July 2014, a side effect was that mentoring became downplayed - as was mentor education. Another survey carried out in the autumn of 2019 showed that three of the 15 surveyed universities offered some kind of mentor education, although these courses did not have a specific focus on education for mentors of NQTs.

In the autumn of 2019, these three courses were officially announced in the university applications system (www.studera.nu). However, two of these courses focused on mentoring (and coaching) in a general sense and addressed different kinds of professional occupations. An example of the course description reads as below:

We highlight and problematise the meaning of being a mentor in all professions and activities where mentoring is a relevant part of the professional socialisation and a development of the organisation. (University of Borås, translated from Swedish)

At this university the required qualification for the course is a teaching certificate or degree for preschool teachers, teachers or leisure-time teachers and three years of professional occupational experience.

The course offered by the University of Gothenburg focused on the 'assessment of learning' in educational contexts, school-based supervisors for student teachers and also, to some extent, on mentors for NQTs. Thus, these types of mentor education are in line with Norwegian courses for mentors aimed at both student teachers and mentors for NQTs (Ulvik \& Sunde, 2013).

Depending on the specific skills that are required, having joint and combined education for 'mentors' for student teachers and NQTs could be a sensible move. However, in some circumstances it may be better to have separate training courses. The reasons for having combined or 
separate courses may be practical, ideological or depend on the contextual circumstances (Aspfors \& Fransson, 2015a).

In their metasynthesis of mentor education for NQTs, Aspfors and Fransson (2015a) found that three dimensions could guide the development of mentor education: (a) the theoretical-analytical dimension, (b) the relational dimension, and (c) the contextual dimension. The theoreticalanalytical dimension stresses the layers of content and professional knowledge and analytical skills that a mentor education needs to address, while the relational dimension emphasises the importance of relationships when becoming a mentor. The contextual dimension addresses the importance of acknowledging local, regional, national and international contexts when implementing, developing and researching mentor education. The importance of acknowledging local circumstances as well as changes at the policy level is below exemplified by the experiences of researchers at a Swedish university.

At the University of Gävle, researchers and teacher educators have been involved in mentor education for NQTs since 1998. From 1998 to approximately 2010, the researchers' and the university's approach was to not offer university-based mentor education, but instead help different municipalities to develop their own mentor education. In this way, municipalities not only developed the kinds of competencies that mentors needed, but also the 'ownership' of mentoring and mentor education (Morberg \& Gustafsson, 2007). This approach was used in collaboration with a network of nine municipalities and involved different kinds of local education with a variety of ambitions and scope.

However, when the reform package of teacher registration, probationary year and induction system was implemented in 2011, researchers at the university changed track because they found that mentors also risked becoming involved in the evaluation of NQTs, even though this was formally a task for the principals (Fransson, 2010). This meant that mentors would have to navigate a more complicated landscape of evaluations and professional development and possibly conflicting tasks, roles, interests and ethics, even though it was the principal's evaluation that was crucial for teacher registration. From 2013 to 2015, the university delivered some specially designed courses for mentors that took this complex landscape 
into account (Fransson, 2016). These courses were not offered after 2015 due to a reprioritisation of resources at the university, not due to the discontinuation of probation years in 2014 .

\section{Different actors supporting NQTs}

The formal responsibility for involving NQTs in professional development and induction activities and offering mentoring lies with the principal. In some municipalities resources are provided for these kinds of activities and also for bringing NQTs from different schools together.

The need to support NQTs has been recognised by other actors too. Webbased information is offered by the Swedish Teachers' Union (Lärarförbundet, 2018) and the National Union of Teachers in Sweden (Lärarnas Riksförbund, 2019). The Swedish National Agency for Education also offers support material (Skolverket, 2015b; 2020). Here, the two teacher unions are powerful stakeholders in highlighting the right to induction and mentoring for NQTs. Some membership magazines for teachers also publish articles about NQTs' experiences and mentoring activities.

Another example of initiatives to support NQTs is the Swedish Educational Broadcasting Company (UR), which is a media company 'in the service of the public' owned by the foundation for Radio Sweden (SR), Swedish Television (SVT) and the Swedish Educational Broadcasting Company (UR). The Swedish Educational Broadcasting Company provides TV and radio programmes as well as web-based materials for the educational sector directed at pupils, teachers and the public. UR has the freedom to choose which issues, themes and materials to produce, and has also chosen to provide material for NQTs in order to 'support NQTs during their first years' and to give 'advice and support in this professional role' (Utbildningsradion, 2019). The material consists of web-based films on leadership, planning, classroom management, stress, relations, evaluation and grades, juridical and relational issues, and how to organise classrooms for teaching and learning. According to officials, UR has tried to 'reflect new teachers' explicit wishes about what they need at the beginning of their professional life' and stresses that it is 'experienced teachers who give tips and advice on requested themes'. 


\section{Summary and future perspective}

This article has provided a brief overview of some of the important milestones in the development of more sustainable structures for mentoring in Sweden. Legislation is in place in the form of the Swedish Education Act and the Swedish National Agency for Education's regulations. However, at present the issue of mentoring does not appear at the top of the educational agenda in Sweden. There is also a need for up-to-date data about the extent to which NQTs have access to mentors and what the quality of mentorship is like. The proposed professional programme with four levels of proficiency may result in a renewed focus on mentoring and mentor education. For this to be placed at a national level will require political decisions and local efforts. The current shortage of teachers may also give added impetus to retaining NQTs in schools and to organise mentoring. In short, there is still a lot to do.

\section{References}

Aspfors, J., \& Fransson, G. (2015a). Research on mentor education for mentors of newly qualified teachers: Meta-synthesis. Teaching and Teacher Education, 48, 75-86. https://doi.org/10.1016/j.tate.2015.02.004

Aspfors, J., \& Fransson, G. (2015b). Att kvalificera sig till mentor - Perspektiv på kompetensbehov och utbildning av mentorer för nya lärare. [Qualifying as a mentor - Perspectives on the need for competence and education for mentors of newly qualified teachers]. Psykologi i Kommunen, 50(2), 17-27.

Bickmore, S. T., \& Bickmore, D. (2010). Revealing the principal's role in the induction process: Novice teachers telling their stories. Journal of School Leadership, 20(4), 445-469.

Buchanan, J., Prescott, A., Schuck, S., Aubusson, P., Burke, P., \& Louviere, J. (2013). Teacher retention and attrition: Views of early career teachers. Australian Journal of Teacher Education, 38(3), 112-129. https://doi.org/10.14221/ajte.2013v38n3.9

Clarke, M., Killeavy, M., \& Moloney, A. (2013). The genesis of mentors' professional and personal knowledge about teaching: Perspectives from the Republic of Ireland. European Journal of Teacher Education, 36(3), 364-375. https://doi.org/10.108o/0261 9768.2012 .755513

Fransson, G. (2010). Mentors assess mentees? An overview and analysis of the mentorship role concerning newly qualified teachers. European Journal of Teacher Education, 33(4), 375-390. 
Fransson, G. (2016). Online (web-based) education for mentors of newly qualified teachers: Challenges and opportunities. International Journal of Mentoring and Coaching in Education, 5(2), 111-126.

Fransson, G., Frelin, A., \& Grannäs, J. (2017). Rektorer och lämplighetsprövningen av nyutbildade lärare, [Head teachers and the evaluation of newly qualified teachers], FoU-rapport No. 45. Gävle: Gävle University Press.

Frelin, A., \& Fransson, G. (2019). Principals' experiences of changes in relationships with newly qualified teachers resulting from a teacher registration reform. International Journal of Educational Management, 33(4), 556-568. https://doi. org/10.1108/IJEM-02-2018-0076

Frostenson, M. (2014). Lärarlegitimationen som organisationsfråga. Strategisk respons och professionella konsekvenser. [Teacher registration as an organisational issue. Strategic response and professional consequences]. Utbildning \& Demokrati, 23(2), 45-69.

Gerrevall, P. (2017). Making sure it's the right one: Induction programme as a gatekeeper to the teaching profession. Scandinavian Journal of Educational Research, 62(4), 631-648. https://doi.org/10.1080/o0313831.2016.1261043

Gustafsson, C., \& Fransson, G. (Eds.) (2012). Kvalificerad som lärare? Om professionell utveckling, mentorskap och bedömning med sikte mot lärarlegitimation. [Qualified as a teacher? On professional development, mentorship and evaluation with a view to teacher registration]. Teacher Education: Research Publications no 5. Gävle: Gävle University Press.

Lundahl, L. (2016). Equality, inclusion and marketization of Nordic education: Introductory notes. Research in Comparative \& International Education. 11(1), 3-12. Lärarförbundet. (2018). Stödmaterial om introduktionen för nyexaminerade. [Support material for the induction of newly qualified teachers]. Retrieved 13 December 2019 from www.lararforbundet.se/artiklar/stodmaterial-omintroduktionen-for-nyexaminerade

Lärarförbundet. (2019). Introduktion och mentorskap för nya lärare och förskollärare. [Induction and mentorship for newly qualified teachers and preschool teachers]. Stockholm: The Swedish Teachers' Union

Lärarnas Riksförbund. (2005). Brist, balans eller överskott? Utmaningar och möjligheter för en effektiv arbetsmarknad och en kvalitetsinriktad skola. Bilaga: Redovisning av statistikmaterial. [Shortage, balance or surplus? Challenges and possibilities for an efficient labour market and a quality focused school. Appendix: Report of statistical data]. Stockholm: National Union of Teachers in Sweden.

Lärarnas Riksförbund. (2019). Ny som lärare. Om att vara nyexaminerad lärare. [New as a teacher. On being a newly qualified teacher]. Retrieved 13 December 2019 from https://www.lr.se/inspiration/lasa/ny-som-larare 
Moir, E. (2009). Accelerating teacher effectiveness: Lessons learned from two decades of new teacher induction. Phi Delta Kappan, 91(2), 14-21. https://doi. org/10.1177/003172170909100204

Morberg, Å., \& Gustafsson, L. (2007). Söderhamnsmodellen - mentorstöd för nybörjarlärare i yrkesutveckling och lokal skolutveckling. [The Söderhamn model - mentor support for new teachers in professional development and local school development]. Teacher Education: Research Publications no 3, Gävle: Gävle University Press.

OECD. (2019). TALIS 2018 Results (Volume I): Teachers and School Leaders as Lifelong Learners. Paris: OECD Publishing. https://doi.org/10.1787/1dobc92a-en

Orland-Barak, L. (2001). Learning to mentor as learning a second language of teaching. Cambridge Journal of Education, 31(1), 53-68.

Peters, J., \& Pearce, J. (2012). Relationships and early career teacher resilience: a role for school principals. Teachers and Teaching: Theory and Practice, 18(2), 249-262. https://doi.org/10.1080/13540602.2012.632266.

Proposition 2010/11:20. (2010). Legitimation för lärare och förskollärare presenteras. [Government Bill: Registration for teachers and preschool teachers]. Government proposition dated 2010-10-07. Swedish Government.

SKOLFS 2014:44. (2014). Skolverkets föreskrifter om introduktionsperiod för lärare och förskollärare. [The Swedish National Agency for Education's regulations on induction periods for teachers and preschool teachers]. Decided June 26, 2014. Statens Skolverks författningssamling. Skolverket (The Swedish National Agency for Education).

SKOLFS 2019:30. (2019). Föreskrifter om ändring i Skolverkets föreskrifter (SKOLFS 2014:44) om introduktionsperiod för lärare och förskollärare. [Regulations on the changes in the Swedish National Agency for Education's regulations (SKOLFS 2014:44) for induction periods for teachers and preschool teachers]. Decided October 2, 2019. Statens Skolverks författningssamling. Skolverket (The Swedish National Agency for Education).

Skolinspektionen. (2019). Huvudmannens arbete för kontinuitet på skolor med många rektorsbyten - Utan spaning ingen aning. [The responsible authority's work for continuity at schools with a large turnover of principals]. DNR: 400- 2018:7409. Stockholm: The Swedish Schools Inspectorate.

Skolverket. (2015a). Svenska rektorers erfarenhet i nordiskt perspektiv. En analys av TALIS 2013. [The experiences of Swedish principals from a Nordic perspective. An analysis by TALIS 2013]. Skolverkets Aktuella analyser 2015. Stockholm: The Swedish National Agency for Education.

Skolverket. (2015b). Introduktionsperiod för lärare och förskollärare. Skolverkets stödmaterial om introduktionsperiod för nyanställda lärare och förskollärare. Nytt stödmaterial från 2015. [Induction periods for teachers and preschool teachers. 
Support material from the National Swedish Agency for Education on the induction period for newly appointed teachers and preschool teachers. New support material from 2015]. Stockholm: The Swedish National Agency for Education

Skolverket. (2020). Introduktionsperiod för lärare och förskollärare. [Induction periods for teachers and preschool teachers]. Retrieved 5 January 2020 from https:// www.skolverket.se/skolutveckling/leda-och-organisera-skolan/leda-personal/ introduktionsperiod-for-larare-och-forskollarare?fbclid=IwAR1G4TwHIRQVaug 9d7NFs4PX2dxheoBSbqjil3oJrsLRovWFGPS2 99 gr $_{4} 6 \mathrm{M}$

SOU 1978:86. Lärare för skola i utveckling. Betänkande av 1974 års lärarutbildningsutredning (LUT 74) [Swedish Government Official Reports 1978:86 Teachers for a school in transition. Proposal presented by 1974 Swedish Commission on Teacher Education.]. Stockholm: Ministry of Education and Research.

SOU 2008:52. Legitimation och skärpta behörighetsregler. Stockholm: Fritzes offentliga publikationer. [Swedish Government Official Report 2008:52. Registration and stricter qualifying rules]. Stockholm: Ministry of Education and Research.

SOU 2018:17. Med undervisningsskicklighet i centrum - ett ramverk för lärares och rektorers professionella utveckling. Slutbetänkande av Utredningen om en bättre skola genom mer attraktiva skolprofessioner. [Swedish Government Official Report 2018:17. Opinion on the report 'With teaching skills in focus - A framework for the professional development of teachers and principals. Final report on the Inquiry of a better school through more attractive school professions]. Stockholm: Ministry of Education and Research.

The Swedish Education Act 2014. (Skollagen) Chapter 2. \$22a (Induction period). Tiplic, D., Lejonberg, E., \& Elstad, E. (2016). Antecedents of newly qualified teachers' turnover intentions: Evidence from Sweden. International Journal of Learning, Teaching and Educational Research, 15(5), 103 - 127.

Ulvik, M., \& Sunde, E. (2013). The impact of mentor education: Does mentor education matter? Professional Development in Education, 39(5), 754-770.

Ulvik, M., \& Langørgen, K. (2012). What can experienced teachers learn from newcomers? Newly qualified teachers as a resource in schools. Teachers and Teaching: Theory and Practice, 18(1), 43-57.

Universitetskanslerämbetet. (2019). Statistisk analys. Ämneslärare i årskurs 7-9 och gymnasiet: Ökande behov väntas i flera undervisningsämnen. [Statistical analysis. Subject teachers in years 7-9 and upper secondary school.]. Datum löpnummer 2019-03-26/3. Stockholm: Swedish Higher Education Authority.

Utbildningsdepartementet. (2013). Ändrade regler om introduktionsperiod och legitimation för lärare och förskollärare [Changed rules for the induction period and the registration of teachers and preschool teachers]. Promemoria 17.12.2013 U2013/7686/S. Stockholm: Ministry of Education and Research. 
Utbildningsradion. (2019). Nya lärare [New teachers]. Retrieved 13 December 2019 from www.ur.se/nyalarare/

Wood, A. (2005). The importance of principals: Site administrators' roles in novice teacher induction. American Secondary Education, 33(2), 39-62.

ÖLA 2000 (Avtal 2000). Överenskommelse om lön och allmänna anställningsvillkor samt rekommendation om lokalt kollektivavtal m.m. [Agreement on salaries and general terms of employment and recommendations for local collective agreements etc]. Swedish Association of Local Authorities and Regions (SALAR), National Union of Teachers in Sweden (Lärarnas Riksförbund, LR) and the Swedish Teachers' Union. 



\section{Author Biographies}

Birna Svanbjörnsdóttir (birnas@unak.is) is an Associate Professor at the Faculty of Education at the University of Akureyri. She has a long teaching career in primary school and was the director for The Centre of School Development at the University 2010-2016. Birna completed a Ph.D. in Educational sciences from University of Iceland 2015. Her main emphasises in research are teacher development, mentoring and professional learning communities. She is the supervisor for the mentoring program at the University of Akureyri.

Hildur Hauksdóttir (hildur@ma.is) completed BA degree in English from the University of Iceland in 2000, a teacher's degree from the University of Akureyri in 2005 and a master's degree from the same institute in 2016. In her master's studies, Hildur specialised in mentoring and professional development. She has worked as a secondary teacher and project manager in Akureyri Junior College since 2004.

María Steingrímsdóttir (maria@unak.is) is Associate Professor at the Faculty of Education in the School of Humanities and Social Sciences at the University of Akureyri. She has a long teaching career in elementary schools. María completed M.Ed. degree, specialising in management, from the Faculty of Education at the University of Akureyri in 2005. Her main research interests are mentoring of new teachers, teacher education, and teachers' professional development.

Göran Fransson (Goran.Fransson@hig.se) is a Professor in Curriculum Studies and an Associate Professor of Education at the Faculty of Education and Business Studies, University of Gävle, Sweden. His research centers on digital technologies in educational contexts, teacher commitment, teachers' professional development and induction and mentoring in different professions, with a primary focus on teachers. He has published in different international journals, books and anthologies, most recently in 
The Wiley-Blackwell International Handbook of mentoring (2020), with a chapter focusing Mentoring Policies: Possibilities, Challenges and Future Directions.

Hannu L. T. Heikkinen (hannu.l.t.heikkinen@jyu.fi) is Professor of Education at the Finnish Institute for Educational Research (FIER), University of Jyväskylä, Finland. He has written on teacher education and professional development of teachers, especially from the view of induction and mentoring of newly qualified teachers. He is one of the developers of the Finnish peer group mentoring model (PGM). Heikkinen is the link convener of EERA network 'Professional Learning and Development' and holds adjunct professorships in University of Tampere, University of Jyväskylä and Åbo Akademi University in Finland, and in Griffith University and Charles Sturt University in Australia.

Ilona Markkanen (ilona.markkanen@jyu.fi) is a Project Researcher at the Finnish Institute for Educational Research (FIER), University of Jyväskylä, Finland. She has participated in research and development work on teacher induction in Finland and has contributed in a number of projects on teacher education, related to physical and health education, attractiveness of teaching profession and peer group mentoring (PGM). She has been working as the coordinator of the Finnish Network for Peer Group Mentoring since 2010, and her responsibilities have included, for example, organising training for teachers who study as PGM mentors.

Matti Pennanen (matti.a.pennanen@jyu.fi) is a Project Researcher at the Finnish Institute for Educational Research (FIER), University of Jyväskylä, Finland. His main research interests are on teachers' professional development and collaborative practices in the Finnish education system, including tutoring teachers to improve their digital teaching skills and peer group mentoring (PGM). Pennanen is currently working for his doctoral study in Faculty of Education, University of Jyväskylä, and the research theme of his dissertation is related to the practices of the Finnish peer group mentoring model.

Päivi Tynjälä (paivi.tynjala@jyu.fi) is a Professor of Education at the Finnish Institute for Educational Research (FIER), University of Jyväskylä, 
Finland. Her main research area is learning and teaching in higher education. Her studies focus particularly on learning at the interface between higher education and the world of work, and the professional development of teachers. She has published widely both nationally and internationally and served as an Editor-in-Chief in Educational Research Review. Currently she is an editorial board member of Educational Research Review, and Vocations and Learning. She is a co-editor of the book Peer-group Mentoring for Teacher Development.

Eve Eisenschmidt (eve.eisenschmidt@tlu.ee) is a Professor of educational leadership at Tallinn University. She has been active in development of teacher education policy on the national level, e.g. preparing the implementation of the induction program for beginning teachers in Estonia, teacher's competence framework and developing initial teacher education program at the university. She has worked as expert an international level and external evaluator of teacher education program in several countries. Her current research areas are professional development of teachers, school improvement and leadership.

Katrin Poom-Valickis (katrinpv@tlu.ee) is a Professor of teacher education at Tallinn University. She has been a project leader and co-coordinator in several projects related to the development of Teacher Education and member of the expert group who prepared the implementation of the induction year for novice teachers in Estonia. Her main research interest is focused on the teacher's professional development, more precisely how to support future teachers' learning and development during their studies and first years of work. She is author and co-author of more than 45 scientific papers in the field of Educational Sciences.

Lisbeth Lunde Frederiksen (lluf@via.dk) is Ph.D. in educational research. She is Head of Research at the Program for Guidance and mentorship at VIA University College in Aarhus, Denmark. She has worked with professional development of teachers since 1993 and has almost as many years of experience with research management. She is an expert in methods and approaches in educations. Her particular interests in research is relationship between theory and practice in higher education, 
relationship between profession and education, counselling and mentoring, educational guidance and leadership continuing professional development and development of professional identity. She has more than 90 publications, including books, newspaper articles and journals.

Knut-Rune Olsen (knut.r.olsen@usn.no) is Associate Professor in pedagogy at the University of South-Eastern Norway. His particular interests are educational guidance and induction and mentoring for newly qualified teachers. He has participated in the Norwegian Network for Mentoring Newly Qualified Teachers in Kindergartens and Schools since 2003. Olsen has edited anthologies and written several articles on guidance, mentoring and induction. Latest book: Lesson Study and teacher learning published at Gyldendal Akademisk in 2017.

Åse Bonde (ABO@dlf.org) is educated as a teacher from Copenhagen Teacher Training College, and has worked for many years as a teacher. Åse has a thorough knowledge of the teaching profession and has participated in a long series of pedagogical development projects. Åse is a trained student-teacher mentor and external examiner of practice at teacher-training colleges and has taken part in the training of many future teachers. Åse Bonde is employed in the Danish Union of Teachers. Among her tasks is the continuous development of the teaching profession and newly qualified teachers.

Eva M. Bjerkholt (Eva.Bjerkholt@usn.no) is a researcher/teacher educator at the University of South-Eastern Norway (USN) and Associate Professor II at Inland Norway University of Applied Sciences (INN). She is the leader of the Norwegian Network for Mentoring Newly Qualified Teachers (Directorate of Education and Training), the leader of the network Newly Qualified Teachers and Induction: A Nordic Cross-Sectorial Network. - (NTI) (Nordplus Horizontal) and convener of the Nordic Educational Research Association's (NERA) - network 25: Guidance, Counselling and Mentoring. Bjerkholt is one of the two leader of the research group "Supervision and Mentoring in Education and in Teacher Profession” (USN). 